NBER WORKING PAPER SERIES

\title{
LOW INFLATION: HIGH DEFAULT RISK AND HIGH EQUITY VALUATIONS
}

\author{
Harjoat S. Bhamra \\ Christian Dorion \\ Alexandre Jeanneret \\ Michael Weber \\ Working Paper 25317 \\ http://www.nber.org/papers/w25317
NATIONAL BUREAU OF ECONOMIC RESEARCH
1050 Massachusetts Avenue
Cambridge, MA 02138
November 2018

We are grateful for comments and suggestions from Hui Chen, Pierre Collin-Dufresne (discussant), Jens Hilscher, Erica Li (discussant), Philippe Mueller (discussant), Francisco Palomino (discussant), Monika Piazzesi, Carolin Pflueger (discussant), Andrea Tamoni (discussant), Lukas Schmid (discussant), Gustavo Schwenkler (discussant), Min Wei (discussant), and participants at the 2017 Adam Smith Asset Pricing, 2017 HEC-McGill Winter Finance Workshop, 2017 BoCFRBSF-SFU Conference, 2017 SAFE Asset Pricing Workshop, 2017 Conference on Corporate Policies and Asset Prices, 2017 Society for Economic Dynamics, 2018 Cavalcade, 2018 WFA, 2018 EFA, 2018 NFA, BIS, ESSEC, Federal Reserve Board, HEC Lausanne, HEC Montréal, McGill, University of Lugano, University of Neuchâtel, University of Maryland, and University of Paris-Dauphine. A previous version of this paper circulated under the title Deflation, Sticky Leverage and Asset Prices. We thank Xiao Yin for excellent research assistance. The authors acknowledge the financial support from Imperial College, HEC Montréal and the HEC Montréal Foundation, Chicago Booth, and the Social Sciences and Humanities Research Council (SSHRC). All errors are ours. The views expressed herein are those of the authors and do not necessarily reflect the views of the National Bureau of Economic Research. Christian Dorion and Alexandre Jeanneret acknowledge financial support from SSHRC and the HEC Foundation.

NBER working papers are circulated for discussion and comment purposes. They have not been peer-reviewed or been subject to the review by the NBER Board of Directors that accompanies official NBER publications.

(C) 2018 by Harjoat S. Bhamra, Christian Dorion, Alexandre Jeanneret, and Michael Weber. All rights reserved. Short sections of text, not to exceed two paragraphs, may be quoted without explicit permission provided that full credit, including $(\subset$ notice, is given to the source. 
Low Inflation: High Default Risk AND High Equity Valuations

Harjoat S. Bhamra, Christian Dorion, Alexandre Jeanneret, and Michael Weber

NBER Working Paper No. 25317

November 2018

JEL No. E44,G12,G32,G33

\section{ABSTRACT}

We develop an asset-pricing model with endogenous corporate policies that explains how inflation jointly impacts real asset prices and corporate default risk. Our model includes two empirically grounded nominal frictions: fixed nominal coupons and sticky profitability. Taken together, these two frictions result in higher real equity prices and credit spreads when inflation falls. An increase in inflation has opposite effects, but with smaller magnitudes. In the cross section, the model predicts the negative impact of inflation on real equity values is stronger for low leverage firms. We find empirical support for the model predictions.

Harjoat S. Bhamra

Imperial College London

United Kingdom

and CEPR

h.bhamra@imperial.ac.uk

Christian Dorion

HEC Montreal

3000 Cote-Sainte-Catherine

Department of finance

Montreal, Canada H3T 2A7

christian.dorion@hec.ca

\author{
Alexandre Jeanneret \\ HEC Montreal \\ 3000, ch de la Cote-Ste-Catherine \\ Montreal H3T 2A7 \\ Canada \\ alexandre.jeanneret@hec.ca \\ Michael Weber \\ Booth School of Business \\ University of Chicago \\ 5807 South Woodlawn Avenue \\ Chicago, IL 60637 \\ and NBER \\ michael.weber@chicagobooth.edu
}




\section{Introduction}

Corporate defaults spike during times of low expected inflation. But so do firms' equity valuations, despite increased default risk. Figure 1 documents these two stylized facts for the U.S. over the period 1970Q2-2016Q4. Panel A illustrates the strong negative relation between expected inflation and the number of quarterly defaults in the U.S., whereas Panel B shows a similar negative relation between expected inflation and price-dividend ratios.

The existing literature has overlooked the connection between these two empirical facts and examined them separately. One branch of the literature focuses on the link between expected inflation and credit spreads. See, for example, Bhamra, Fisher, and Kuehn (2011), Kang and Pflueger (2015), or Gomes, Jermann, and Schmid (2016), in which lower expected inflation reduces the nominal risk-free rate, thereby increasing firms' indebtedness, and nominal expected growth rates - both effects increase default risk. A second branch of the literature investigates the link between expected inflation and equity values. See, for example, Modigliani and Cohn (1979), Feldstein et al. (1980), Ritter and Warr (2002), Sharpe (2002), and Campbell and Vuolteenaho (2004). ${ }^{1}$ A common explanation for the link between inflation and equity prices is money illusion: Investors discount real cash flows with nominal

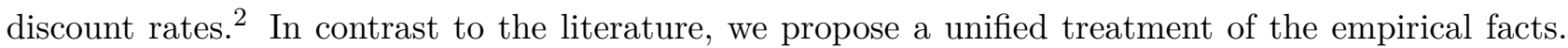
We do so by asking how shareholders can rationally value stocks more favorably during periods of low expected inflation, despite facing greater bankruptcy risk.

We construct a dynamic asset-pricing model with endogenous corporate financing decisions to explain these puzzling observations. We model firms that issue nominal debt and equity. Our framework provides asset-pricing predictions from a corporate finance perspective, whereby firms' financing and default policies are endogenous. We consider a representative agent with Epstein-Zin-Weil preferences. $^{3}$ The economy switches randomly between expansion or recession, creating intertemporal macroeconomic risk. A two-state Markov regime-switching model with parameter estimates based on quarterly U.S. consumption data over the period 1970Q2-2016Q4 determines the switches between real states. We also introduce three expected inflation states (low, moderate, and high) via a second, independent Markov regime-switching process that matches the one-year mean inflation forecast from the Survey of Professional Forecasters. We refer to fluctuations in the expected inflation rate as nominal risk, which is distinct from real macroeconomic risk.

\footnotetext{
${ }^{1}$ See also Lintner (1975), Bodie (1976), Fama and Schwert (1977), Miller, Jeffrey, and Mandelker (1976), Nelson (1976), Fama (1981), Schwert (1981), Geske and Roll (1983), Gultekin (1983), Solnik (1983), Pindyck et al. (1984), Kaul (1987), Pearce and Roley (1988), Kaul and Seyhun (1990), Boudoukh and Richardson (1993), and Bekaert and Wang (2010).

${ }^{2}$ Alternative explanations are the non-neutrality of inflation and the existence of an inflation risk premium. We describe the relevant literature in more detail below.

${ }^{3}$ Our work builds on Bhamra, Kuehn, and Strebulaev (2010a,b) and Chen (2010), who analyze firms' capital-structure and default decisions, as well as levered asset prices, in a consumption-based model with changing macroeconomic conditions.
} 

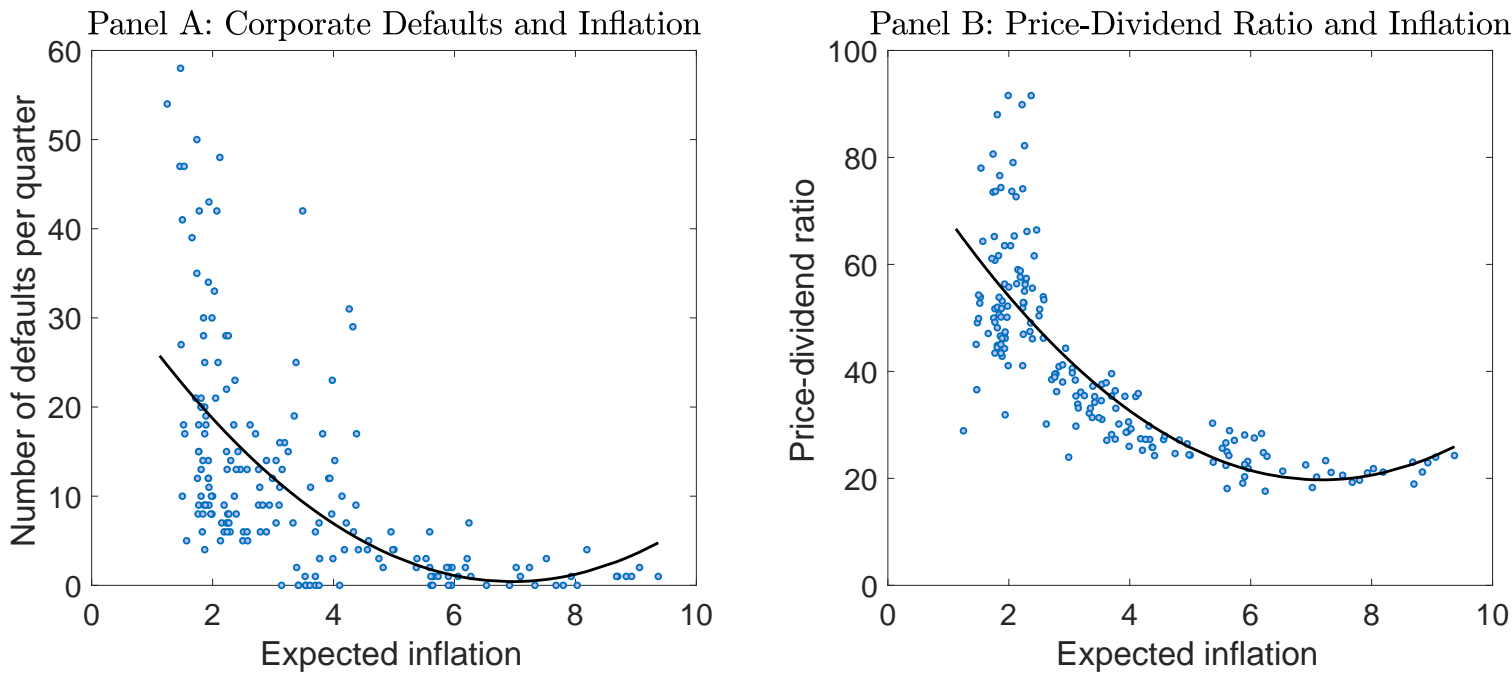

Figure 1: Defaults, stock valuation, and inflation in the U.S.

This figure illustrates the relation between expected inflation, default risk, and stock valuation. Panel A reports the number of quarterly defaults of firms domiciled in the U.S. with debt rated by Moody's. Panel B displays the price-dividend ratio, computed as the value-weighted CRSP price index in the last month of the quarter divided by the sum of dividends paid in the last 12 months. Defaults are obtained from Moody's Default and Recovery Database. Expected inflation is the one-year-ahead inflation forecast from the Survey of Professional Forecasters. The sample spans the period 1970Q2-2016Q4.

Our model contains two key frictions, both of which act as nominal rigidities. First, firms keep their nominal debt coupons fixed. This stickiness of leverage means changes in inflation impact real asset prices via shifts in the real values of debt coupons. Second, price stickiness implies nominal cash flow growth is sticky in the short run, and so expected nominal cash-flow growth changes less than one-for-one with changes in expected inflation. In the model, nominal cash-flow growth equals expected real cash-flow growth plus a multiple smaller than one of expected inflation. We denote this friction as sticky cash flows and find strong empirical support for this nominal rigidity in U.S. data. ${ }^{4}$ We show these two empirically motivated nominal frictions are sufficient to explain the stylized facts in Figure 1, but we do not aim to micro found the existence of these frictions in the current paper.

The two frictions we introduce imply changes in expected inflation impact both real corporate debt and equity prices. Our model is able to rationalize both high credit spreads and equity values during periods of low expected inflation. The model makes additional cross-sectional implications, which the data support.

In the model, a fall in expected inflation affects credit spreads through distinct channels. First, a lower nominal cash-flow growth rate increases a firm's risk-neutral default probability, which raises

\footnotetext{
${ }^{4}$ We provide direct evidence on the stickiness of profits below. Nominal price rigidities are the leading explanation of the real effects of monetary policy. For example, menu-cost models generate a band of inaction, rationalizing price non-adjustment to shocks (see, e.g., Mankiw (1985) and Ball and Mankiw (1994)). On the empirical side, ample evidence confirms the stickiness of output prices (see, e.g., Nakamura and Steinsson (2008) and Gorodnichenko and Weber (2016)).
} 
a firm's credit spread. Second, lower expected inflation decreases the nominal risk-free rate, which increases a firm's leverage ratio and thus its credit spread. Both effects induce greater credit risk as expected inflation falls. Similarly, a fall in expected inflation affects equity values through distinct channels. The nominal risk-free rate falls with expected inflation, but this effect is not perfectly offset by a fall in nominal expected cash flows, because of their stickiness. This effect leads to an increase in the value of unlevered equity, but also in the present value of coupons paid to debtholders. The former effect dominates the latter, so a decrease in expected inflation increases the value of levered equity. The increase in equity valuation becomes smaller for firms with more debt outstanding. The model thus implies that, in the cross section of firms, the increase in equity prices during times of low expected inflation is less pronounced for high-leverage firms.

We test the model predictions at the firm level. We use CRSP-Compustat merged data from April 1972 to December 2016 and exploit two measures of equity valuation: the firm's market-to-book (M/B) ratio and the price-dividend ratio. ${ }^{5}$ We measure default risk as a firm's financial-distress risk, following Campbell, Hilscher, and Szilagyi (2008). We find that at the portfolio level, default risk and equity valuation decrease with the level of expected inflation. Our results continue to hold when we condition on firms that remain in our sample throughout the period, which ensures a firm-selection effect does not explain our findings. The conclusions remain identical when we run firm-level regressions with a rich set of macroeconomic and firm-level controls, and when we consider conditional double sorts. We also find evidence that the level of debt reduces, rather than exacerbates, the sensitivity of stock prices to changes in nominal conditions. The validation of these cross-sectional predictions provides further support for our model.

The model also generates the asymmetry Figure 1 suggests: Low expected inflation is not merely the mirror image of high expected inflation, because the relation between equity valuation and inflation is non-linear. Low expected inflation increases the expected future value of fixed nominal coupons, thereby increasing the real value of debt. Hence, the assumption that an increase in expected inflation of the same size will result in an equal-sized decrease of real debt values appears natural. But such an analysis is incomplete, because it ignores how shifts in the nominal risk-free rate impact levered equity values non-linearly via a nominal discounting channel. We obtain this prediction even though default probabilities are convex in the distance-to-default. The convexity implies an increase in default risk depresses the value of equity more than a decrease in default risk of the same size. But we show this effect is not sufficient to offset the asymmetry arising from the nominal-discount-rate channel. This asymmetric effect of expected inflation on asset prices is important in light of the extremely low inflation levels we have observed during and after the Great Recession.

\footnotetext{
${ }^{5}$ The availability of forecasts for inflation determines the starting point of the sample.
} 
A related implication of the model is that nominal risk has a positive-and not a negative-effect on real asset values. Because lower expected inflation increases stock prices more than higher expected inflation depresses them, fluctuations in expected inflation increase equity prices on average. ${ }^{6}$ The presence of fluctuations in expected inflation also increases debt values on average. Our paper thus contributes to understanding the impact of inflation fluctuations on investors and in showing that nominal fluctuations can be economically beneficial.

Our paper makes several contributions. First, we build an asset-pricing model of multiple firms that can issue debt and equity with the option to default, where inflation risk impacts firms' asset prices. We explain the negative relation between stock valuation and expected inflation without any inflation risk premium or behavioral dimension. Second, our model generates the negative impact of expected inflation on default risk through variations in real leverage. Third, we show that a decrease in expected inflation has a greater impact on equity prices than the risk of higher expected inflation, which suggests a fundamental asymmetry in the asset-pricing implications of inflation risk. Fourth, we find the risk of expected inflation is stronger for less levered firms. Finally, we empirically validate all these predictions at the firm level. Hence, our paper allows us to shed light on the role of fluctuating expected inflation for asset prices and to identify the firm characteristics and economic conditions that make equity prices more sensitive to changes in expected inflation. We are thereby able to better understand both the cross-sectional and time-series asset-pricing implications of inflation risk.

Existing studies going back to Fama (1981) provide explanations for the negative relation between stock valuations and inflation, based on the idea that expected inflation is non-neutral because it has a negative effect on real growth. Agents demand a positive inflation risk premium, which reduces stock prices (e.g., Eraker, Shaliastovich, and Wang (2015)). However, these models typically ignore default risk. We are able to generate the negative relation in the data without requiring an inflation risk premium. In fact, we intentionally have a real stochastic discount factor, which is completely independent of the nominal state, in line with the view that periods of low/ high inflation can be associated with either good or bad economic conditions. ${ }^{7}$ Our model shows that sticky leverage combined with sticky cash flows is sufficient to generate relations between inflation, equity valuation, and default risk we observe in the data.

This paper also contributes to the literature exploring theoretically the interaction between inflation and stock returns. These studies include Day (1984), Stulz (1986), Wachter (2006), Gabaix (2008), Hess and Lee (1999), Chen (2010), Bansal and Shaliastovich (2013), and Gomes et al. (2016). Chen,

\footnotetext{
${ }^{6}$ To reach this conclusion, we compare the model's prediction with that of an hypothetical economy with expected inflation set at its unconditional mean.

${ }^{7}$ There is no consensus that agents should like higher or lower inflation. For example, Piazzesi and Schneider (2006) show inflation predicts consumption growth negatively, whereas Boons, Duarte, de Roon, and Szymanowska (2016) suggest the relation is time-varying. This finding is consistent with the evidence inflation periods do not always reflect a bad state of the economy. See, for example, Bekaert and Wang (2010), Campbell, Sunderam, and Viceira (2017), and David and Veronesi (2013).
} 
Roll, and Ross (1986) and Ang, Briere, and Signori (2012) find inflation risk is priced in the cross section of U.S. stock returns, whereas Boons et al. (2016) show the inflation risk premium varies over time conditional on the relation between inflation and the real economy. We depart from this literature by explaining the relation between inflation and equity valuation without linking inflation to consumption. Our work is closely related to Weber (2015) who shows how inflation risk impacts equity returns via a sticky-price channel. We combine the idea of sticky cash flows with sticky leverage. Finally, Kang and Pflueger (2015), which studies how inflation risk impacts corporate bond prices is another closely related paper. Our paper complements this study by jointly studying expected inflation, default risk, and equity prices in a unified framework. Furthermore, we provide empirical evidence and a theoretical explanation for the asymmetric relation between asset prices and expected inflation.

Section 2 presents a simple model to clarify the qualitative relations between equity valuation, credit risk, and expected inflation, whereas Section 3 describes the fully fledged consumption-based asset-pricing model with inflation risk. Section 4 derives asset prices together with optimal default and capital-structure decisions. Section 5 shows how we calibrate the model. Section 6 discusses the model's theoretical predictions, which we test empirically in Section 7. Section 8 concludes.

\section{Intuition from a Simple Model}

In this section, we develop a simple, static capital-structure model with exogenous financing and default policies to develop intuition for the negative relationships between equity valuation and credit risk with expected inflation. We also discuss why equity prices and credit risk are more sensitive to a decrease in expected inflation than to an increase in expected inflation, that is, why the relations are asymmetric.

\section{$2.1 \quad$ Economy}

The date- $t$ price index is denoted by $P_{t}$, where

$$
\frac{d P_{t}}{P_{t}}=\mu_{P} d t
$$

and $\mu_{P}$ is expected inflation, which is constant. We also assume the price index is locally risk-free.

Consider a firm with time- $t$ nominal cash flow $X_{t}$, the evolution of which under the risk-neutral probability measure $\mathbb{Q}$ is given by

$$
\frac{d X_{t}}{X_{t}}=\widehat{\mu}_{X} d t+\sigma_{Y} d W_{t}^{\mathbb{Q}}
$$


where $W^{\mathbb{Q}}$ is a standard Brownian motion under $\mathbb{Q}$, risk-neutral expected nominal cash-flow growth, $\widehat{\mu}_{X}=\widehat{\mu}_{Y}+\varphi \mu_{P}$, is the sum of risk-neutral real expected cash-flow growth $\widehat{\mu}_{Y}$ and a multiple $\varphi$ of expected inflation $\mu_{P}$. Note that $\varphi$ measures the sensitivity of nominal cash-flow growth to expected inflation. Because the price index is locally risk free, nominal cash-flow growth volatility $\sigma_{Y}$ equals real cash-flow growth volatility.

Cash-flow growth is sticky when $\varphi<1$, which reflects an incomplete inflation passthrough. The data strongly supports the assumption that $\varphi<1$. In Table 1 , we regress the consensus forecast for the growth rates of corporate profits over the next 12 months on the median forecast for inflation over the same period and additional macroeconomic controls using expectations data from the Survey of Professional Forecasters. In the data, the estimate of interest, $\hat{\varphi}$, is 0.415 in the full specification in column (4). The standard error is 0.167 , which suggests the estimate $\hat{\varphi}$ is significantly lower than 1 ( $t$-stat of 3.5). Hence, cash flows are sticky with respect to changes in nominal conditions. Consistent with this evidence, we hereafter assume $\varphi=0.5$, which is in the confidence interval of our estimate.

Table 1 [about here]

The firm has to service perpetual debt with a fixed nominal flow coupon of $c$. The capital structure is constant, that is, leverage is sticky. Coupons and cash flows are discounted with the nominal riskfree rate, which is given by $r^{\$}=r+\mu_{P}$. It is equal to the real interest rate $r$ plus expected inflation $\mu_{P}$. Default occurs when $X_{t}$ falls to an exogenously-specified default threshold $X_{D}$. The firm has no residual value when default occurs. For now, we ignore taxes and set the parameter values to $\widehat{\mu}_{Y}=2 \%, \sigma_{Y}=15 \%, X_{D}=0.5, X_{0}=c=1$, and $r=4 \%$.

\subsection{Negative relation and inflation asymmetry}

To examine how asset prices depend on expected inflation, we consider three scenarios. The economy can be in a state of low $\left(\mu_{P}=0 \%\right)$, moderate $\left(\mu_{P}=3 \%\right)$, or high expected inflation $\left(\mu_{P}=6 \%\right)$. Figure 2 shows the asset-pricing predictions for each of these cases. Equity valuations and credit spreads are both negatively related to expected inflation. Hence, the firm displays higher equity prices and, at the same time, faces a higher risk of default when expected inflation decreases. Furthermore, a change from moderate to low expected inflation has a greater impact than a change to high expected inflation, although we consider symmetric variations in expected inflation. Hence, low expected inflation is not the mirror image of high expected inflation. We call this effect inflation asymmetry.

Figure 2 [about here]

We now turn to the explanation of these predictions. First, the nominal value of equity $S^{\$}$ equals the nominal value of the firm's assets $V^{\$}$ minus the nominal value of debt $B^{\$}$, under no arbitrage. 
The total nominal value of the firm assets depends on expected inflation as follows

$$
\begin{aligned}
V_{t}^{\$} & =\frac{X_{t}-X_{D} q_{D, t}^{\$}}{r^{\$}-\widehat{\mu}_{X}} \\
& =\frac{X_{t}-X_{D} q_{D, t}^{\$}}{r-\widehat{\mu}_{Y}+(1-\varphi) \mu_{P}},
\end{aligned}
$$

where $q_{D, t}^{\$}$ is the Arrow-Debreu price of default, that is, the date $t$ price of the security that pays out one unit of the numeraire (one dollar) at the time of default. ${ }^{8}$ The total asset value decreases (nonlinearly) with expected inflation in the case of sticky cash flows $(\varphi<1)$. We refer to this mechanism as the discounting channel.

By contrast, the nominal value of debt is given by

$$
B_{t}^{\$}=\frac{c}{r+\mu_{P}}\left(1-q_{D, t}^{\$}\right)
$$

Lower inflation $\mu_{P}$ reduces the nominal risk-free rate, $r^{\$}=r+\mu_{P}$, which increases the value of debt $B^{\$}$. When lower expected inflation increases the total asset value more than it increases the value of debt, the value of equity increases. Hence, the negative and asymmetric relation between equity prices and expected inflation occurs, as illustrated in Figure 2 (Panel A).

A complementary default-risk channel explains the negative relation between expected inflation and credit risk. Nominal cash flows slow down as expected inflation decreases, which increases the likelihood of reaching the default threshold. The default probability, $q_{D}^{\$}$, varies negatively with the level of expected inflation, as in Bhamra et al. (2011) and Kang and Pflueger (2015); that is, $\frac{\partial q_{D}^{\$}}{\partial \mu_{P}}<0$. To grasp the importance of the default-risk channel, recall the credit spread for perpetual debt is given by

$$
\begin{aligned}
s_{t} & =\frac{c}{B_{t}^{\$}}-r^{\$} \\
& =r^{\$} \frac{q_{D, t}^{\$}}{1-q_{D, t}^{\$}} .
\end{aligned}
$$

\footnotetext{
${ }^{8}$ From Karatzas and Shreve (1991), $q_{D, t}^{\$}=\mathbb{E}^{\mathbb{Q}}\left[e^{-r^{\$} \tau_{D}}\right]=\left(\frac{X_{t}}{X_{D}}\right)^{\omega}$ if default occurs at time $\tau_{D}=\inf \left\{t \geq 0 \mid X_{t} \leq X_{D}\right\}$, where $\omega=\frac{1}{2}-\frac{\widehat{\mu}_{Y}+\varphi \mu_{P}}{\sigma_{Y}^{2}}-\sqrt{\left(\frac{1}{2}-\frac{\widehat{\mu}_{Y}+\varphi \mu_{P}}{\sigma_{Y}^{2}}\right)^{2}+\frac{2 r^{\$}}{\sigma_{Y}^{2}}}<0$.
} 
The credit spread increases as expected inflation decreases through higher $q_{D}^{\$}$. The functional form is also non-linear, thereby generating an asymmetric relation between the credit spread and expected inflation.

This default-risk effect is distinct from the discounting channel, because it occurs for any $\varphi>0$. The negative relation between credit risk and expected inflation is thus not related to the sticky-cashflow channel. Rather, it originates from the stickiness of the firm's nominal coupons, which are not adjusted with inflation. As in Bhamra et al. (2011) and Gomes et al. (2016), sticky leverage plays a critical role in our analysis. Note that credit risk increases although financial leverage actually decreases, as illustrated in Figure 2 (Panel D). The mechanism that we highlight thus differs from the argument in Fisher (1933), which implies lower inflation translates into higher credit risk because of a higher debt valuation.

The default-risk channel attenuates the negative relation between equity prices and expected inflation that originates from the discounting channel. However, this default-risk channel is not strong enough to reverse the sign, consistent with the data. Figure 1 shows lower expected inflation leads to higher equity valuations.

Overall, this analysis demonstrates how firms can have higher levered equity valuations and higher default risk when expected inflation decreases. This simple model assumes no arbitrage and does not make specific assumptions about preferences. The two critical features driving our results are sticky cash flows, for which we find strong support in the data, and sticky leverage.

Based on these insights, we now develop a richer model and explore quantitatively the negative and asymmetric impact of expected inflation for asset prices and corporate financial decisions.

\section{Model}

This section presents a dynamic asset-pricing model with real and nominal risk, and endogenous corporate financing decisions. We first define aggregate consumption and inflation and derive the real and nominal stochastic discount factors, using an Epstein-Zin-Weil representative agent. We then derive the asset values of firms, which issue nominal debt and equity, and describe their optimal policies.

\subsection{Aggregate economic variables}

Aggregate consumption at date- $t$ is denoted by $C_{t}$ and its dynamics are given exogenously by

$$
\frac{d C_{t}}{C_{t}}=\mu_{C, t} d t+\sigma_{C, t} d Z_{t}
$$


where $Z_{t}$ is a standard Brownian motion under the physical probability measure $\mathbb{P}$. The conditional first and second moments of aggregate consumption growth, $\mu_{C, t}$ and $\sigma_{C, t}$, respectively, can take different values, depending on the current state of the real economy, denoted by $\nu_{t}$. The real economy is risky and transitions between a recession state, $\nu_{t}=R$, and an expansion state, $\nu_{t}=E$, according to a two-state Markov chain. The probability under the physical probability measure of moving from the expansion state to the recession state within an instant $d t$ is $\lambda_{E R}^{\text {real }}$. Similarly, the probability under the physical measure of moving from the recession state to the expansion state within an instant $d t$ is $\lambda_{R E}^{\text {real }} d t$. We have $\mu_{C, R}<\mu_{C, E}$ and $\sigma_{C, R}>\sigma_{C, E}$ to ensure the mean and volatility of consumption growth are procyclical and countercyclical, respectively.

Inflation dynamics are specified exogenously. The date- $t$ level of the price index is denoted by $P_{t}$ and satisfies

$$
\frac{d P_{t}}{P_{t}}=\mu_{P, t} d t
$$

where we neglect inflation volatility stemming from small Brownian shocks, and assume that date- $t$ conditional expected inflation, $\mu_{P, t}$, depends on the nominal state $\epsilon_{t}$. We assume three nominal states: a low expected inflation state, $\epsilon_{t}=L$; a moderate expected inflation state, $\epsilon_{t}=M$; and a state of high expected inflation, $\epsilon_{t}=H$. From the definition of the nominal state, $\mu_{P, L}<\mu_{P, M}<\mu_{P, H}$. The physical probability of moving from the nominal state $l$ to $k$, within the instant $d t$, is $\lambda_{l k}^{\$} d t$, and the probability of moving back within a later instant is $\lambda_{k l}^{\$} d t$, where $k, l \in\{L, M, H\}$ and $l \neq k$.

For ease of notation, we combine the real and nominal states into six distinct states, where the current combined state is denoted by $s_{t}=\left(\nu_{t}, \epsilon_{t}\right)$. In summary, the different states are

\begin{tabular}{lccccc} 
& $s_{t}$ & $\left(\nu_{t}, \epsilon_{t}\right)$ & $g_{t}$ & $\sigma_{C, t}$ & $\mu_{P, t}$ \\
\hline Recession \& Low Expected Inflation (RL) & 1 & $(R, L)$ & $\mu_{C, R}$ & $\sigma_{C, R}$ & $\mu_{P, L}$ \\
Recession \& Moderate Expected Inflation (RM) & 2 & $(R, M)$ & $\mu_{C, R}$ & $\sigma_{C, R}$ & $\mu_{P, M}$ \\
Recession \& High Expected Inflation (RH) & 3 & $(R, H)$ & $\mu_{C, R}$ & $\sigma_{C, R}$ & $\mu_{P, H}$ \\
Expansion \& Low Expected Inflation (EL) & 4 & $(E, L)$ & $\mu_{C, E}$ & $\sigma_{C, E}$ & $\mu_{P, L}$ \\
Expansion \& Moderate Expected Inflation (EM) & 5 & $(E, M)$ & $\mu_{C, E}$ & $\sigma_{C, E}$ & $\mu_{P, M}$ \\
Expansion \& High Expected Inflation (EH) & 6 & $(E, H)$ & $\mu_{C, E}$ & $\sigma_{C, E}$ & $\mu_{P, H}$
\end{tabular}

The transitions between combined real and nominal states are given exogenously by a six-state Markov chain. Real and nominal regimes switch independently over period $d t$, and so the physical probability of the combined state switching from $s_{t-}=\left(\nu_{t-}, \epsilon_{t-}\right)$ to $s_{t}=\left(\nu_{t}, \epsilon_{t}\right)$, where $s_{t} \neq s_{t-}$ within a time interval of length $d t$ is given by

$$
\lambda_{s_{t-}, s_{t}} d t=\lambda_{\nu_{t-}, \nu_{t}}^{\mathrm{real}} \lambda_{\epsilon_{t-}, \epsilon_{t}}^{\$} d t
$$


where $\lambda_{\nu_{t-}, \nu t}^{\text {real }}=1$ if $\nu_{t-}=\nu_{t}$ (i.e. the real state does not change) and $\lambda_{\epsilon_{-,}, \epsilon t}^{\$}=1$ if $\epsilon_{t-}=\epsilon_{t}$. (i.e. the nominal state does not change).

\subsection{Representative agent and stochastic discount factors}

The representative agent has the continuous-time analog of Epstein-Zin-Weil preferences. ${ }^{9}$ The real stochastic discount factor (SDF) at time- $t, \pi_{t}$, depends on the state of the real economy and is given by (see Appendix OA.B for the derivation)

$$
\pi_{t}=\left(\beta e^{-\beta t}\right)^{\frac{1-\gamma}{1-\frac{1}{\psi}}} C_{t}^{-\gamma}\left(p_{C, t} e^{\int_{0}^{t} p_{C, u}^{-1} d u}\right)^{-\frac{\gamma-\frac{1}{\psi}}{1-\frac{1}{\psi}}}
$$

where $\beta$ is the rate of time preference, $\gamma$ is the coefficient of relative risk aversion (RRA), and $\psi$ is the elasticity of intertemporal substitution under certainty (EIS). The date- $t$ value of the claim to aggregate consumption per unit of time is denoted by $p_{C, t}$. This price-consumption ratio depends only on the real state of the economy, denoted by $\nu$ :

$$
p_{C, t}= \begin{cases}p_{C, R} & , \text { if } \nu_{t}=R \\ p_{C, E} & , \text { if } \nu_{t}=E\end{cases}
$$

When $\psi>1, p_{C, t}$ is procyclical and the real SDF increases in the recession state, $R .^{10}$

The real stochastic discount factor at date- $t, \pi_{t}$, evolves as follows

$$
\left.\frac{d \pi_{t}}{\pi_{t}}\right|_{\nu_{t-}=i, \nu_{t}=j}=-r_{i} d t-\gamma \sigma_{C, i} d Z_{t}+\left(\omega_{i j}-1\right) d N_{i j, t}^{P}, i, j \in\{R, E\}, j \neq i
$$

where $r_{i}$ is the equilibrium real risk-free interest rate in state $i \in\{R, E\}$, given by

$$
r_{i}= \begin{cases}r_{R}, & i=R \\ r_{E}, & i=E\end{cases}
$$

with $r_{E}>r_{R}$ so that the real interest rate is procyclical with respect to the real economy. The real interest rates are identical to those of Bhamra et al. (2010a) and Bhamra et al. (2010b), and given in the Online Appendix. Two types of risk are priced. The increment in the standard Brownian

\footnotetext{
${ }^{9}$ The continuous-time version of the recursive preferences introduced by Epstein and Zin (1989) and Weil (1989) is known as stochastic differential utility, and is derived in Duffie and Epstein (1992). Schroder and Skiadas (1999) provide a proof of existence and uniqueness for the finite-horizon case.

${ }^{10}$ The price-consumption ratios for each real state are derived from a coupled system of nonlinear algebraic equations given in (OA.20) of the Online Appendix.
} 
motion $d Z_{t}$ represents small high-frequency changes in unexpected consumption growth, and $\gamma \sigma_{C, i}$ is the associated price of risk. The compensated Poisson process $N_{\nu_{t-}, \nu_{t}, t}^{P}$ is given by

$$
N_{\nu_{t-}, \nu_{t}, t}^{P}=d N_{\nu_{t-}, \nu_{t}, t}-\lambda_{\nu_{t-}, \nu_{t}}^{\mathrm{real}} d t, \nu_{t-}, \nu_{t} \in\{R, E\}, \nu_{t} \neq \nu_{t-}
$$

where $N_{\nu_{t-}, \nu_{t}, t}$ is a Poisson process that jumps up by 1 when the real state of the economy switches; that is, $N_{\nu_{t-}, \nu_{t}, t}=1$ if $\nu_{t} \neq \nu_{t-}$. The increment in the compensated Poisson process, $d N_{\nu_{t-}, \nu_{t}, t}^{P}$, is a martingale (under the physical measure $\mathbb{P}$ ) that represents the risk the real state of the economy changing with price of risk $\omega_{i j}$. The representative agent only prices real risks. If the real state of the economy moves from expansion to recession, that is, if $\nu_{t-}=E$ and $\nu_{t}=R$, then $\omega_{E R}=\omega$, where $\omega=\left(p_{C, R} / p_{C, E}\right)^{-\frac{\gamma-\frac{1}{\psi}}{1-\frac{1}{\psi}}}$. Similarly, if the real state of the economy moves from recession to expansion, that is, $\nu_{t-}=R$ and $\nu_{t}=E$, then $\omega_{R E}=\omega^{-1}$. Intuitively, a negative shock to the economy results in an increase in the real SDF, and so $\omega>1$.

The pricing of securities is based on the risk-neutral switching probabilities per unit of time (i.e., transition intensities), $\hat{\lambda}_{s_{t-}, s_{t}}$, which are related to the physical switching probabilities, $\lambda_{s_{t-}, s_{t}}$, via

$$
\hat{\lambda}_{s_{t-}, s_{t}}=\omega_{\nu_{t-}, \nu_{t}} \lambda_{\nu_{t-}, \nu_{t}}^{\text {real }} \lambda_{\epsilon_{t-}, \epsilon_{t}}^{\$}, s_{t-} \neq s_{t}
$$

where $\omega_{\nu_{t-}, \nu_{t}}=1$ if $\nu_{t-}=\nu_{t}$ (i.e. the real state does not change). Hence, under Epstein-Zin-Weil preferences, $\omega_{E R}=\omega=\omega_{R E}^{-1}$ acts as a distortion factor, distorting physical transition intensities. The representative agent cares about future consumption growth and prefers early resolution of intertemporal risk $(\gamma>1 / \psi)$, and so $\omega>1$, which implies the risk-neutral probability per unit of time of switching from expansion to recession is higher than the physical probability. The agent prices only real risks, so the risk-neutral and the physical transition intensities coincide when only the nominal state changes $\left(\omega_{\nu_{t-}, \nu_{t}}=1\right.$ when $\left.\nu_{t-}=\nu_{t}\right)$.

Financial securities have nominal prices, which requires us to consider a nominal stochastic discount factor for asset pricing. The date- $t$ nominal SDF, denoted by $\pi_{t}^{\$}$, is defined as

$$
\pi_{t}^{\$}=\frac{\pi_{t}}{P_{t}}
$$

whose dynamics satisfy

$$
\left.\frac{d \pi_{t}^{\$}}{\pi_{t}^{\$}}\right|_{s_{t-}=i, s_{t}=j}=-r_{i}^{\$} d t-\gamma \sigma_{C, i} d Z_{t}+\sum_{j \neq i}\left(\omega_{i j}-1\right) d N_{i j, t}^{P} .
$$


$r_{i}^{\$}$ is the nominal interest rate in state $i$, given by

$$
r_{i}^{\$}=r_{i}+\mu_{P, i}
$$

The nominal interest rate depends on both real and nominal states and can thus takes six different values; it changes when the conditional moments of consumption growth change and also when expected inflation changes. The nominal risk-free rate is lowest during the recession/low-inflation state and highest during the expansion/high-inflation state.

\subsection{Firm cash flows}

The date- $t$ level of the real cash flow of an individual firm is denoted by $Y_{t}$ and evolves under the physical probability measure $\mathbb{P}$ according to the process

$$
\frac{d Y_{t}}{Y_{t}}=\mu_{Y, t} d t+\sigma_{Y, t} d W_{t}
$$

Real cash flows have a conditional expected growth rate $\mu_{Y, t}$ and a conditional volatility $\sigma_{Y, t}$. Both moments are identical across firms. Increments in the standard Brownian motion (under $\mathbb{P}$ ) $W$ represent small but frequent shocks to the firm's cash-flow growth. We assume cash-flow shocks are independent across firms and from shocks to consumption growth. ${ }^{11}$ Consequently, systematic risk in real cash flows is exclusively associated with low-frequency changes in economic conditions. The expected growth rate is higher in expansions than in recessions, whereas the conditional volatility is lower in expansions than in recessions. In sum, for all firms, we have $\mu_{Y, t}=\mu_{Y, R}, \sigma_{Y, t}=\sigma_{Y, R}$ in recessions and $\mu_{Y, t}=\mu_{Y, E}, \sigma_{Y, t}=\sigma_{Y, E}$ in expansions, where $\mu_{Y, R}<\mu_{Y, E}$ and $\sigma_{Y, R}>\sigma_{Y, E}$.

Because firms issue nominal securities and pay nominal taxes, investors care about the dynamics of nominal cash flows. The firm's nominal date- $t$ cash-flow level is then given by $X_{t}$, where

$$
X_{t} \equiv Y_{t} P_{t}^{\varphi}
$$

which satisfies

$$
\frac{d X_{t}}{X_{t}}=\mu_{X, t} d t+\sigma_{X, t} d W_{t}
$$

with $\mu_{X, t}=\mu_{Y, t}+\varphi \mu_{P, t}$. Because we ignore instantaneous Brownian shocks to the price index, the volatility of the nominal cash flows is given by $\sigma_{X, t}=\sigma_{Y, t}$. The sticky-cash-flow parameter, $\varphi$, captures the extent to which changes in inflation expectations are reflected in the firm's cash-flow growth rate.

\footnotetext{
${ }^{11}$ We ignore a non-zero correlation between real cash flows and consumption, because the asset-pricing literature shows the associated risk premium is negligible. Similarly, we ignore any correlation in cash-flow growth, because the asset-pricing and corporate financing implications are negligible. See, for example, Bhamra et al. (2010a, 2010b).
} 
Overall, firms exhibit heterogeneity in their cash flows due to firm-specific shocks but, at the same time, all firms have identical conditional moments for the expected growth rate.

\section{Asset Prices and Corporate Financing Decisions}

In this section, we derive asset prices together with optimal default and capital-structure decisions.

\subsection{Nominal debt and leverage stickiness}

Firms pay taxes on nominal cash flows $X_{t}$ and issue debt to shield profits from taxes. Each firm has a debt contract that is characterized by a constant and perpetual nominal debt coupon $c$. Leverage is sticky because the coupon is fixed in nominal terms. Hence, when the nominal state changes, the real coupon changes, which affects valuations. Consequently, sticky leverage acts as a nominal rigidity. In other words, firms cannot adjust the nominal quantity of debt to news about the inflation state.

\subsection{Liquidation value}

When a firm's nominal cash-flows reach a state-dependent boundary $X_{D, i}$, which is selected by equityholders to maximize equity value, the firm is liquidated. Debtholders recover a fraction of the after-tax unlevered asset value of the firm, whereas the remaining fraction is lost due to bankruptcy costs.

The nominal asset value at the time of liquidation, denoted by $A_{i, t}^{\$}$ in state $i \in\{1, \ldots, 6\}$, corresponds to the present value of the after-tax nominal unlevered cash flows. Unlevered cash flows equal

$$
A_{i, t}^{\$}=(1-\eta) X_{t} \frac{1}{r_{A, i}}
$$

where $\eta$ is the corporate tax rate and $\frac{1}{r_{A, i}}$ is defined by

$$
\frac{1}{r_{A, i}}=E_{t}\left[\int_{t}^{\infty} \frac{\pi_{u}^{\$}}{\pi_{t}^{\$}} \frac{X_{u}}{X_{t}} d u \mid s_{t}=i\right]
$$

The value of $r_{A, i}=v_{A, i}^{-1}$ is given by the reciprocal of the $i^{\top}$ th element of the vector $V_{A}=\left[v_{A, 1}, \ldots, v_{A, 6}\right]^{\top}$ where

$$
V_{A}=\left(R_{A}-\widehat{\Lambda}\right)^{-1} 1_{6 \times 1}
$$


where $1_{6 \times 1}$ is a $6 \times 1$ vector of ones, $R_{A}$ is the following $6 \times 6$ diagonal matrix

$$
R_{A}=\operatorname{diag}\left(r_{1}^{\$}-\mu_{X, 1}, \ldots, r_{6}^{\$}-\mu_{X, 6}\right)
$$

and $\widehat{\Lambda}$ is the $6 \times 6$ risk-neutral generator matrix of the Markov chain characterizing the real and nominal states of the economy, defined by

$$
\begin{aligned}
& {[\widehat{\Lambda}]_{i j}=\widehat{\lambda}_{i j}, i, j \in\{1, \ldots, 6\}, j \neq i} \\
& {[\widehat{\Lambda}]_{i i}=-\sum_{j \neq i} \widehat{\lambda}_{i j}, i, j \in\{1, \ldots, 6\}, j \neq i}
\end{aligned}
$$

We can interpret $r_{A, i}$ as the discount rate for a perpetuity with stochastic expected growth rate $\mu_{X, t}$, which is currently equal to $\mu_{X, i}$. If the economy stays in state $i$ forever, the discount rate reduces to the standard expression $r_{A, i}=r_{i}^{\$}-\mu_{X, i}$. In general, however, the economy can change states, and so the discount rate depends on the risk-neutral generator matrix of the Markov chain governing the economy's transitions. The presence of the risk-neutral generator matrix as opposed to the physical generator matrix incorporates the pricing of risk. However, as previously discussed, our SDF does not give risk to an inflation risk premium.

\subsection{Arrow-Debreu default claims}

Default risk is central to firm valuation. We now express the value of a firm's asset as a function of a set of Arrow-Debreu default claims. We define an Arrow-Debreu default claim as an asset that pays out $\$ 1$ if default occurs in state $j$ and the current state is $i$. We denote the nominal price of such a security by $q_{D, i j, t}^{\$}$, which satisfies (see Appendix OA.F)

$$
q_{D, i j, t}^{\$}=E_{t}\left[\frac{\pi_{\tau_{D}}^{\$}}{\pi_{t}^{\$}} I_{\left\{s_{\tau_{D}}=j\right\}} \mid s_{t}=i\right],
$$

where $\tau_{D}$ is the date at which default occurs and $I_{\left\{s_{\tau_{D}}=j\right\}}$ is an the indicator function that equals 1 , if default occurs in state $j$, and zero otherwise.

When valuing assets that depend on the level of cash flows at time of default, $X_{\tau_{D}}$, we have to consider additional Arrow-Debreu securities, because our economy features "deep defaults." These defaults can occur when the state of the economy jumps from its current state to a worse state. Default boundaries are countercyclical and can suddenly move upward when the economy deteriorates, for example, when a low expected inflation period starts. In such a situation, a fraction of firms may immediately default upon a change in state. Consider a firm that has a nominal cash-flow level of $\$ 10$ 
while the default boundary is $\$ 8$. If the economy suddenly deteriorates by moving into a new state where the default boundary is $\$ 11$, the firm will immediately default. All firms with a nominal cashflow level below $\$ 11$ would immediately default, thereby creating a default cluster. More formally, we can consider a firm with a nominal cash-flow level $X_{\tau_{D^{-}}}$, at time $\tau_{D^{-}}$, which is the time just before default, where $X_{\tau_{D^{-}}}$is below the new state's default boundary, $X_{D, j}$. This firm will default as soon as the economy enters the new state, and so $X_{\tau_{D^{-}}}=X_{\tau_{D}}<X_{D, j}\left(X_{\tau_{D^{-}}}=X_{\tau_{D}}\right.$ because $X$ is a continuous process). Hence, it not necessarily the case that at default, a firm's cash-flow level is at the default boundary. Consequently, to value securities that depend on a firm's cash flows, we need a modified set of Arrow-Debreu default claims. We derive them in Appendix OA.G.

This second type of Arrow-Debreu default claims pay out $\frac{X_{\tau_{D}}}{X_{D, j}}$ at default if default occurs in state $j$ and the current state is $i$. The date- $t$ nominal price of this security is denoted by $\widetilde{q}_{D, i j, t}^{\$}$, where

$$
\tilde{q}_{D, i j, t}^{\$}=E_{t}\left[\frac{\pi_{\tau_{D}}^{\$}}{\pi_{t}^{\$}} \frac{X_{\tau_{D}}}{X_{D, j}} I_{\left\{s_{\tau_{D}}=j\right\}} \mid s_{t}=i\right] .
$$

Overall, thirty six Arrow-Debreu default prices exist for each type, because six states characterize the aggregate economy.

\subsection{Corporate bond value}

A firm that issues debt promises to pay the nominal coupon $c$ per unit time. If the firm defaults, debtholders receive a fraction of the firm's liquidation value, the constant recovery rate $\alpha$. Hence, the date- $t$ nominal value of corporate debt, conditional on the current state being $i$, is given by

$$
B_{i, t}^{\$}=c E_{t}\left[\int_{t}^{\tau_{D}} \frac{\pi_{u}^{\$}}{\pi_{t}^{\$}} d u\right]+\alpha E_{t}\left[\frac{\pi_{\tau_{D}}^{\$}}{\pi_{t}^{\$}} A_{s_{\tau_{D}}}^{\$}\left(X_{\tau_{D}}\right) d u\right] .
$$

The above expression is simply the present value of future coupon flows up until some random default time, $\tau_{D}$, plus the present value of the unlevered firm assets net of bankruptcy costs. We can rewrite the above expression as

$$
B_{i, t}^{\$}=c\left(\frac{1}{r_{P, i}^{\$}}-\sum_{j=1}^{6} q_{D, i j, t}^{\$} \frac{1}{r_{P, j}^{\$}}\right)+\sum_{j=1}^{6} \alpha A_{j}^{\$}\left(X_{D, j}\right) \tilde{q}_{D, i j, t}^{\$}
$$


where $r_{P, i}^{\$}$ is the nominal discount rate for a perpetuity paying a flow of $\$ 1$, conditional on the current state being $i$. Observe that

$$
\frac{1}{r_{P, i}^{\$}}=E_{t}\left[\int_{t}^{\infty} \frac{\pi_{u}^{\$}}{\pi_{t}^{\$}} d u \mid s_{t}=i\right]
$$

To gain intuition for corporate bond price (33), note $c \frac{1}{r_{P, i}^{\$}}$ is the present value in nominal terms of a default-free bond paying a coupon flow of $c$ dollars in perpetuity. The expression $c \sum_{j=1}^{6} q_{D, 1, i j}^{\$} \frac{1}{r_{P, j}^{\$}}$ is the present value of coupons lost because of the possibility of default, and $\sum_{j=1}^{6} \alpha A_{j}^{\$}\left(X_{D, j}\right) \tilde{q}_{D, i j, t}^{\$}$ is the present value of the assets recovered.

The nominal discount rate for a constant nominal perpetuity, $r_{P, i}^{\$}$, is given by $r_{P, i}^{\$}=v_{B, i}^{-1}$, where $v_{B, i}$ is the $i$-th element of the vector $V_{B}=\left[v_{B, 1}, \ldots, v_{B, 6}\right]^{\prime}$, given by

$$
V_{B}=\left(R^{\$}-\widehat{\Lambda}\right)^{-1} 1_{6 \times 1},
$$

and $R^{\$}$ represents the $6 \times 6$ diagonal matrix such that $R_{i i}^{\$}=r_{i}^{\$}$. Therefore, $r_{P, i}^{\$}$ accounts for the possibility that the nominal risk-free rate takes different future values as macroeconomic fundamentals and expected inflation fluctuate over time.

\subsection{Equity value}

Shareholders are entitled to the firm's cash flows net of taxes and debt servicing as long as the firm does not default. When the firm is in default, which occurs at some random time $\tau_{D}$, shareholders recover nothing and lose their rights to any future cash flows. The nominal value of equity at date- $t$, conditional on the current state $i$, is then given by

$$
S_{i, t}^{\$}=(1-\eta) E_{t}\left[\int_{t}^{\tau_{D}} \frac{\pi_{u}^{\$}}{\pi_{t}^{\$}}\left(X_{u}-c\right) d u \mid s_{t}=i\right]
$$

We can rewrite $(36)$ as

$$
S_{i, t}^{\$}=A_{i}^{\$}\left(X_{t}\right)-(1-\eta) \frac{c}{r_{P, i}^{\$}}-\sum_{j=1}^{6}\left(A_{j}^{\$}\left(X_{D, j}\right) \tilde{q}_{D, i j, t}^{\$}-(1-\eta) q_{D, i j, t}^{\$} \frac{c}{r_{P, j}^{\$}}\right) .
$$

The first two terms represent the present value of cash flows net of coupon payments in the absence of default, whereas the summation term captures the present value of the net cash flows that shareholders lose in the case of default. 


\subsection{Default and capital structure decisions}

Shareholders maximize the value of their default option by choosing when to default. The statecontingent endogenous default boundary $X_{D, s_{t}}$ depends on the current real and nominal state of the economy, that is, $s_{t} \in\{1, \ldots, 6\}$. Expected inflation matters for default decisions because a change in the nominal cash flow growth is not offset by a change in the nominal coupon rate; that is, leverage is sticky. Hence, equityholders are entitled to smaller expected future cash flows when expected inflation is low than when expected inflation is high.

The default boundaries satisfy the following six standard smooth-pasting conditions

$$
\left.\frac{\partial S_{s t}^{\$}(X)}{\partial X}\right|_{X=X_{D, s_{t}}}=0, s_{t} \in\{1, \ldots, 6\}
$$

Shareholders also choose the optimal nominal coupon to maximize firm value at date 0 by balancing marginal tax benefits from debt against marginal expected distress costs. Two important features are noteworthy. First, as is standard in the capital-structure literature (Leland, 1994), by maximizing firm value, shareholders internalize debtholders' value at date 0. However, in choosing default times, they ignore the considerations of debtholders. This feature creates the usual conflict of interest between equity- and debtholders. Second, the optimal coupon depends on the state of the economy at date 0 . We denote the date- 0 coupon by $c_{s_{0}}$, where, to emphasize this dependence, $s_{0}$ is the date- 0 state of the economy. Shareholders choose the coupon to maximize date- 0 firm value, $F_{s_{0}, 0}^{\$}=B_{s_{0}, 0}^{\$}+S_{s_{0}, 0}^{\$}$; that is,

$$
c_{s_{0}}=\arg \max _{c} F_{s_{0}, 0}^{\$}(c) .
$$

We obtain the optimal default and capital-structure decisions numerically by maximizing equation (39) subject to the conditions stated in equation (38). As a result, the optimal default boundaries depend on the debt policy, which is determined by the initial financing state. Hence, if the economy is in state $i$, the default boundary for nominal earnings is given by $X_{D, i}\left(c_{s_{0}}\right)$, where $i$ denotes the dependence on the current state and $c_{s_{0}}$.

\section{Calibration}

We calibrate the model to the U.S. economy over the period 1970Q1-2016Q4. The real states are characterized by the conditional moments of aggregate consumption growth. We obtain the transi-

tion probabilities $\lambda_{\nu_{t}-\nu_{t}}^{\text {real }}$ by estimating a two-state Markov regime-switching model on quarterly U.S. consumption, jointly with real aggregate earnings data. 
We proxy for aggregate consumption with real non-durable goods plus service-consumption expenditures from the Bureau of Economic Analysis. To determine real cash flows, we first obtain aggregate, nominal earnings from S\&P provided by Robert J. Shiller's website and then use the personal consumption expenditure chain-type price index as the deflator. The conditional moments of real consumption and cash-flow growth rates are reported in Table $2 .{ }^{12}$ The estimates of the physical probabilities of being in a recession and expansion are $f_{R}=f_{1}+f_{2}+f_{3}=18.2 \%$ and $f_{E}=f_{4}+f_{5}+f_{6}=81.8 \%$, respectively.

Table 2 [about here]

We determine the nominal states based on quarterly expected inflation data. We use the mean, one-year-ahead inflation forecasts from the Survey of Professional Forecasters, as reported by the Federal Reserve Bank of Philadelphia. ${ }^{13}$ We estimate a three-state Markov regime-switching model and set expected inflation to the unconditional mean in the medium nominal state. We discipline the chain such that the stationary probabilities of being in low-, moderate- or high-expected inflation regimes are $f_{L}=f_{1}+f_{4}=25 \%, f_{M}=f_{2}+f_{5}=50 \%$, and $f_{H}=f_{3}+f_{6}=25 \%$, respectively. This calibration ensures symmetry in the probabilities of being in the $L$ or $H$ expected-inflation regimes.

Regarding the firm parameters, the corporate tax rate is set to $\eta=15 \%$ and the liquidation value in default is $\alpha=50 \%$. We normalize the initial value of the cash flow to $X_{0}=1$. Preferences involve a risk aversion of $\gamma=10$, an elasticity of intertemporal substitution (EIS) of $\psi=2$, and a subjective discount factor of $\beta=0.03$. Finally, the sensitivity of nominal cash-flow growth to expected inflation is set to $\varphi=0.5$, following the empirical evidence on cash-flow stickiness we discuss in section 2 .

Based on this calibration, the expected inflation rate is $1.96 \%$ in the low-inflation state, $3.54 \%$ in moderate inflation, and $5.13 \%$ during times of high inflation. The nominal growth rate of cash flows ranges between $-9.91 \%$ in the recession/low-inflation state to $7.50 \%$ in the expansion/highinflation state. The nominal risk-free rate varies between $4.79 \%$ in recession/low inflation and $9.12 \%$ in expansion/high inflation.

\section{Theoretical Predictions}

This section discusses the model predictions focusing on the role of expected inflation for corporate asset prices and default risk.

\footnotetext{
${ }^{12}$ Following Bhamra et al. (2010a,b), we account for an additional $22.58 \%$ of firm-specific volatility. The total cash-flow volatility is thus approximately $25 \%$ for our benchmark firm, which is the average volatility of firms with outstanding rated corporate debt.

${ }^{13}$ The availability of the data determines our start date.
} 


\subsection{Characteristics of the economy}

Table 3 first reports the characteristics of the economy. Unconditionally, the representative firm services a debt coupon that is equal to $80.22 \%$ of the initial cash flow and defaults optimally when the firm's cash flows fall to a boundary that is approximately equal to $26 \%$ of the initial level. With such policies, financial leverage is $44.89 \%$, the credit spread is $156 \mathrm{bps}$, and the value of equity is 11.39 . We can interpret equity value as the price-earning ratio, given that nominal cash flows (earnings) are normalized to unity. Our predictions thus reflect the impact of nominal conditions on real equity valuation. We now investigate how default risk and asset prices vary with expected inflation.

\section{Table 3 [about here]}

\subsection{Implications for default risk}

Our model features two channels through which a change in expected inflation affects a firm's default risk. First, nominal cash flows grow less rapidly in times of low expected inflation, which increases the probability of reaching the default boundary. This channel increases a firm's default risk, as captured by the higher prices of Arrow-Debreu default claims, $q_{D, i j, t}^{\$}$. Second, the nominal risk-free rate decreases as expected inflation decreases, which increases the present value of debt payments. Firms have a greater debt burden, thereby further increasing default risk. Table 3 shows default risk is indeed highest in a low-expected-inflation environment. The credit spread increases from 139 bps to $151 \mathrm{bps}$ from state EH to EL even though the level of cash flows is identical.

These effects occur because a firm's capital structure is fixed and cannot be adjusted in the short term to a change in nominal conditions. As the economy moves into lower expected inflation, firms would benefit from a decrease in their debt level (e.g., through debt buyback) to attenuate the increase in credit risk, but are stuck with their existing debt issues. Leverage stickiness is thus key to understanding why default risk varies with fluctuating nominal prices, in line with Bhamra et al. (2011), Kang and Pflueger (2015), and Gomes et al. (2016).

A change in expected inflation has two opposing effects on debt value. Lower expected inflation reduces the nominal risk-free rate, thereby increasing the present value of the coupons and thus the market value of debt. However, firms face a higher default probability, which reduces the value of the debt claim because of bankruptcy costs. Overall, the first effect dominates (see Table 3). Our model thus indicates that periods of low expected inflation are jointly associated with greater debt value and higher credit risk. 


\subsection{Implications for equity valuation}

Because low expected inflation results in higher default risk, one might expect lower equity valuations in low expected inflation states. And indeed, a higher likelihood of default reduces the present value of the cash flows to shareholders. However, another mechanism works in the opposite direction and generates an increase in equity prices when expected inflation decreases: The nominal risk-free rate is more sensitive than the cash flows to changes in expected inflation. This channel, which we label the "discounting effect," arises from the stickiness of cash flows. Overall, the model predicts that equity prices are higher during times of low expected inflation than in periods of high expected inflation (see Table 3).

Our model thus explains why increases in expected inflation are negative for shareholders, whereas a decrease in expected inflation is good news. We highlight two central mechanisms of nominal risk: an increase in default risk and a decrease in the nominal discount rate during times of low expected inflation. The second effect dominates, and disinflation has a positive real effect on financial asset prices. The model thus helps explain the forces driving the beneficial impact of lower expected inflation for equity investors.

\subsection{Low versus high inflation: Asymmetry}

We now separately analyze the risk of low and high expected inflation to highlight an asymmetry: Low expected inflation is not the mere mirror image of high expected inflation for a representative firm.

Low and high expected inflation impact equity prices in opposite directions. Table 3 indicates the equity valuation increases by $9.6 \%$ (from 11.77 to 12.90 ) when the economy switches from moderate expected inflation to low expected inflation. By contrast, the equity valuation decreases by only $3.1 \%$ (from 11.77 to 11.41 ) when expected inflation switches to the high state. ${ }^{14}$ Hence, the quantitative predictions are not of equal size. Figure 3 illustrates this non-linear effect for equity valuation and the credit spread. The impact of low expected inflation on equity prices is stronger than the impact of high expected inflation, although both states are equally likely. The reason is that a shift in nominal risk-free rates impacts equity prices non-linearly via the discounting effect. The same asymmetric effect applies to the value of debt (i.e., financial leverage) and thus to credit risk.

Figure 3 [about here]

Our theory predicts that the presence of nominal risk increases equity values, as a direct consequence of the asymmetry. Given the convex relation between equity valuation and expected inflation, the average equity value across the low and high expected inflation states are higher than the equity

\footnotetext{
${ }^{14}$ We consider being in the expansion state, but the message is qualitatively similar when considering the recession state.
} 
value during the average expected inflation state. Following the same reasoning, nominal risk also increases debt valuation on average.

To quantify the role of nominal risk, we compare the results of the full model (see Table 3) with the case in which we switch off variations in the nominal state (Table 4). In this latter specification, the expected inflation rate is set at its unconditional mean, which corresponds to the "moderate inflation" regime. Table 5 indicates the risk of fluctuating nominal prices on average increases asset valuations adding up to $0.66 \%$ of firm value. This increase in firm value translates, using a simple back-of-theenvelope calculation, into an increase in firm value of approximately US $\$ 425$ billion, given a market capitalization of listed companies at the NYSE of US\$19.3 trillion (as of June 2016) and an average leverage ratio of 0.3 . The impact of nominal risk for investors is thus economically important.

Tables 4 and 5 [about here]

\subsection{Cross-sectional predictions}

In the cross section, equity prices of firms with higher leverage should be less sensitive to variations in expected inflation, because of two offsetting effects. On the one hand, with sticky cash flows, lower expected inflation increases the present value of cash flows and thus firm value. On the other hand, the value of debt also increases. The sticky leverage channel drives the second channel, which is naturally stronger for high-leverage firms. Hence, for such firms, equity valuation (determined by firm value minus debt value) becomes less sensitive to changes in expected inflation. Consequently, the presence of debt reduces, rather than exacerbates, the sensitivity of stock prices to changes in nominal conditions. By contrast, no such opposing forces drive the relation between credit risk and expected inflation conditional on leverage, which implies the cross-sectional implications are likely much weaker for credit spreads than for equity prices.

Table 6 compares the predictions for firms with low versus high leverage. Nominal fluctuations have greater asset-pricing implications for firms that are less levered. In comparison, the difference in the relation between credit risk and expected inflation for high- versus low-leverage firms is negligible. ${ }^{15}$

Table 6 [about here]

\subsection{Discussion}

Our model shows higher expected inflation negatively affects equity prices, although nominal risk is unpriced. In fact, we intentionally use a model in which nominal risk is not priced in the real stochastic discount factor. This approach ensures an inflation risk premium does not drive any of our predictions.

\footnotetext{
${ }^{15}$ The difference is slightly positive due to a convexity effect: The sensitivity of credit spreads to news increases with the level of credit risk (David, 2008).
} 
Only the impact of inflation on the quantity of risk drives our predictions for equity valuation and credit risk. Hence, nominal conditions have no effect on the representative agent's pricing kernel, but nonetheless have a non-trivial influence on asset prices. Furthermore, the agent is fully rational in our economy and thus does not suffer from any type of money illusion.

The key channel for the relation between default risk and inflation is the presence of sticky leverage, whereas the stickiness in cash flows determines the negative sensitivity of equity prices to expected inflation. ${ }^{16}$ As illustrated in Figure 4, the absence of cash flow stickiness reverts the relation between equity prices and inflation but not the relation with credit risk. To sum up, both the sticky-cash-flow and the sticky-leverage channels are necessary ingredients to understand the joint relations between inflation, equity valuation, and default risk.

Figure 4 [about here]

\section{Empirical Validation}

In this section, we test the predictions of the model. We examine whether a decrease in expected inflation results in both greater default risk and higher equity valuation, for the same set of firms. We also explore the cross-sectional implication that the relation between equity prices and expected inflation are weaker for more levered firms and investigate whether these relations are asymmetric.

\subsection{Data}

Our empirical analysis is based on the following data. Expected inflation is the year-on-year expected GDP-deflator inflation from the Federal Reserve Bank of Philadelphia's Survey of Professional Forecasters. We consider two measures of equity valuation: the firm's market-to-book (M/B) equity ratio and the price-dividend ratio. Default risk is measured by a firm's financial-distress risk, following Campbell, Hilscher, and Szilagyi (2008), which we convert into the next quarter's default probability. Appendix A provides details on the computation of these measures. Accounting variables are from Compustat Fundamental Quarterly data, whereas stock price variables are from CRSP. The dataset spans from April 1972 to December 2016. Table 7 displays the summary statistics.

Table 7 [about here]

\subsection{Relations between equity valuation, default risk, and expected inflation}

We first analyze the relations between equity valuations and default risk with expected inflation. Figure 5 displays the results for the price-dividend ratio (top panels), the market-to-book ratio (middle

\footnotetext{
${ }^{16} \mathrm{~A}$ model in which a monetary authority sets short-term nominal interest rates endogeneously and in which the Taylor principle is satisfied delivers similar predictions without relying on the sticky cash flow channel.
} 
panels), and the bankruptcy probability (bottom panels). The panels plot the (value-weighted) averages of the firm characteristics against the level of expected inflation observed in the corresponding quarter. We disentangle the relations by level of financial leverage, which we define as long-term debt and debt in current liabilities over the sum of the numerator and stockholders' equity. The left panels report portfolios of firms with below-median leverage, whereas the right panels report firms with above-median leverage. Each panel displays the fit of a quadratic regression.

Figure 5 [about here]

This graphical analysis suggests the price-dividend ratio, the market-to-book ratio, and the bankruptcy probability are all negatively related to the level of expected inflation. Importantly, each portfolio contains the same set of firms, thereby indicating a decrease in expected inflation simultaneously increases both a firm's equity valuation and its default risk. Furthermore, as our model predicts, the relations based on equity valuation appear to be stronger for low-leverage firms.

\subsection{Portfolio sorts}

As a formal test of these relations, we now exploit double sorts. We first sort all firms into two portfolios based on their financial leverage. We then create three equal-sized portfolios depending on the level of expected inflation.

Table 8 reports the results. Panel A shows for conditional double sorts that both equity valuation and default risk decrease in expected inflation. The high expected inflation-minus-low expected inflation estimates are all negative and statistically significant within each leverage sort. In terms of magnitude, for low- (high-) leverage firms, the price-dividend ratio is on average 102.8 (66.4) when expected inflation is low and 47.0 (25.4) when expected inflation is high. The market-to-book ratios are $4.24(2.25)$ and 1.95 (0.98), respectively. These differences are economically large. Further, the double difference by leverage ratios (i.e., the difference between estimates of the high expected inflation minus low expected inflation estimates across high- and low-leverage firms) are also highly statistically significant. ${ }^{17}$ This test confirms the relation between equity valuation and expected inflation is negative and is stronger for firms with lower levels of financial leverage. The conditional double sorts also confirm that the sensitivity of the default probability to expected inflation is stronger for high-leverage firms $(\mathrm{H}-\mathrm{L}=3.59-4.98=-1.39)$ than for low-leverage firms $(\mathrm{H}-\mathrm{L}=2.15-3.22=-1.07)$. Both the sign and the (low) magnitude of this difference are consistent with our theory.

Table 8 [about here]

\footnotetext{
${ }^{17}$ We bootstap the double difference to calculate standard errors.
} 
We report several alternative tests to provide robustness of these empirical findings. First, Panel B of Table 8 shows the results remain similar when we perform unconditional double sorts. Second, we consider a measure of expected inflation that is independent of the business cycle, because in the model, real and nominal states are independent. That is, we first orthogonalize the level of expected inflation with respect to an NBER recession indicator and reproduce Table 8 with this orthogonalized measure. Table 9 displays the results and confirms our baseline analyses. Third, Table 10 focuses on the 1972Q2-2007Q4 period to ensure the recent Great Recession does not exclusively drive the asymmetry in the relation between expected inflation with valuations and default risk. The relations between equity valuation, default risk, and expected inflation continue to hold with the same economic magnitude and statistical significance.

Tables 9 and 10 [about here]

\subsection{Firm-level regression analysis}

As a second test, we examine how the valuation ratios and default risk at the firm level vary with expected inflation when we keep constant other firm characteristics and aggregate economic conditions.

Equity valuations and default probabilities vary with firm characteristics; therefore, accounting for such drivers is critical. Following Fama and French (2015), we consider the level of investment, profitability, and firm size as firm-level controls (see Appendix A for details of the variable definitions). We also include the year-on-year growth rate of U.S. industrial production, a recession indicator based on the NBER business-cycle dates, the trailing one-year return of the S\&P 500 index, and the slope of the yield curve measured by the yield spread between the 10-year Treasury note and the three-month Treasury bill, because these factors predict U.S. defaults. ${ }^{18}$ We also control for the recent period of unconventional monetary policies by including a dummy variable that is equal to 1 over the 2008Q12016Q4 period, and zero otherwise. These data are from the Federal Reserve Bank of St. Louis. Table 11 reports the regression results. We cluster standard errors at the quarter level to allow for correlations in error terms of unknown form across firms in a given quarter.

Table 11 [about here]

We see in columns (1)-(3) that expected inflation is a strong driver of the price-dividend ratio, the market-to-book ratio, and the level of distress risk beyond the information contained in firm fundamentals and economic/financial conditions. A one-standard-deviation decrease in the expected

\footnotetext{
${ }^{18}$ See, for example, Das, Duffie, Kapadia, and Saita (2007), Duffie, Saita, and Wang (2007), Campbell et al. (2008), Duffie, Eckner, Horel, and Saita (2009), Giesecke, Longstaff, Schaefer, and Strebulaev (2011), and Azizpour, Giesecke, and Schwenkler (2018).
} 
inflation rate increases the price-dividend ratio by 16.7 , which is economically sizable. Columns (4)(6) repeat the analysis for the 1972Q2-2007Q4 period. The empirical results are robust to this sample variation.

\subsection{Asymmetric relations}

We now turn to another central prediction of the model: A decrease in expected inflation has a stronger impact on equity valuation and default risk than an increase in expected inflation. The following analysis tests for such asymmetry in the data.

To investigate a potential non-linearity in the relation between the valuation ratios (or default risk) and expected inflation, we interact expected inflation with a dummy variable, $\mathcal{D}_{L, M}$, that takes the value of 1 when expected inflation is below the $75^{\text {th }}$ percentile. This choice follows from our calibration, in which high expected inflation corresponds to the top quartile.

Table 12 (columns (1)-(3)) shows the relation between equity valuations and expected inflation is stronger when expected inflation is lower. The difference in the sensitivity to expected inflation is economically and statistically significant. The same result holds for distress risk. Notably, ignoring the recent period (2008Q1-2016Q4) yields similar results (columns (4)-(6)). The data thus support the asymmetry the model predicts.

We consider alternative samples to verify the robustness of our results. First, we compare the findings with and without financial firms and utilities in Table 13, because they operate in regulated markets or have special capital structures. Second, Table 14 excludes all tech firms, which tend to display relatively high equity valuations, and, third, we exclude the pre-1980 period, which is characterized by particularly high expected inflation. The results remain similar in all of these cases.

Tables 12, 14, and 13 [about here]

Overall, our empirical analysis validates the model mechanism, which suggests default risk and equity valuation decrease with the level of expected inflation, and that these relations are asymmetric. That is, a decrease in expected inflation has a stronger impact on default risk and valuation ratios when expected inflation is low than when it is high. The increase in expected inflation is therefore not the mirror image of a decrease in expected inflation.

\section{Conclusion}

Defaults increase in times of low expected inflation but so do equity valuations. We develop a model which jointly rationalizes these two stylized patterns in the data. In the model, nominal risk impacts real asset prices via a sticky-cash-flow and a sticky-leverage channels. There are two key mechanisms at 
play. First, long-term nominal debt coupons are fixed, but expected inflation varies. This assumption makes expected future real debt coupons dependent on future expected inflation, ensuring that nominal risk impacts real corporate bond values and hence default risk. Second, cash-flow growth is less sensitive to variations in expected inflation than the nominal risk-free rate, which induces stickiness in firm profitability. This feature makes equity prices convex in the nominal risk-free rate and hence expected inflation.

Our model thus implies that lower expected inflation simultaneously increases real asset values and default risk. The effect on equity prices is stronger for firms with less leverage. Hence, leverage dampens rather than exacerbates the sensitivity of equity valuation to inflation expectations. Importantly, a decrease in expected inflation from moderate to low increases real equity values by more than a decrease from high to moderate expected inflation of equal size. We find support for the model predictions in the data, lending credence to the idea that the sticky-leverage and cash-flow channels are important for understanding the economics behind how expected inflation risk impacts real asset values and corporate default risk.

In our framework, the stochastic discount factor is exogenous. As such, understanding how default clusters caused by lower expected inflation impact aggregate consumption and hence the stochastic discount factor, which will in turn impact default decisions, is beyond the scope of this paper. Understanding the general equilibrium implications for how inflation risk can amplify default risk and its impact on real asset values is an interesting topic for future research. 


\section{References}

Ang, A. A., M. Briere, and O. Signori (2012). Inflation and individual equities. Financial Analysts Journal 68(4), 36-55.

Azizpour, S., K. Giesecke, and G. Schwenkler (2018). Exploring the sources of default clustering. Journal of Financial Economics, Forthcoming.

Ball, L. and N. G. Mankiw (1994). Asymmetric price adjustment and economic fluctuations. The Economic Journal 104, 247-261.

Bansal, R. and I. Shaliastovich (2013). A long-run risks explanation of predictability puzzles in bond and currency markets. Review of Financial Studies 26(1), 1-33.

Beeler, J. and J. Y. Campbell (2012). The long-run risks model and aggregate asset prices: An empirical assessment. Critical Finance Review 1(1), 141-182.

Bekaert, G. and X. Wang (2010). Inflation risk and the inflation risk premium. Economic Policy 25(64), 755-806.

Bhamra, H. S., A. J. Fisher, and L.-A. Kuehn (2011). Monetary policy and corporate default. Journal of Monetary Economics 58(5), 480-494.

Bhamra, H. S., L.-A. Kuehn, and I. A. Strebulaev (2010a). The aggregate dynamics of capital structure and macroeconomic risk. Review of Financial Studies 23(12), 4187-4241.

Bhamra, H. S., L.-A. Kuehn, and I. A. Strebulaev (2010b). The levered equity risk premium and credit spreads: A unified framework. Review of Financial Studies 23(2), 645-703.

Bodie, Z. (1976). Common stocks as a hedge against inflation. The Journal of Finance 31 (2), 459-470.

Boons, M., F. Duarte, F. de Roon, and M. Szymanowska (2016). Time-varying inflation risk and the cross section of stock returns. Working paper, Federal Reserve Bank of New York.

Boudoukh, J. and M. Richardson (1993). Stock returns and inflation: A long-horizon perspective. The American Economic Review 83(5), 1346-1355.

Campbell, J. Y., J. Hilscher, and J. Szilagyi (2008). In search of distress risk. The Journal of Finance 63(6), 2899-2939.

Campbell, J. Y., A. Sunderam, and L. M. Viceira (2017). Inflation bets or deflation hedges? the changing risks of nominal bonds. Critical Finance Review 6(2), 263-301.

Campbell, J. Y. and T. Vuolteenaho (2004). Inflation illusion and stock prices. American Economic Review 94(2), 19-23.

Chen, H. (2010). Macroeconomic conditions and the puzzles of credit spreads and capital structure. The Journal of Finance 65(6), 2171-2212. 
Chen, N.-F., R. Roll, and S. A. Ross (1986). Economic forces and the stock market. Journal of Business, 383-403.

Das, S. R., D. Duffie, N. Kapadia, and L. Saita (2007). Common failings: How corporate defaults are correlated. The Journal of Finance 62(1), 93-117.

David, A. (2008). Inflation uncertainty, asset valuations, and the credit spreads puzzle. The Review of Financial Studies $21(6), 2487-2534$.

David, A. and P. Veronesi (2013). What ties return volatilities to price valuations and fundamentals? Journal of Political Economy 121(4), 682-746.

Day, T. E. (1984). Real stock returns and inflation. The Journal of Finance 39(2), 493-502.

Duffie, D., A. Eckner, G. Horel, and L. Saita (2009). Frailty correlated default. The Journal of Finance 64(5), 2089-2123.

Duffie, D. and L. G. Epstein (1992). Asset pricing with stochastic differential utility. Review of Financial Studies 5(3), 411-436.

Duffie, D., L. Saita, and K. Wang (2007). Multi-period corporate default prediction with stochastic covariates. Journal of Financial Economics 83(3), 635-665.

Duffie, D. and C. Skiadas (1994). Continuous-time security pricing: A utility gradient approach. Journal of Mathematical Economics 23(2), 107-131.

Elliott, R. J. (1982). Stochastic calculus and applications, Volume 2. Springer.

Epstein, L. G. and S. E. Zin (1989). Substitution, risk aversion, and the temporal behavior of consumption and asset returns: A theoretical framework. Econometrica 57(4), 937-969.

Eraker, B., I. Shaliastovich, and W. Wang (2015). Durable goods, inflation risk, and equilibrium asset prices. The Review of Financial Studies 29(1), 193-231.

Fama, E. F. (1981). Stock returns, real activity, inflation, and money. American Economic Review $71(4), 545-565$.

Fama, E. F. and K. R. French (2015). A five-factor asset pricing model. Journal of Financial Economics $116(1), 1-22$.

Fama, E. F. and G. W. Schwert (1977). Asset returns and inflation. Journal of Financial Economics 5(2), 115-146.

Feldstein, M. et al. (1980). Inflation and the stock market. American Economic Review 70(5), 839-47.

Fisher, I. (1933). The debt-deflation theory of great depressions. Econometrica 1(4), 337-57.

Gabaix, X. (2008). Variable rare disasters: A tractable theory of ten puzzles in macro-finance. American Economic Review 98(2), 64-67.

Geske, R. and R. Roll (1983). The fiscal and monetary linkage between stock returns and inflation. The Journal of Finance 38(1), 1-33. 
Giesecke, K., F. A. Longstaff, S. Schaefer, and I. Strebulaev (2011). Corporate bond default risk: A 150-year perspective. Journal of Financial Economics 102(2), 233-250.

Gomes, J. F., U. J. Jermann, and L. Schmid (2016). Sticky leverage. The American Economic Review 106(12), 3800-3828.

Gorodnichenko, Y. and M. Weber (2016). Are sticky prices costly? evidence from the stock market. American Economic Review 106(1), 165-99.

Gultekin, N. B. (1983). Stock market returns and inflation forecasts. The Journal of Finance 38(3), $663-673$.

Hess, P. J. and B.-S. Lee (1999). Stock returns and inflation with supply and demand disturbances. Review of Financial Studies 12(5), 1203-1218.

Jobert, A. and L. C. Rogers (2006). Option pricing with markov-modulated dynamics. SIAM Journal on Control and Optimization 44(6), 2063-2078.

Kang, J. and C. E. Pflueger (2015). Inflation risk in corporate bonds. The Journal of Finance 70(1), $115-162$.

Karatzas, I. and S. E. Shreve (1991). Brownian motion and stochastic calculus. Springer-Verlag, New York.

Kaul, G. (1987). Stock returns and inflation: The role of the monetary sector. Journal of Financial Economics 18(2), 253-276.

Kaul, G. and H. N. Seyhun (1990). Relative price variability, real shocks, and the stock market. The Journal of Finance 45(2), 479-496.

Leland, H. E. (1994). Corporate debt value, bond covenants, and optimal capital structure. Journal of Finance 49(4), 1213-1252.

Lintner, J. (1975). Inflation and security returns. The Journal of Finance 30(2), 259-280.

Mankiw, N. G. (1985). Small menu costs and large business cycles: A macroeconomic model of monopoly. Quarterly Journal of Economics $100(2), 529-538$.

Miller, K. D., F. J. Jeffrey, and G. Mandelker (1976). The "fisher effect" for risky assets: An empirical investigation. The Journal of Finance 31(2), 447-458.

Modigliani, F. and R. A. Cohn (1979). Inflation, rational valuation and the market. Financial Analysts Journal 35(2), 24-44.

Nakamura, E. and J. Steinsson (2008). Five facts about prices: A reevaluation of menu cost models. Quarterly Journal of Economics 123(4), 1415-1464.

Nelson, C. R. (1976). Inflation and rates of return on common stocks. The Journal of Finance 31(2), $471-483$. 
Pearce, D. K. and V. V. Roley (1988). Firm characteristics, unanticipated inflation, and stock returns. The Journal of Finance 43(4), 965-981.

Piazzesi, M. and M. Schneider (2006). Equilibrium yield curves. NBER macroeconomics Annual 21, $389-472$.

Pindyck, R. S. et al. (1984). Risk, inflation, and the stock market. American Economic Review 74(3), $335-351$.

Ritter, J. R. and R. S. Warr (2002). The decline of inflation and the bull market of 1982-1999. Journal of Financial and Quantitative Analysis 37(1), 29-61.

Schroder, M. and C. Skiadas (1999). Optimal consumption and portfolio selection with stochastic differential utility. Journal of Economic Theory 89(1), 68-126.

Schwert, G. W. (1981). The adjustment of stock prices to information about inflation. The Journal of Finance 36(1), 15-29.

Sharpe, S. A. (2002). Reexamining stock valuation and inflation: The implications of analysts' earnings forecasts. The Review of Economics and Statistics 84(4), 632-648.

Solnik, B. (1983). The relation between stock prices and inflationary expectations: The international evidence. The Journal of Finance 38(1), 35-48.

Stulz, R. M. (1986). Asset pricing and expected inflation. The Journal of Finance 41(1), 209-223.

Wachter, J. A. (2006). A consumption-based model of the term structure of interest rates. Journal of Financial Economics 79(2), 365-399.

Weber, M. (2015). Nominal rigidities and asset pricing. Chicago Booth, Working paper.

Weil, P. (1989). The equity premium puzzle and the risk-free rate puzzle. Journal of Monetary Economics 24(3), 401-421. 


\section{Table 1: Empirical evidence on cash flow stickiness}

This table reports the sensitivity of cash flow growth to expected inflation. Cash flow growth is measured as the mean forecast for the one-year-ahead corporate profit growth rate, and expected inflation is measured as the mean forecast for one-year-ahead inflation. All growth rates are annualized. We report standard errors corrected for heteroskedasticity and serial correlation in parentheses. Statistical significance at the 10\%, 5\%, and $1 \%$ levels is denoted by $*, * *$, and $* * *$, respectively. Forecast data are obtained from the Survey of Professional Forecasters provided by the Federal Reserve Bank of Philadelphia. The control variables are retrieved from the Federal Reserve of St-Louis. The sample period is 1970Q2-2016Q4.

Dependent variable: Expected cash flow growth

\begin{tabular}{|c|c|c|c|c|}
\hline & $\begin{array}{c}(1) \\
\text { Expected } \\
\text { Economic Growth }\end{array}$ & $\begin{array}{l}\text { (2) } \\
\text { Consumption } \\
\text { Growth }\end{array}$ & $\begin{array}{c}(3) \\
\text { Economic } \\
\text { Growth }\end{array}$ & $\begin{array}{c}(4) \\
\text { Business } \\
\text { Cycle Indicator }\end{array}$ \\
\hline Expected inflation $_{t}$ & $\begin{array}{c}\mathbf{0 . 3 8 2}^{\text {*** }} \\
(0.180)\end{array}$ & $\begin{array}{c}\mathbf{0 . 3 9 7}{ }^{* *} \\
(0.176)\end{array}$ & $\begin{array}{c}\mathbf{0 . 4 2 5}^{* *} \\
(0.174)\end{array}$ & $\begin{array}{c}\mathbf{0 . 4 1 5}^{* *} \\
(0.168)\end{array}$ \\
\hline Expected GDP growth $_{t}$ & $\begin{array}{c}3.773^{* * *} \\
(0.285)\end{array}$ & $\begin{array}{c}4.068^{* * *} \\
(0.327)\end{array}$ & $\begin{array}{c}4.265^{* * *} \\
(0.318)\end{array}$ & $\begin{array}{c}4.278^{* * *} \\
(0.317)\end{array}$ \\
\hline Cons. growth ${ }_{t-1}$ & & $\begin{array}{l}-0.259 \\
(0.167)\end{array}$ & $\begin{array}{l}-0.024 \\
(0.171)\end{array}$ & $\begin{array}{l}-0.014 \\
(0.182)\end{array}$ \\
\hline Ind. prod. growth ${ }_{t-1}$ & & & $\begin{array}{c}-0.196^{* * *} \\
(0.061)\end{array}$ & $\begin{array}{c}-0.189 * * * \\
(0.064)\end{array}$ \\
\hline NBER recession $_{t}$ & & & & $\begin{array}{c}0.377 \\
(1.227)\end{array}$ \\
\hline Constant & $\begin{array}{c}-4.280^{* * *} \\
(1.011)\end{array}$ & $\begin{array}{c}-4.349^{* * *} \\
(0.999)\end{array}$ & $\begin{array}{c}-5.278^{* * *} \\
(0.982)\end{array}$ & $\begin{array}{c}-5.376^{* * *} \\
(1.055)\end{array}$ \\
\hline $\begin{array}{l}\text { Nobs } \\
\mathrm{R}^{2}\end{array}$ & $\begin{array}{c}186 \\
0.575\end{array}$ & $\begin{array}{c}185 \\
0.581\end{array}$ & $\begin{array}{c}185 \\
0.605\end{array}$ & $\begin{array}{c}185 \\
0.605\end{array}$ \\
\hline
\end{tabular}




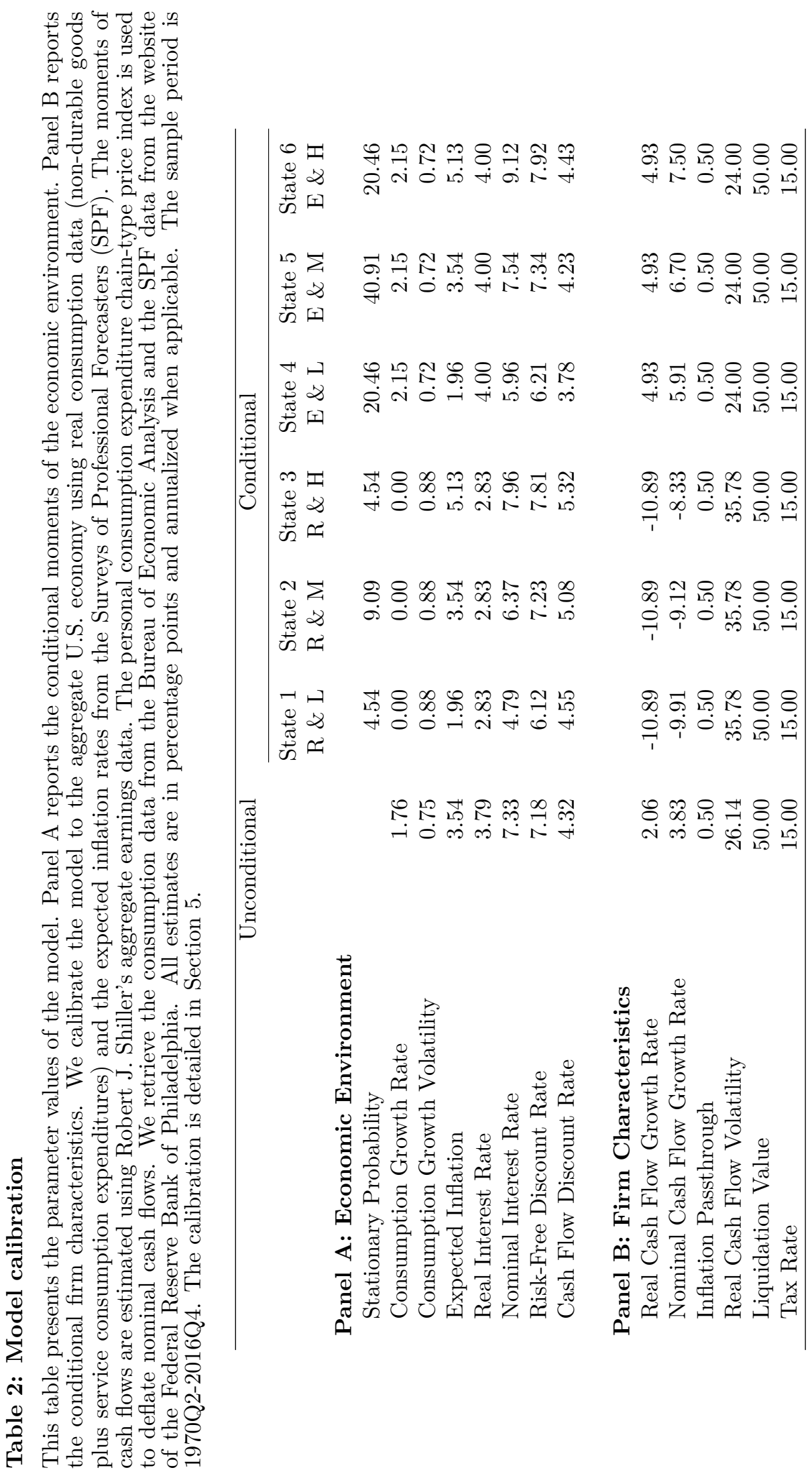




\section{Table 3: Asset prices with nominal risk}

This table presents the predictions of the model with fluctuating nominal conditions. Panel A reports the coupon and the conditional default boundaries. The capital structure is chosen optimally in the state of expansion with moderate inflation. Panel B reports the conditional asset pricing quantities for the economy. Each column displays the predictions for a specific state of the economy: the expected inflation rate can be low (L), moderate $(\mathrm{M})$, or high $(\mathrm{H})$, whereas the real economy can be in recession $(\mathrm{R})$ or in expansion $(\mathrm{E})$. We also report the unconditional predictions for a weighted average of these states. Market leverage is the ratio of the market value of debt to the sum of the market values of debt and equity. The parameter values of the model are reported in Table 2 and discussed in Section 5.

\begin{tabular}{|c|c|c|c|c|c|c|c|}
\hline \multicolumn{2}{|c|}{ Unconditional } & \multicolumn{6}{|c|}{ Conditional } \\
\hline Stationary Probability & & $\begin{array}{c}\text { State } 1 \\
\text { R \& L } \\
0.0454\end{array}$ & $\begin{array}{l}\text { State } 2 \\
\mathrm{R} \& \mathrm{M} \\
0.0909\end{array}$ & $\begin{array}{c}\text { State } 3 \\
\text { R \& H } \\
0.0454\end{array}$ & $\begin{array}{c}\text { State } 4 \\
\text { E \& L } \\
0.2046\end{array}$ & $\begin{array}{l}\text { State } 5 \\
\text { E \& M } \\
0.4091\end{array}$ & $\begin{array}{c}\text { State } 6 \\
\text { E \& H } \\
0.2046\end{array}$ \\
\hline $\begin{array}{l}\text { Panel A: Corporate Policies } \\
\text { Default Boundaries (Coupon: } 0.8022 \text { ) }\end{array}$ & & 0.2655 & 0.2689 & 0.2679 & 0.2598 & 0.2625 & 0.2611 \\
\hline $\begin{array}{l}\text { Panel B: Asset Pricing Quantities } \\
\text { Equity Value } \\
\text { Debt Value }\end{array}$ & $\begin{array}{r}11.39 \\
9.22\end{array}$ & $\begin{array}{l}9.45 \\
9.66\end{array}$ & $\begin{array}{l}8.65 \\
8.58\end{array}$ & $\begin{array}{l}8.41 \\
8.10\end{array}$ & $\begin{array}{l}12.90 \\
10.40\end{array}$ & $\begin{array}{r}11.77 \\
9.16\end{array}$ & $\begin{array}{r}11.41 \\
8.61\end{array}$ \\
\hline $\begin{array}{l}\text { Market Leverage (\%) } \\
\text { Credit Spreads (bps) }\end{array}$ & $\begin{array}{r}44.89 \\
156.01\end{array}$ & $\begin{array}{r}50.54 \\
219.14\end{array}$ & $\begin{array}{r}49.78 \\
212.26\end{array}$ & $\begin{array}{r}49.06 \\
210.06\end{array}$ & $\begin{array}{r}44.63 \\
150.76\end{array}$ & $\begin{array}{r}43.76 \\
141.58\end{array}$ & $\begin{array}{r}43.02 \\
139.08\end{array}$ \\
\hline
\end{tabular}

Table 4: Firm policies and asset prices without nominal risk

This table presents the predictions of the model without fluctuating nominal conditions. Panel A reports the coupon and the conditional default boundaries. The capital structure is chosen optimally in the state of expansion. In absence of nominal risk, the inflation rate is set to its unconditional mean over the sample period, which corresponds to the "moderate inflation" state (M). Panel B reports the conditional asset pricing quantities for the economy. Each column displays the predictions for a specific state of the economy, which can be in recession $(\mathrm{R})$ or in expansion $(\mathrm{E})$. We also report the unconditional predictions for a weighted average of these states. Market leverage is the ratio of the market value of debt to the sum of the market values of debt and equity. The parameter values of the model are reported in Table 2 and discussed in Section 5.

\begin{tabular}{|c|c|c|c|}
\hline & Unconditional & Cond & ional \\
\hline & & State 2 & State 5 \\
\hline & & $\mathrm{R} \& \mathrm{M}$ & $\mathrm{E} \& \mathrm{M}$ \\
\hline Stationary Probability & & 0.1817 & 0.8183 \\
\hline Panel A: Corporate Policies & & & \\
\hline Default Boundaries (Coupon: 0.7952) & & 0.2659 & 0.2596 \\
\hline Panel B: Asset Pricing Quantities & & & \\
\hline Equity Value & 11.38 & 8.80 & 11.96 \\
\hline Debt Value & 9.09 & 8.61 & 9.20 \\
\hline Market Leverage (\%) & 44.58 & 49.48 & 43.49 \\
\hline Credit Spreads (bps) & 152.52 & 209.42 & 139.88 \\
\hline
\end{tabular}


Table 5: Asset pricing implications of nominal risk

This table presents the impact of nominal risk on asset prices. We report the differences in asset pricing predictions with and without nominal risk. In the latter case, the expected inflation rate is constant and set to its unconditional mean (i.e. moderate inflation state), and the model predictions are those of Table 4. We use the default and capital structure decisions of Table 3 in the case of endogenous policies. In the case of exogenous policies, the default and capital structure decisions are those of Table 4 . The differences in asset values are in relative terms (\%). The differences in leverage are in percentage points, while the difference in credit spreads are in basis points. Each column reports model predictions for a different current state of the economy. The expected inflation rate can be low $(\mathrm{L})$, moderate $(\mathrm{M})$, or high $(\mathrm{H})$, whereas the real economy can be in recession (R) or in expansion (E). The parameter values of the model are reported in Table 2 and discussed in Section 5.

\begin{tabular}{|c|c|c|c|c|c|c|c|}
\hline \multicolumn{2}{|c|}{ Unconditional } & \multicolumn{6}{|c|}{ Conditional } \\
\hline Stationary Probability & & $\begin{array}{c}\text { State } 1 \\
\text { R \& L } \\
0.0454\end{array}$ & $\begin{array}{r}\text { State } 2 \\
\mathrm{R} \& \mathrm{M} \\
0.0909\end{array}$ & $\begin{array}{c}\text { State } 3 \\
\mathrm{R} \& \mathrm{H} \\
0.0454\end{array}$ & $\begin{array}{c}\text { State } 4 \\
\text { E \& L } \\
0.2046\end{array}$ & $\begin{array}{r}\text { State } 5 \\
\text { E \& M } \\
0.4091\end{array}$ & $\begin{array}{c}\text { State } 6 \\
\mathrm{E} \& \mathrm{H} \\
0.2046\end{array}$ \\
\hline Equity Value & 0.05 & 7.46 & -1.63 & -4.41 & 7.88 & -1.51 & -4.57 \\
\hline Debt Value & 1.43 & 12.11 & -0.43 & -5.99 & 13.00 & -0.41 & -6.37 \\
\hline Firm Value & 0.66 & 9.76 & -1.04 & -5.20 & 10.11 & -1.03 & -5.35 \\
\hline Market Leverage (\%) & 0.31 & 1.06 & 0.30 & -0.42 & 1.14 & 0.27 & -0.47 \\
\hline Credit Spreads (bps) & 3.49 & 9.72 & 2.83 & 0.64 & 10.88 & 1.70 & -0.80 \\
\hline
\end{tabular}

Table 6: Cross-sectional impact of nominal risk

This table presents the asset pricing impact of nominal risk for firms with different leverage ratios. All firms initially choose identical corporate policies (cf. Table 3). We consider different levels of cash flow to generate cross-sectional differences in market leverage. Lower (higher) cash flow induces higher (lower) market leverage. Panel A reports the predictions for low-leverage firm $(\mathrm{X}=1.25)$, whereas Panel $\mathrm{B}$ reports the predictions for high-leverage firm $(\mathrm{X}=0.75)$. Panel $\mathrm{C}$ presents cross-sectional differences in equity valuation and credit spreads.

\begin{tabular}{lrrrr}
\hline & \multicolumn{3}{c}{ Expected Inflation } & \\
\cline { 2 - 3 } & Low & Moderate & High & High-Low \\
Panel A: Low Leverage & & & & \\
$\quad$ Equity Value & 17.44 & 15.88 & 15.34 & -2.10 \\
$\quad$ Credit Spreads (bps) & & 118.34 & 116.19 & -10.58 \\
& & & & \\
Panel B: High Leverage & 7.28 & 6.68 & 6.51 & -0.77 \\
$\quad$ Equity Value & 231.19 & 222.88 & 220.04 & -11.15 \\
$\quad$ Credit Spreads (bps) & & & & \\
$\quad$ Panel C: High Leverage - Low Leverage & -10.16 & -9.20 & -8.83 & 1.33 \\
$\quad$ Equity Value & 104.42 & 104.55 & 103.85 & -0.56 \\
$\quad$ Credit Spreads (bps) & & &
\end{tabular}




\section{Table 7: Descriptive statistics}

This table reports the summary statistics of the main variables. Financial variables at the firm level are value-weighted. Expected inflation is from the Survey of Professional Forecasters from the Federal Reserve Bank of Philadelphia. Distress risk is computed as in Campbell et al. (2008). Section 7.1 provides details on the computation of the firm variables. $\mathrm{N}$ is the number of observations. The sample period is 1972Q2-2016Q4.

\begin{tabular}{lccccc}
\hline & Mean & SD & $25 \%$ Perc & Median & $75 \%$ Perc \\
\hline Price-Dividend Ratio & 75.816 & 61.153 & 23.827 & 39.634 & 70.625 \\
Market-Book Ratio & 3.173 & 2.076 & 0.955 & 1.554 & 2.673 \\
Financial Risk & -7.867 & 1.013 & -8.151 & -7.641 & -7.009 \\
Implied Default Probability (bps) & 3.831 & 0.008 & 2.883 & 4.800 & 9.028 \\
Expected Inflation & 3.773 & 1.896 & 2.292 & 3.308 & 4.765 \\
Market Leverage & 0.233 & 0.242 & 0.041 & 0.209 & 0.458 \\
Net Income to Total Assets (\%) & 0.612 & 2.116 & -0.230 & 0.532 & 1.209 \\
Excess Return (\%) & 4.061 & 47.223 & -30.277 & -2.068 & 24.405 \\
Return Volatility (\%) & 33.153 & 31.795 & 28.508 & 42.815 & 66.603 \\
Size to Market & -8.963 & 2.593 & -12.595 & -10.837 & -8.376 \\
Short Term Assets to Total & 0.063 & 0.100 & 0.018 & 0.050 & 0.114 \\
Log Share Price & 0.579 & 2.370 & 0.257 & 0.797 & 2.476 \\
Change in Total Assets (\%) & 2.496 & 8.001 & -1.870 & 1.307 & 5.430 \\
Profitability & 0.099 & 9.496 & -0.020 & 0.040 & 0.080 \\
Size & 6.140 & 2.048 & 4.613 & 6.067 & 7.572 \\
IP Growth (\%) & 1.709 & 4.218 & 0.585 & 2.742 & 5.149 \\
S\&P500 (\%) & 9.253 & 16.436 & 1.165 & 10.926 & 22.163 \\
Slope & 1.450 & 1.421 & 0.270 & 1.430 & 2.270 \\
N & 743,536 & 743,536 & 743,536 & 743,536 & 743,536 \\
\hline
\end{tabular}




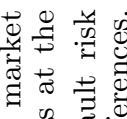

घี 웜

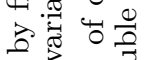

(ิ)를

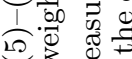

ป d

छ 敢

००

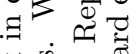

क्ष

$=$ 의

궁

흥

चี สี

ङ․ㄹㄹ

त्व

击 $\equiv$

घี की

등 चै ส .

- $\quad$.

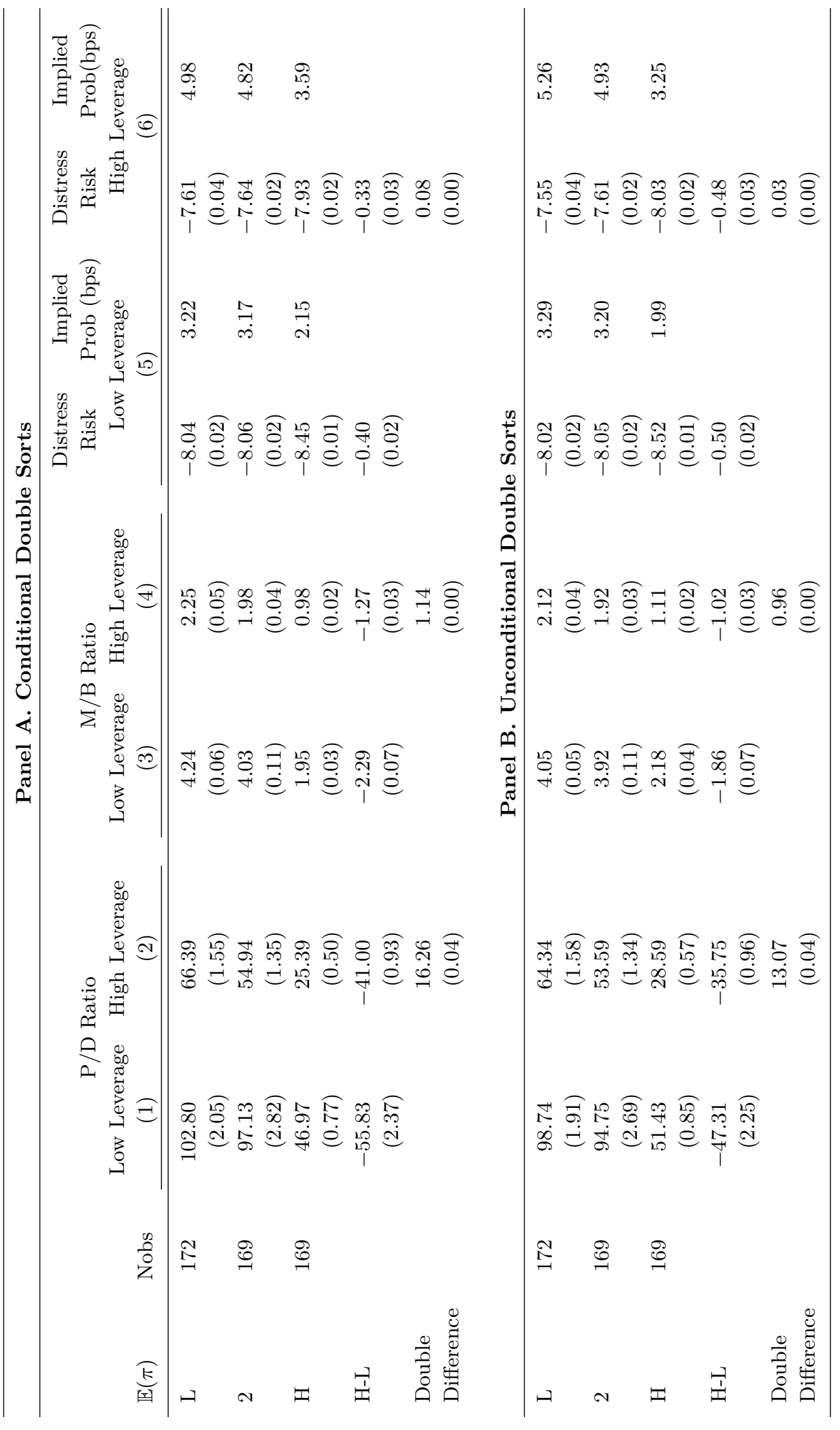




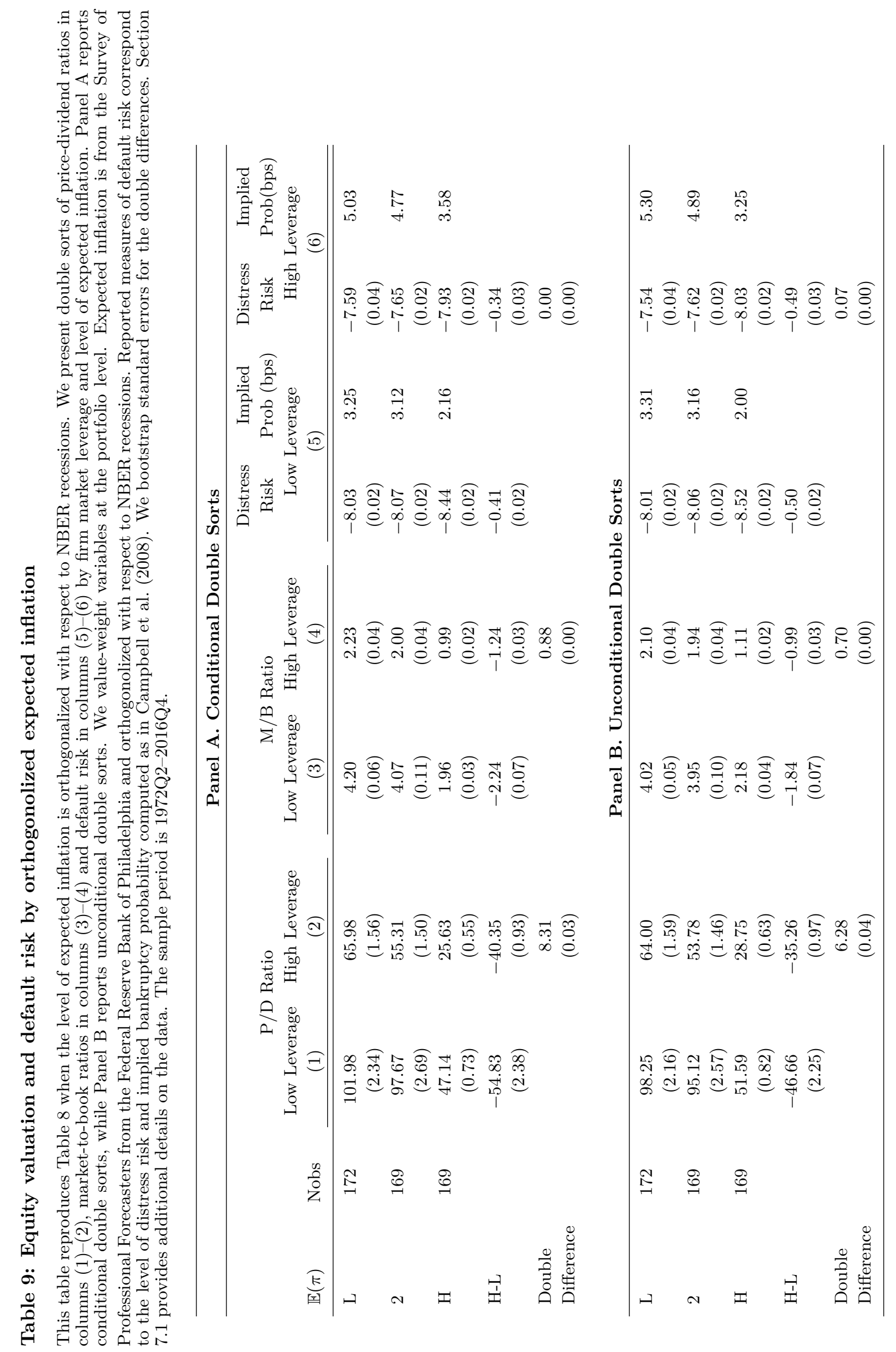




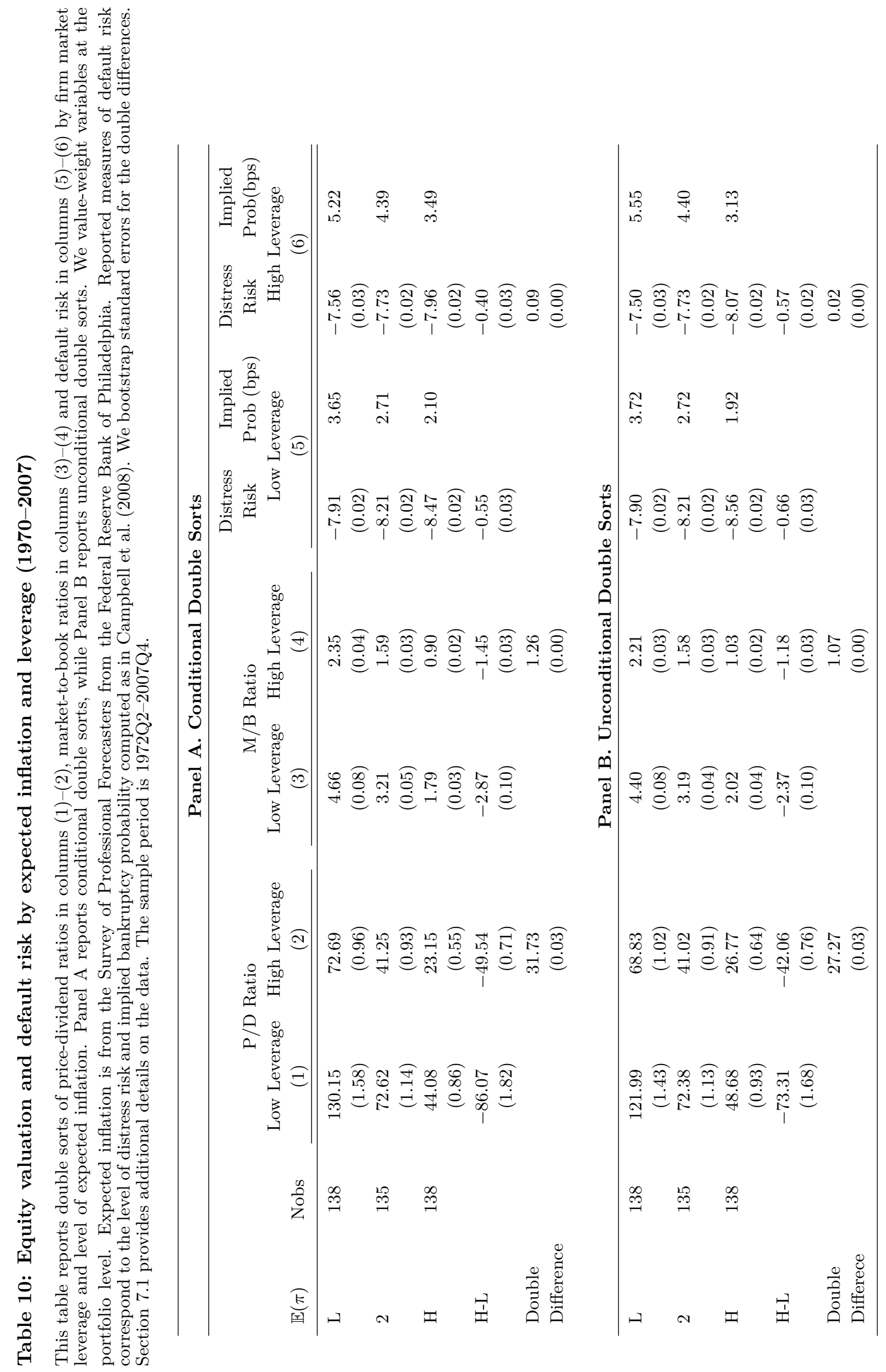


Table 11: Regressions on expected inflation

This table reports regressions of price-dividend ratios, market-to-book ratios and default risk on expected inflation, firm characteristics, and macro aggregates. Expected inflation is from the Survey of Professional Forecasters from the Federal Reserve Bank of Philadelphia. Default risk corresponds to the level of distress risk computed as in Campbell et al. (2008). Section 7.1 provides additional details on the data. The sample period is 1972Q2-2016Q4 in columns (1)-(3) and 1972Q2-2007Q4 in columns (4)-(6). We report standard errors in parentheses. Standard errors are clustered at the quarter level and all specifications include industry fixed effects at the Fama \& French 17 industry classification.

\begin{tabular}{|c|c|c|c|c|c|c|}
\hline & $\begin{array}{c}\mathrm{P} / \mathrm{D} \text { Ratio } \\
(1)\end{array}$ & $\begin{array}{c}\text { M/B Ratio } \\
(2) \\
\end{array}$ & $\begin{array}{c}\text { Default Risk } \\
(3)\end{array}$ & $\begin{array}{c}\mathrm{P} / \mathrm{D} \text { Ratio } \\
(4) \\
\end{array}$ & $\begin{array}{c}\text { M/B Ratio } \\
(5)\end{array}$ & $\begin{array}{c}\text { Default Risk } \\
(6)\end{array}$ \\
\hline $\mathbb{E}(\pi)$ & $\begin{array}{c}-8.81 \\
(0.30)\end{array}$ & $\begin{array}{c}-0.15 \\
(0.00)\end{array}$ & $\begin{array}{c}-0.19 \\
(0.01)\end{array}$ & $\begin{array}{c}-9.90 \\
(0.51)\end{array}$ & $\begin{array}{c}-0.14 \\
(0.00)\end{array}$ & $\begin{array}{c}-0.18 \\
(0.01)\end{array}$ \\
\hline Investment & $\begin{array}{r}104.24 \\
(2.69)\end{array}$ & $\begin{array}{c}1.64 \\
(0.05)\end{array}$ & $\begin{array}{c}-0.80 \\
(0.05)\end{array}$ & $\begin{array}{r}107.26 \\
(3.21)\end{array}$ & $\begin{array}{c}1.69 \\
(0.05)\end{array}$ & $\begin{array}{r}-0.62 \\
(0.05)\end{array}$ \\
\hline Profitability & $\begin{array}{c}-0.01 \\
(0.01)\end{array}$ & $\begin{array}{c}0.00 \\
(0.00)\end{array}$ & $\begin{array}{c}0.00 \\
(0.00)\end{array}$ & $\begin{array}{c}-0.01 \\
(0.01)\end{array}$ & $\begin{array}{c}0.00 \\
(0.00)\end{array}$ & $\begin{array}{c}0.00 \\
(0.00)\end{array}$ \\
\hline $\log$ Size & $\begin{array}{c}3.56 \\
(0.18)\end{array}$ & $\begin{array}{c}0.24 \\
(0.00)\end{array}$ & $\begin{array}{c}-0.05 \\
(0.00)\end{array}$ & $\begin{array}{c}3.67 \\
(0.22)\end{array}$ & $\begin{array}{c}0.23 \\
(0.01)\end{array}$ & $\begin{array}{c}-0.04 \\
(0.00)\end{array}$ \\
\hline IP Growth & $\begin{array}{l}31.63 \\
(8.55)\end{array}$ & $\begin{array}{r}-0.02 \\
(0.15)\end{array}$ & $\begin{array}{c}-0.90 \\
(0.23)\end{array}$ & $\begin{array}{c}8.85 \\
(10.53)\end{array}$ & $\begin{array}{c}0.16 \\
(0.16)\end{array}$ & $\begin{array}{c}-0.51 \\
(0.24)\end{array}$ \\
\hline $\mathrm{S} \& \mathrm{P}$ return & $\begin{array}{l}15.89 \\
(2.86)\end{array}$ & $\begin{array}{c}0.39 \\
(0.05)\end{array}$ & $\begin{array}{r}-0.02 \\
(0.06)\end{array}$ & $\begin{array}{l}12.18 \\
(3.18)\end{array}$ & $\begin{array}{c}0.42 \\
(0.05)\end{array}$ & $\begin{array}{c}0.07 \\
(0.06)\end{array}$ \\
\hline Yield Curve & $\begin{array}{c}-1.61 \\
(0.29)\end{array}$ & $\begin{array}{c}-0.06 \\
(0.00)\end{array}$ & $\begin{array}{r}-0.07 \\
(0.01)\end{array}$ & $\begin{array}{c}-2.03 \\
(0.30)\end{array}$ & $\begin{array}{c}-0.05 \\
(0.00)\end{array}$ & $\begin{array}{r}-0.07 \\
(0.01)\end{array}$ \\
\hline Leverage & $\begin{array}{r}-33.77 \\
(0.74)\end{array}$ & $\begin{array}{c}-1.83 \\
(0.02)\end{array}$ & $\begin{array}{c}1.56 \\
(0.02)\end{array}$ & $\begin{array}{r}-35.55 \\
(0.83)\end{array}$ & $\begin{array}{c}-1.80 \\
(0.02)\end{array}$ & $\begin{array}{c}1.50 \\
(0.01)\end{array}$ \\
\hline Recession & $\begin{array}{c}1.57 \\
(1.77)\end{array}$ & $\begin{array}{c}0.02 \\
(0.03)\end{array}$ & $\begin{array}{c}0.20 \\
(0.04)\end{array}$ & $\begin{array}{c}1.18 \\
(2.23)\end{array}$ & $\begin{array}{c}0.05 \\
(0.03)\end{array}$ & $\begin{array}{c}0.13 \\
(0.04)\end{array}$ \\
\hline Dummy $_{\text {post } 2008}$ & $\begin{array}{r}-15.63 \\
(1.02)\end{array}$ & $\begin{array}{c}-0.23 \\
(0.02)\end{array}$ & $\begin{array}{c}0.02 \\
(0.02)\end{array}$ & & & \\
\hline Industry FE & $\mathrm{X}$ & $\mathrm{X}$ & $\mathrm{X}$ & $\mathrm{X}$ & $\mathrm{X}$ & $\mathrm{X}$ \\
\hline Nobs & 743,536 & 743,536 & 743,536 & 592,966 & 592,966 & 592,966 \\
\hline $\mathrm{R}^{2}$ & $17.22 \%$ & $33.65 \%$ & $49.21 \%$ & $19.78 \%$ & $35.95 \%$ & $46.50 \%$ \\
\hline
\end{tabular}




\section{Table 12: Regressions on expected inflation - Convexity}

This table reports regressions of price-dividend ratios, market-to-book ratios and default risk on expected inflation, firm characteristics, and macro aggregates. Expected inflation is from the Survey of Professional Forecasters from the Federal Reserve Bank of Philadelphia. $\mathcal{D}_{L, M}$ denotes a dummy variable that equals 1 when expected inflation is below the third quartile. Default risk corresponds to the level of distress risk computed as in Campbell et al. (2008). Section 7.1 provides additional details on the data. The sample period is 1972Q2-2016Q4 in columns (1)-(3) and 1972Q2-2007Q4 in columns (4)-(6). We report standard errors in parentheses. Standard errors are clustered at the quarter level and all specifications include industry fixed effects at the Fama \& French 17 industry classification.

\begin{tabular}{|c|c|c|c|c|c|c|}
\hline & $\begin{array}{c}\mathrm{P} / \mathrm{D} \text { Ratio } \\
(1)\end{array}$ & $\begin{array}{c}\text { M/B Ratio } \\
(2)\end{array}$ & $\begin{array}{c}\text { Default Risk } \\
(3)\end{array}$ & $\begin{array}{c}\text { P/D Ratio } \\
(4)\end{array}$ & $\begin{array}{c}\text { M/B Ratio } \\
(5)\end{array}$ & $\begin{array}{c}\text { Default Risk } \\
(6)\end{array}$ \\
\hline $\mathbb{E}(\pi)$ & $\begin{array}{r}-3.95 \\
(0.38)\end{array}$ & $\begin{array}{r}-0.09 \\
(0.01)\end{array}$ & $\begin{array}{r}-0.01 \\
(0.02)\end{array}$ & $\begin{array}{r}-4.18 \\
(0.38)\end{array}$ & $\begin{array}{r}-0.09 \\
(0.01)\end{array}$ & $\begin{array}{r}-0.01 \\
(0.02)\end{array}$ \\
\hline $\mathbb{E}(\pi) \times \mathcal{D}_{L, M}$ & $\begin{array}{r}-12.65 \\
(0.69)\end{array}$ & $\begin{array}{c}-0.10 \\
(0.01)\end{array}$ & $\begin{array}{c}-0.14 \\
(0.01)\end{array}$ & $\begin{array}{r}-12.74 \\
(0.91)\end{array}$ & $\begin{array}{c}-0.13 \\
(0.02)\end{array}$ & $\begin{array}{r}-0.13 \\
(0.01)\end{array}$ \\
\hline Investment & $\begin{array}{r}103.19 \\
(2.66)\end{array}$ & $\begin{array}{c}1.64 \\
(0.05)\end{array}$ & $\begin{array}{r}-0.80 \\
(0.05)\end{array}$ & $\begin{array}{r}106.92 \\
(3.08)\end{array}$ & $\begin{array}{c}1.70 \\
(0.04)\end{array}$ & $\begin{array}{r}-0.62 \\
(0.05)\end{array}$ \\
\hline Profitability & $\begin{array}{c}0.14 \\
(0.02)\end{array}$ & $\begin{array}{c}0.01 \\
(0.00)\end{array}$ & $\begin{array}{c}0.00 \\
(0.00)\end{array}$ & $\begin{array}{c}0.19 \\
(0.02)\end{array}$ & $\begin{array}{c}0.01 \\
(0.00)\end{array}$ & $\begin{array}{c}0.00 \\
(0.00)\end{array}$ \\
\hline $\log$ Size & $\begin{array}{c}3.35 \\
(0.17)\end{array}$ & $\begin{array}{c}0.24 \\
(0.00)\end{array}$ & $\begin{array}{r}-0.06 \\
(0.00)\end{array}$ & $\begin{array}{c}3.38 \\
(0.22)\end{array}$ & $\begin{array}{c}0.23 \\
(0.01)\end{array}$ & $\begin{array}{r}-0.04 \\
(0.00)\end{array}$ \\
\hline IP Growth & $\begin{array}{l}48.21 \\
(6.00)\end{array}$ & $\begin{array}{c}0.17 \\
(0.13)\end{array}$ & $\begin{array}{r}-0.72 \\
(0.23)\end{array}$ & $\begin{array}{l}26.45 \\
(6.37)\end{array}$ & $\begin{array}{c}0.41 \\
(0.13)\end{array}$ & $\begin{array}{r}-0.24 \\
(0.23)\end{array}$ \\
\hline $\mathrm{S} \& \mathrm{P}$ return & $\begin{array}{l}18.03 \\
(1.96)\end{array}$ & $\begin{array}{c}0.40 \\
(0.04)\end{array}$ & $\begin{array}{r}-0.05 \\
(0.06)\end{array}$ & $\begin{array}{l}15.78 \\
(2.17)\end{array}$ & $\begin{array}{c}0.46 \\
(0.05)\end{array}$ & $\begin{array}{c}0.04 \\
(0.06)\end{array}$ \\
\hline Yield Curve & $\begin{array}{c}-0.34 \\
(0.21)\end{array}$ & $\begin{array}{c}-0.04 \\
(0.00)\end{array}$ & $\begin{array}{c}-0.06 \\
(0.01)\end{array}$ & $\begin{array}{c}-0.50 \\
(0.21)\end{array}$ & $\begin{array}{c}-0.03 \\
(0.00)\end{array}$ & $\begin{array}{c}-0.06 \\
(0.01)\end{array}$ \\
\hline Leverage & $\begin{array}{r}-33.88 \\
(0.75)\end{array}$ & $\begin{array}{c}-1.82 \\
(0.02)\end{array}$ & $\begin{array}{c}1.57 \\
(0.02)\end{array}$ & $\begin{array}{r}-35.44 \\
(0.84)\end{array}$ & $\begin{array}{r}-1.79 \\
(0.02)\end{array}$ & $\begin{array}{c}1.51 \\
(0.01)\end{array}$ \\
\hline Recession & $\begin{array}{c}1.91 \\
(1.24)\end{array}$ & $\begin{array}{c}0.03 \\
(0.02)\end{array}$ & $\begin{array}{c}0.20 \\
(0.03)\end{array}$ & $\begin{array}{c}0.03 \\
(0.02)\end{array}$ & $\begin{array}{c}0.05 \\
(0.02)\end{array}$ & $\begin{array}{c}0.14 \\
(0.04)\end{array}$ \\
\hline Dummy post 2008 & $\begin{array}{r}-23.37 \\
(0.95)\end{array}$ & $\begin{array}{c}-0.29 \\
(0.02)\end{array}$ & $\begin{array}{c}0.03 \\
(0.03)\end{array}$ & & & \\
\hline Industry FE & $\mathrm{X}$ & $\mathrm{X}$ & $\mathrm{X}$ & $\mathrm{X}$ & $\mathrm{X}$ & $\mathrm{X}$ \\
\hline Nobs & 743,536 & 743,536 & 743,536 & 592,966 & 592,966 & 592,966 \\
\hline $\mathrm{R}^{2}$ & $17.87 \%$ & $33.70 \%$ & $49.53 \%$ & $20.62 \%$ & $36.08 \%$ & $47.04 \%$ \\
\hline
\end{tabular}


Table 13: Regressions on expected inflation - Convexity: excl Finance and Utilities

This table reports regressions of price-dividend ratios, market-to-book ratios and default risk on expected inflation, firm characteristics, and macro aggregates. Expected inflation is from the Survey of Professional Forecasters from the Federal Reserve Bank of Philadelphia. $\mathcal{D}_{L, M}$ denotes a dummy variable that equals 1 when expected inflation is below the third quartile. Default risk corresponds to the level of distress risk computed as in Campbell et al. (2008). Section 7.1 provides additional details on the data. The sample period is 1972Q2-2016Q4 in columns (1)-(3) and 1972Q2-2007Q4 in columns (4)-(6). We report standard errors in parentheses. Standard errors are clustered at the quarter level and all specifications include industry fixed effects at the Fama \& French 17 industry classification.

\begin{tabular}{|c|c|c|c|c|c|c|}
\hline & $\begin{array}{c}\mathrm{P} / \mathrm{D} \text { Ratio } \\
(1)\end{array}$ & $\begin{array}{c}\text { M/B Ratio } \\
(2)\end{array}$ & $\begin{array}{c}\text { Default Risk } \\
(3)\end{array}$ & $\begin{array}{c}\text { P/D Ratio } \\
(4)\end{array}$ & $\begin{array}{c}\text { M/B Ratio } \\
(5)\end{array}$ & $\begin{array}{c}\text { Default Risk } \\
(6)\end{array}$ \\
\hline $\mathbb{E}(\pi)$ & $\begin{array}{r}-5.23 \\
(0.47)\end{array}$ & $\begin{array}{r}-0.04 \\
(0.02)\end{array}$ & $\begin{array}{r}-0.02 \\
(0.02)\end{array}$ & $\begin{array}{r}-5.25 \\
(0.48)\end{array}$ & $\begin{array}{r}-0.10 \\
(0.01)\end{array}$ & $\begin{array}{r}-0.01 \\
(0.02)\end{array}$ \\
\hline $\mathbb{E}(\pi) \times \mathcal{D}_{L, M}$ & $\begin{array}{r}-16.68 \\
(0.94)\end{array}$ & $\begin{array}{c}-0.10 \\
(0.01)\end{array}$ & $\begin{array}{c}-0.15 \\
(0.01)\end{array}$ & $\begin{array}{r}-18.62 \\
(0.87)\end{array}$ & $\begin{array}{c}-0.08 \\
(0.02)\end{array}$ & $\begin{array}{c}-0.14 \\
(0.01)\end{array}$ \\
\hline Investment & $\begin{array}{r}122.30 \\
(3.49)\end{array}$ & $\begin{array}{c}1.71 \\
(0.05)\end{array}$ & $\begin{array}{r}-0.86 \\
(0.05)\end{array}$ & $\begin{array}{r}122.42 \\
(3.89)\end{array}$ & $\begin{array}{c}1.81 \\
(0.05)\end{array}$ & $\begin{array}{r}-0.67 \\
(0.05)\end{array}$ \\
\hline Profitability & $\begin{array}{c}0.13 \\
(0.02)\end{array}$ & $\begin{array}{c}0.01 \\
(0.00)\end{array}$ & $\begin{array}{c}0.00 \\
(0.00)\end{array}$ & $\begin{array}{c}0.16 \\
(0.01)\end{array}$ & $\begin{array}{c}0.01 \\
(0.00)\end{array}$ & $\begin{array}{c}0.00 \\
(0.00)\end{array}$ \\
\hline $\log$ Size & $\begin{array}{c}3.24 \\
(0.21)\end{array}$ & $\begin{array}{c}0.30 \\
(0.01)\end{array}$ & $\begin{array}{c}-0.05 \\
(0.00)\end{array}$ & $\begin{array}{c}2.93 \\
(0.25)\end{array}$ & $\begin{array}{c}0.28 \\
(0.01)\end{array}$ & $\begin{array}{c}-0.03 \\
(0.00)\end{array}$ \\
\hline IP Growth & $\begin{array}{l}47.42 \\
(7.09)\end{array}$ & $\begin{array}{c}0.33 \\
(0.16)\end{array}$ & $\begin{array}{r}-0.73 \\
(0.22)\end{array}$ & $\begin{array}{l}27.31 \\
(7.74)\end{array}$ & $\begin{array}{c}0.64 \\
(0.15)\end{array}$ & $\begin{array}{r}-0.47 \\
(0.24)\end{array}$ \\
\hline S\&P return & $\begin{array}{l}21.87 \\
(2.46)\end{array}$ & $\begin{array}{c}0.52 \\
(0.06)\end{array}$ & $\begin{array}{r}-0.08 \\
(0.06)\end{array}$ & $\begin{array}{l}20.52 \\
(2.75)\end{array}$ & $\begin{array}{c}0.58 \\
(0.06)\end{array}$ & $\begin{array}{c}0.00 \\
(0.06)\end{array}$ \\
\hline Yield Curve & $\begin{array}{c}-0.55 \\
(0.27)\end{array}$ & $\begin{array}{c}-0.05 \\
(0.01)\end{array}$ & $\begin{array}{c}-0.06 \\
(0.01)\end{array}$ & $\begin{array}{r}-0.58 \\
(0.28)\end{array}$ & $\begin{array}{c}-0.04 \\
(0.01)\end{array}$ & $\begin{array}{c}-0.06 \\
(0.01)\end{array}$ \\
\hline Leverage & $\begin{array}{r}-32.64 \\
(0.95)\end{array}$ & $\begin{array}{c}-2.33 \\
(0.04)\end{array}$ & $\begin{array}{c}2.11 \\
(0.02)\end{array}$ & $\begin{array}{r}-34.90 \\
(1.02)\end{array}$ & $\begin{array}{c}-2.32 \\
(0.04)\end{array}$ & $\begin{array}{c}2.09 \\
(0.01)\end{array}$ \\
\hline Recession & $\begin{array}{c}3.04 \\
(1.61)\end{array}$ & $\begin{array}{c}0.00 \\
(0.03)\end{array}$ & $\begin{array}{c}0.23 \\
(0.03)\end{array}$ & $\begin{array}{r}-0.34 \\
(1.43)\end{array}$ & $\begin{array}{c}0.08 \\
(0.02)\end{array}$ & $\begin{array}{c}0.17 \\
(0.03)\end{array}$ \\
\hline Dummy post 2008 & $\begin{array}{r}-33.63 \\
(1.38)\end{array}$ & $\begin{array}{c}-0.16 \\
(0.04)\end{array}$ & $\begin{array}{c}-0.04 \\
(0.03)\end{array}$ & & & \\
\hline Industry FE & $\mathrm{X}$ & $\mathrm{X}$ & $\mathrm{X}$ & $\mathrm{X}$ & $\mathrm{X}$ & $\mathrm{X}$ \\
\hline Nobs & 437,012 & 437,012 & 437,012 & 356,938 & 356,938 & 356,938 \\
\hline $\mathrm{R}^{2}$ & $16.37 \%$ & $35.50 \%$ & $48.31 \%$ & $19.01 \%$ & $38.40 \%$ & $48.31 \%$ \\
\hline
\end{tabular}


Table 14: Regressions on expected inflation - Convexity: no Tech or pre-1980

This table reports regressions of price-dividend ratios, market-to-book ratios and default risk on expected inflation, firm characteristics, and macro aggregates. Expected inflation is from the Survey of Professional Forecasters from the Federal Reserve Bank of Philadelphia. $\mathcal{D}_{L, M}$ denotes a dummy variable that equals 1 when expected inflation is below the third quartile. Default risk corresponds to the level of distress risk computed as in Campbell et al. (2008). Section 7.1 provides additional details on the data. The sample period is 1972Q2-2016Q4 in columns (1)-(3) but excludes all tech firms and 1980Q1-2016Q4 in columns (4)-(6). We report standard errors in parentheses. Standard errors are clustered at the quarter level and all specifications include industry fixed effects at the Fama \& French 17 industry classification.

\begin{tabular}{|c|c|c|c|c|c|c|}
\hline & $\begin{array}{c}\mathrm{P} / \mathrm{D} \text { Ratio } \\
(1)\end{array}$ & $\begin{array}{c}\text { M/B Ratio } \\
(2)\end{array}$ & $\begin{array}{c}\text { Default Risk } \\
\text { (3) }\end{array}$ & $\begin{array}{c}\text { P/D Ratio } \\
(4) \\
\end{array}$ & $\begin{array}{c}\text { M/B Ratio } \\
(5)\end{array}$ & $\begin{array}{c}\text { Default Risk } \\
\text { (6) }\end{array}$ \\
\hline $\mathbb{E}(\pi)$ & $\begin{array}{c}-3.95 \\
(0.38)\end{array}$ & $\begin{array}{c}-0.09 \\
(0.01)\end{array}$ & $\begin{array}{c}-0.01 \\
(0.02)\end{array}$ & $\begin{array}{l}-2.55 \\
(0.29)\end{array}$ & $\begin{array}{c}-0.08 \\
(0.01)\end{array}$ & $\begin{array}{c}-0.03 \\
(0.02)\end{array}$ \\
\hline $\mathbb{E}(\pi) \times \mathcal{D}_{L, M}$ & $\begin{array}{r}-12.58 \\
(0.69)\end{array}$ & $\begin{array}{c}-0.10 \\
(0.01)\end{array}$ & $\begin{array}{c}-0.14 \\
(0.01)\end{array}$ & $\begin{array}{r}-13.95 \\
(0.65)\end{array}$ & $\begin{array}{c}-0.11 \\
(0.02)\end{array}$ & $\begin{array}{c}-0.12 \\
(0.01)\end{array}$ \\
\hline Investment & $\begin{array}{c}102.68 \\
(2.67)\end{array}$ & $\begin{array}{c}1.63 \\
(0.04)\end{array}$ & $\begin{array}{c}-0.80 \\
(0.05)\end{array}$ & $\begin{array}{c}115.65 \\
(2.30)\end{array}$ & $\begin{array}{c}1.79 \\
(0.04)\end{array}$ & $\begin{array}{c}-0.87 \\
(0.04)\end{array}$ \\
\hline Profitability & $\begin{array}{c}0.11 \\
(0.09)\end{array}$ & $\begin{array}{c}0.03 \\
(0.01)\end{array}$ & $\begin{array}{c}0.00 \\
(0.00)\end{array}$ & $\begin{array}{c}0.13 \\
(0.02)\end{array}$ & $\begin{array}{c}0.01 \\
(0.00)\end{array}$ & $\begin{array}{c}0.00 \\
(0.00)\end{array}$ \\
\hline $\log$ Size & $\begin{array}{c}3.30 \\
(0.17)\end{array}$ & $\begin{array}{c}0.24 \\
(0.00)\end{array}$ & $\begin{array}{c}-0.06 \\
(0.00)\end{array}$ & $\begin{array}{c}3.45 \\
(0.19)\end{array}$ & $\begin{array}{c}0.25 \\
(0.00)\end{array}$ & $\begin{array}{c}-0.06 \\
(0.00)\end{array}$ \\
\hline IP Growth & $\begin{array}{l}48.06 \\
(6.00)\end{array}$ & $\begin{array}{c}0.15 \\
(0.13)\end{array}$ & $\begin{array}{c}-0.72 \\
(0.23)\end{array}$ & $\begin{array}{l}69.22 \\
(7.46)\end{array}$ & $\begin{array}{c}0.25 \\
(0.17)\end{array}$ & $\begin{array}{c}-0.20 \\
(0.27)\end{array}$ \\
\hline $\mathrm{S} \& \mathrm{P}$ return & $\begin{array}{l}17.82 \\
(1.95)\end{array}$ & $\begin{array}{c}0.39 \\
(0.04)\end{array}$ & $\begin{array}{c}-0.05 \\
(0.06)\end{array}$ & $\begin{array}{l}14.41 \\
(1.84)\end{array}$ & $\begin{array}{c}0.37 \\
(0.05)\end{array}$ & $\begin{array}{c}-0.16 \\
(0.06)\end{array}$ \\
\hline Yield Curve & $\begin{array}{c}-0.34 \\
(0.21)\end{array}$ & $\begin{array}{c}-0.04 \\
(0.00)\end{array}$ & $\begin{array}{c}-0.06 \\
(0.01)\end{array}$ & $\begin{array}{c}0.16 \\
(0.20)\end{array}$ & $\begin{array}{c}-0.04 \\
(0.00)\end{array}$ & $\begin{array}{c}-0.06 \\
(0.01)\end{array}$ \\
\hline Leverage & $\begin{array}{r}-33.46 \\
(0.75)\end{array}$ & $\begin{array}{c}-1.82 \\
(0.02)\end{array}$ & $\begin{array}{c}1.57 \\
(0.02)\end{array}$ & $\begin{array}{r}-36.85 \\
(0.76)\end{array}$ & $\begin{array}{c}-1.94 \\
(0.02)\end{array}$ & $\begin{array}{c}1.59 \\
(0.02)\end{array}$ \\
\hline Recession & $\begin{array}{c}1.82 \\
(1.22)\end{array}$ & $\begin{array}{c}0.03 \\
(0.02)\end{array}$ & $\begin{array}{c}0.20 \\
(0.03)\end{array}$ & $\begin{array}{c}1.73 \\
(1.27)\end{array}$ & $\begin{array}{c}0.03 \\
(0.02)\end{array}$ & $\begin{array}{c}0.19 \\
(0.03)\end{array}$ \\
\hline 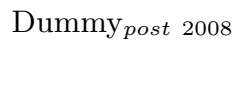 & $\begin{array}{r}-22.89 \\
\quad(0.94)\end{array}$ & $\begin{array}{c}-0.30 \\
(0.02)\end{array}$ & $\begin{array}{c}0.03 \\
(0.03)\end{array}$ & $\begin{array}{r}-23.30 \\
(0.95)\end{array}$ & $\begin{array}{c}-0.30 \\
(0.02)\end{array}$ & $\begin{array}{c}0.04 \\
(0.03)\end{array}$ \\
\hline Industry FE & $\mathrm{X}$ & $\mathrm{X}$ & $\mathrm{X}$ & $\mathrm{X}$ & $\mathrm{X}$ & $\mathrm{X}$ \\
\hline Nobs & 733,532 & 733,532 & 733,532 & 656,631 & 656,631 & 656,631 \\
\hline $\mathrm{R}^{2}$ & $17.89 \%$ & $33.82 \%$ & $49.68 \%$ & $15.79 \%$ & $31.68 \%$ & $47.96 \%$ \\
\hline
\end{tabular}


Figure 2: Negative and asymmetric impact of expected inflation on asset prices - Simple model

The figure illustrates the impact of inflation on equity value (upper-left panel), credit spread (upper-right panel), debt value (lower-left panel), and market leverage (lower-right panel). The expected inflation rate is either low $\left(\mu_{P}=0 \%\right)$, moderate $\left(\mu_{P}=3 \%\right)$, or high $\left(\mu_{P}=6 \%\right)$. Predictions are obtained with the static corporate finance model with exogenous capital structure and default policies discussed in Section 2.
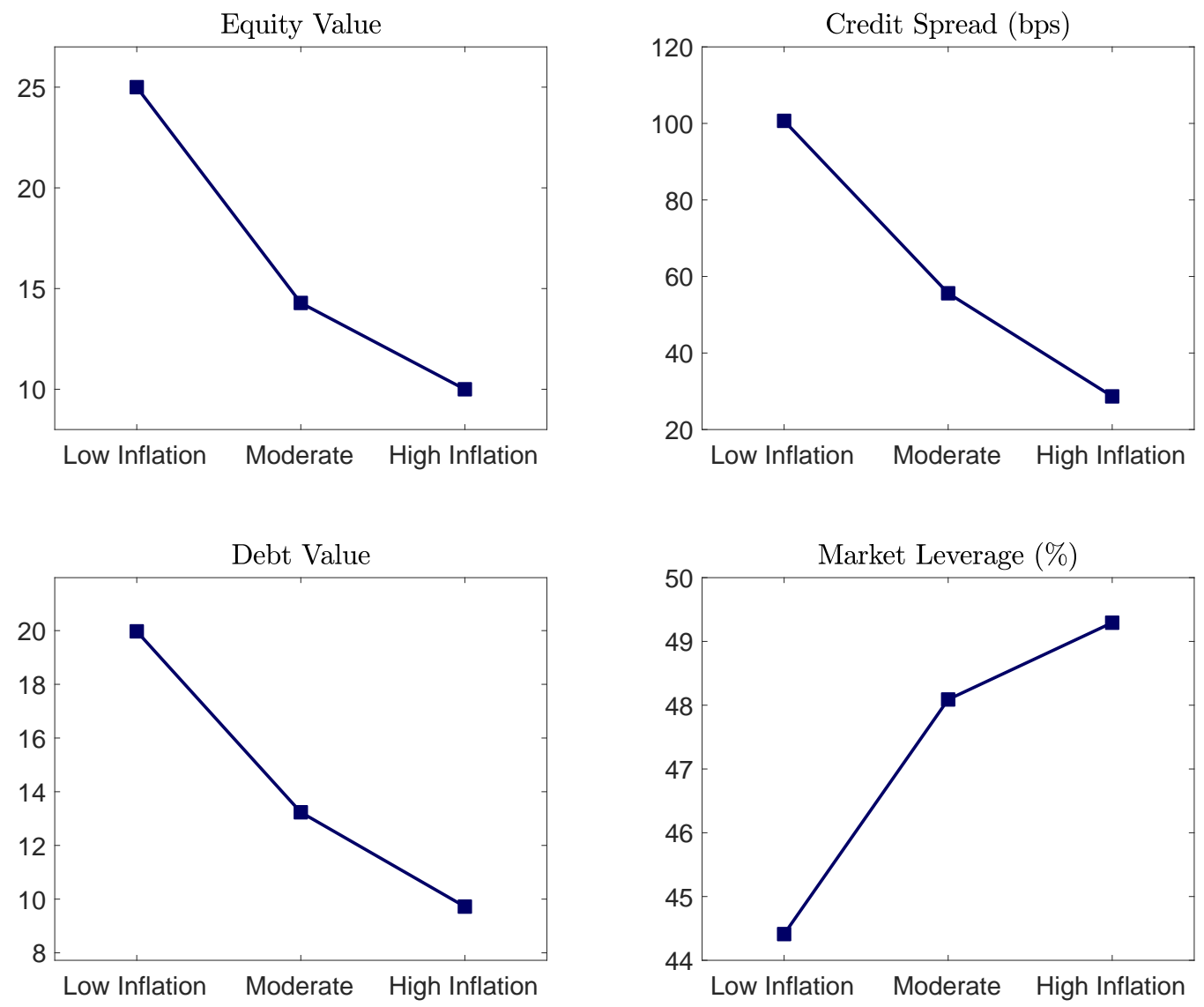
Figure 3: Negative and asymmetric impact of expected inflation on asset prices - Full model

The figure illustrates the impact of expected inflation on equity value (upper-left panel), credit spread (upper-right panel), debt value (lower-left panel), and market leverage (lower-right panel). Each panel reports the value of the asset pricing quantities for different nominal conditions (on the x-axis): low, moderate, and high expected inflation. Firms have the corporate policies presented in Table 3. The parameter values of the model are reported in Table 2 and discussed in Section 5.
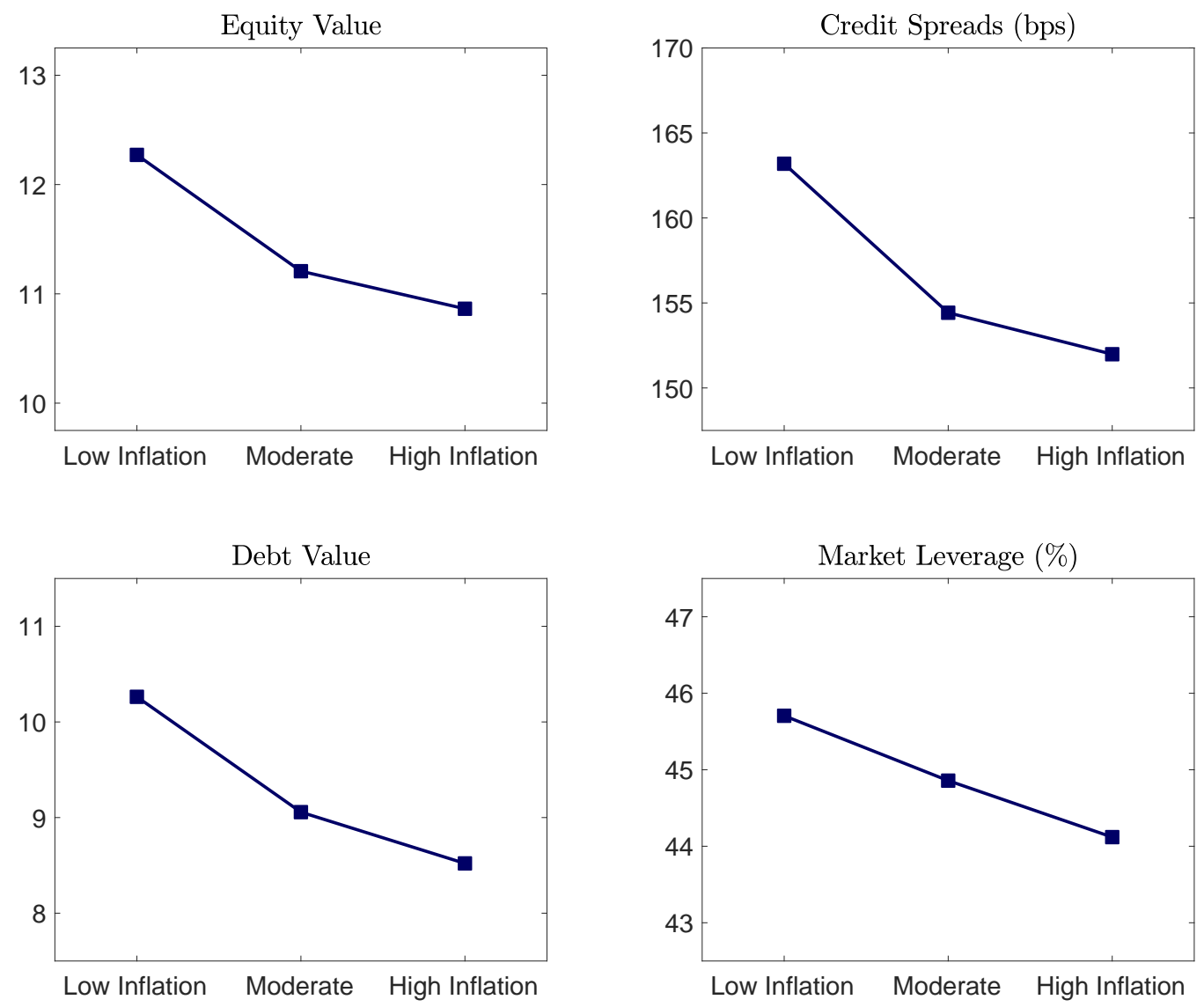


\section{Figure 4: Asset prices and sticky cash flows}

This figure illustrates the asset pricing impact of cash flow stickiness. Panels in the left (right) column report equity (credit spread) values for different nominal conditions (on the x-axis): low, moderate, and high expected inflation. Each row reports predictions for a given degree of inflation passthrough.
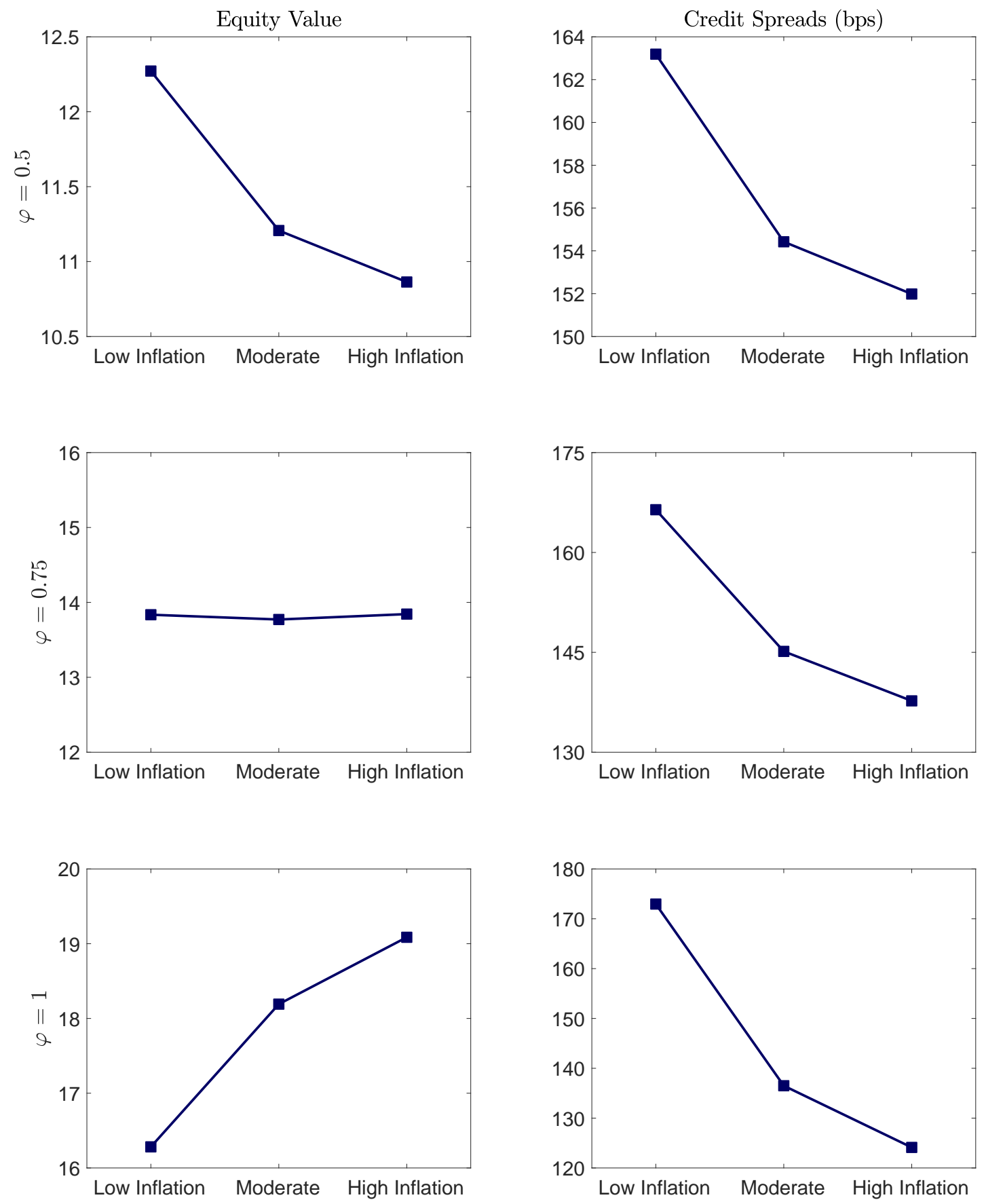


\section{Figure 5: Equity valuation, default risk, and expected inflation}

This figure plots the relations between expected inflation and the price-dividend ratios (top panels), the market-to-book ratios (middle panels), and default risk (bottom panels). We report the relations by levels of market leverage. The left panels show portfolios of firms with below-median leverage, whereas the right panels report firms with above-median leverage. Each observation represents the value-weighted average of the valuation metric across firms for a given level of expected inflation. Expected inflation is from the Survey of Professional Forecasters from the Federal Reserve Bank of Philadelphia. Default risk corresponds to the implied bankruptcy probability computed as in Campbell et al. (2008). Section 7.1 provides additional details on the data. The sample period is 1972Q2-2016Q4.
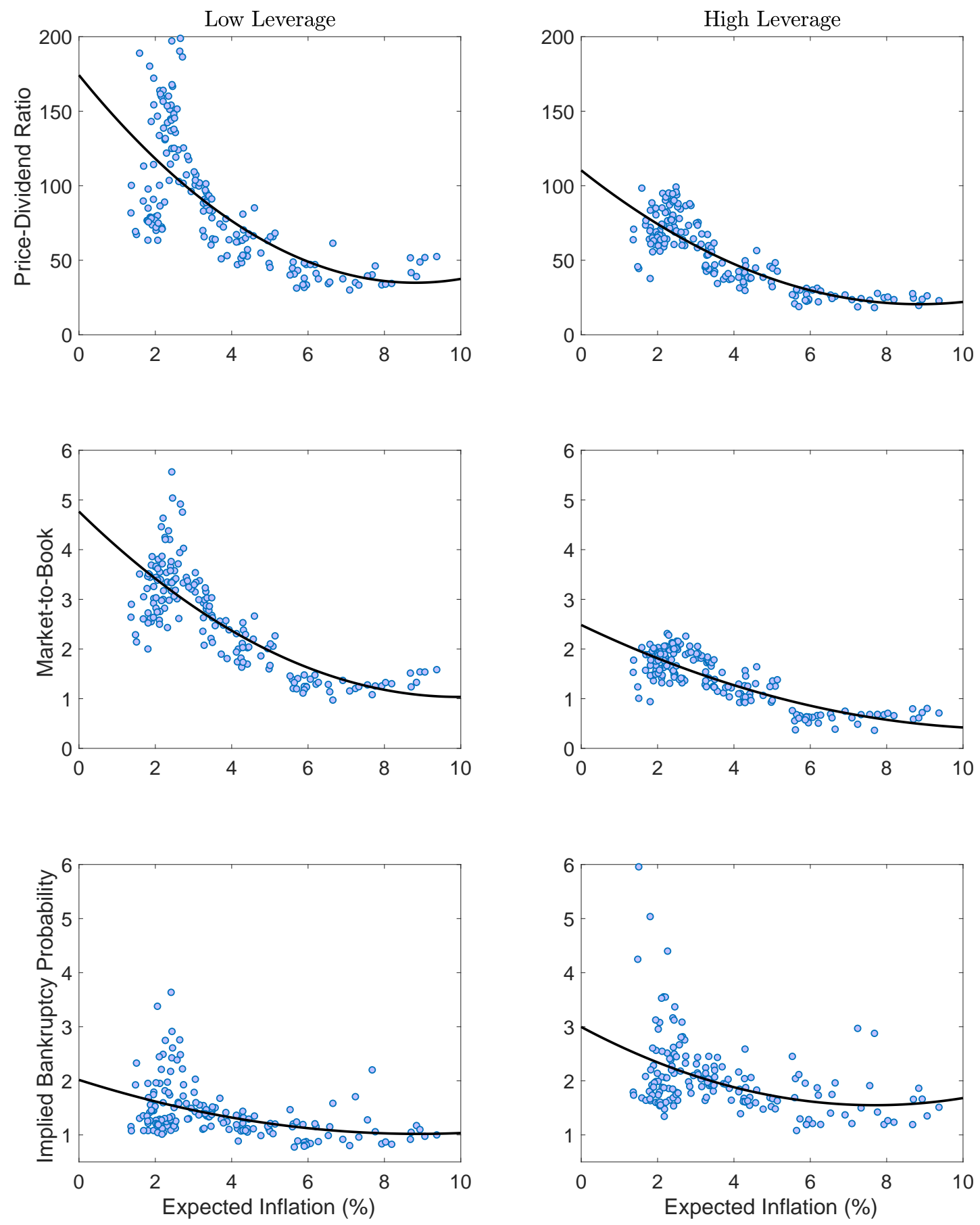


\section{Appendix}

\section{A Data description}

This section describes the data used in our empirical analysis (section 7).

\section{A.1 Valuation ratios}

Market-to-book ratio $(M B)$ is computed as $M E / B E$. Book equity $(B E)$ is shareholders' equity $(S E Q Q+C E Q Q+P S T K Q$ or $A T Q-L T Q)$, plus balance sheet deferred taxes and investment tax credit $(T X D I T C Q)$ if available, minus the book value of preferred stock (PSTKQ). Market capitalization $(M E)$ is the product of quarter-end price $(P R C)$ and share outstanding (Shrout).

The price-dividend ratio is computed as the share price divided by the sum of dividend payments over the last 12 months. We construct dividend payments using cum-dividend return and ex-dividend returns, as in Beeler and Campbell (2012).

\section{A.2 Default risk}

We follow Campbell, Hilscher, and Szilagyi (2008) to calculate financial distress risk $(F R)$ as the logit transformed bankruptcy probability, while excluding leverage in the measurement. $F R$ is then calculated as

$$
\begin{aligned}
F R= & -9.16-20.26 * N I M T A V G-7.13 * \text { EX RET AVG }+1.41 * S I G M A \\
& -0.045 * R S I Z E-2.13 * C A S H M T A+0.075 * M B-0.058 * \text { PRICE, }
\end{aligned}
$$

where

$$
\begin{aligned}
\text { NIMTAVG } & =\sum_{i=0}^{3} \frac{1-\phi^{3}}{1-\phi^{12}}\left(\phi^{3(i-1)} N \operatorname{ITM} A_{t-3 i}\right) \\
\text { EXRETAVG } & =\sum_{i=0}^{11} \frac{1-\phi}{1-\phi^{12}}\left(\phi^{i-1} E X R E T_{t-i}\right)
\end{aligned}
$$

NIMTA and EXRET are net income over total assets $(N I Q / A T Q)$ and the log of gross excess returns over the value-weighted S\&P500 returns, respectively. SIGMA is the square root of the annualized sum of squared stock returns over a 3-month period. RSIZE is the log of firm's market equity over the total valuation of all firms in the $\mathrm{S} \& \mathrm{P} 500$. $C A S H M T A$ is cash and short-term investments over total assets $(C H E Q / A T Q) . M B$ is the market-to-book value of equity. PRICE is the log of price 
per share. The associated 1-quarter bankruptcy probability for firm $i$ at time $t$ is then

$$
P_{t-1}\left(Y_{i, t}=1\right)=\frac{1}{1+\exp \left(-F R_{i, t-1}\right)}
$$

\section{A.3 Leverage, investment and profitability}

Market leverage is the sum of long term debt and debt in current liabilities over the sum of of debt and market capitalization $((D L C Q+D L T T Q) /(D L C Q+D L T T Q+M E))$.

Investment and profitability are calculated following Fama and French (2015) as revenues minus cost of goods sold, minus selling, general, and administrative expenses, minus interest expense all divided by book equity $(I B Q-C O G S Q-X S G A Q-X I N T Q) / B E$ and the percentage change in total asset. 


\section{ONLINE APPENDIX}




\section{OA.A Toy Model}

Under the physical probability measure $\mathbb{P}$, real cashflow growth is given by

$$
\frac{d Y_{t}}{Y_{t}}=\mu_{Y} d t+\sigma_{Y} d W_{t}
$$

where $W$ is a standard Brownian motion under $\mathbb{P}$. The date $t$ nominal cashflow is given by $X_{t}=Y_{t} P_{t}^{\varphi}$, and so nominal cashflow growth is given by

$$
\frac{d X_{t}}{X_{t}}=\left(\mu_{Y}+\varphi \mu_{P}\right) d t+\sigma_{Y} d W_{t}
$$

The real SDF is given by

$$
\frac{d \pi_{t}}{\pi_{t}}=-r d t-\Theta d Z_{t}
$$

where $Z$ is a standard Brownian motion under $\mathbb{P}$ such that $d Z_{t} d W_{t}=\rho d t$. In this section, there is no risk premium associated with sudden shifts in the state of the economy. In contrast with the main model, we therefore assume $\rho>0$ to ensure that the risk premium is not zero. Consequently, conditional on date $t$ information, the risk-neutral probability of event $A$ occuring at date $T$ is given by

$$
E_{t}^{\mathbb{Q}}\left[1_{A}\right]=E_{t}\left[\frac{M_{T}}{M_{t}} 1_{A}\right]
$$

where $M$ is an exponential martingale under $\mathbb{P}$, defined by

$$
\frac{d M_{t}}{M_{t}}=-\Theta d Z_{t}, M_{0}=1
$$

The exogenous price index is given by

$$
P_{t}=P_{0} e^{\mu_{P} t}
$$

where $\mu_{P}$ is the constant inflation rate.

The nominal SDF is given by $\pi_{t}^{\$}=\pi_{t} / P_{t}$, and so

$$
\frac{d \pi_{t}^{\$}}{\pi_{t}^{\$}}=-r^{\$} d t-\Theta d Z_{t},
$$

where

$$
r^{\$}=r+\mu_{P} .
$$

The price-index is not stochastic, so there is no inflation risk premium. We can therefore price risk under the risk-neutral measure $\mathbb{Q}$ with no additional adjustment for an inflation risk premium. If 
there were a risk premium, we would have to define a different probability measure in order to discount nominal cashflows with the nominal interest rate. Using Girsanov's Theorem, we obtain the evolution of $X$ under $\mathbb{Q}$ :

$$
\frac{d X_{t}}{X_{t}}=\left(\widehat{\mu}_{X}+\varphi \mu_{P}\right) d t+\sigma_{X} d W_{t}^{\mathbb{Q}}
$$

where $W^{\mathbb{Q}}$ is a standard Brownian motion under the risk-neutral measure $\mathbb{Q}$ and $\widehat{\mu}_{X}=\mu_{X}-\rho \sigma_{X} \Theta$ is the risk-neutral expected nominal cash flow growth rate.

The date- $t$ nominal after-tax abandonment value of the firm is given by

$$
\begin{aligned}
A_{t}^{\$} & =(1-\eta) X_{t} E_{t}\left[\int_{t}^{\infty} \frac{\pi_{u}^{\$}}{\pi_{t}^{\$}} \frac{X_{u}}{X_{t}}\right] \\
& =(1-\eta) X_{t} E_{t}^{\mathbb{Q}}\left[e^{-r^{\Phi}(u-t)} \frac{X_{u}}{X_{t}}\right] .
\end{aligned}
$$

The date- $t$ nominal price of the corporate bond is given by

$$
B_{t}^{\$}=c E_{t}\left[\int_{t}^{\tau_{D}} \frac{\pi_{u}^{\$}}{\pi_{t}^{\$}} d u\right]+\alpha E_{t}\left[\frac{\pi_{\tau_{D}}^{\$}}{\pi_{t}^{\$}} A\left(X_{\tau_{D}}\right) d u\right]
$$

From Karatzas and Shreve (1991), we know the price of the Arrow-Debreu default claim defined in footnote 8 is given by

$$
q_{D, t}^{\$}=e^{\omega\left(x_{t}-x_{D}\right)}=e^{-|\omega|\left(x_{t}-x_{D}\right)},
$$

where $x_{t}=\ln X_{t}, x_{D}=\ln X_{D}, \omega<0$ and is defined in footnote 8 . Now

$$
\frac{\partial \ln q_{D, t}^{\$}}{\partial \mu_{P}}=-\left(x_{t}-x_{D}\right) \frac{\partial|\omega|}{\partial \mu_{P}}-|\omega| \frac{\partial\left(x_{t}-x_{D}\right)}{\partial \mu_{P}} .
$$

We can show that $\frac{\partial|\omega|}{\partial \mu_{P}}<0$, that is, holding the distance to default, $x_{t}-x_{D}$, fixed, the price of the Arrow-Debreu default claim increases with inflation. With an endogenous default policy, the distance to default is impacted by inflation. A priori, it is possible that equity holders will choose to default later when when inflation is higher, that is the distance to default will increase. However, for the calibration we have chosen, equityholders default earlier when inflation is higher, because the present value of the coupons they have to pay to bondholders is increased. Even if this were not the case, $\frac{\partial|\omega|}{\partial \mu_{P}}$ is much larger than $\frac{\partial\left(x_{t}-x_{D}\right)}{\partial \mu_{P}}$, so any increase in distance to default would not change the overall sign of $\frac{\partial \ln q_{D, t}^{\$}}{\partial \mu_{P}}$. 


\section{OA.B The Economy}

First, we introduce some notation related to jumps in the state of the economy. Suppose that during the small time-interval $[t-\Delta t, t)$ the economy is in state $i$ and that at time $t$ the state changes, so that during the next small time interval $[t, t+\Delta t)$ the economy is in state $j \neq i$. We then define the left-limit of $s$ at time $t$ as

$$
s_{t-}=\lim _{\Delta t \rightarrow 0} s_{t-\Delta t},
$$

and the right-limit as

$$
s_{t}=\lim _{\Delta t \rightarrow 0} s_{t+\Delta t}
$$

Therefore $s_{t-}=i$, whereas $s_{t}=j$, so the left- and right limits are not equal. If some function $E$ depends on the current state of the economy i.e. $E_{t}=E\left(s_{t}\right)$, then $E$ is a jump process which is right continuous with left limits, i.e. RCLL. If a jump from state $i$ to $j \neq i$ occurs at date $t$, then we abuse notation slightly and denote the left limit of $E$ at time $t$ by $E_{i}$, where $i$ is the index for the state. i.e. $E_{t-}=\lim _{s \uparrow t} E_{s}=E_{i}$. Similarly $E_{t}=\lim _{s \downarrow t} E_{s}=E_{j}$. We shall use the same notation for all processes that jump, because of their dependence on the state of the economy.

Using simple algebra we can write the normalized Kreps-Porteus aggregator in the following compact form:

$$
f(c, v)=\beta\left(h^{-1}(v)\right)^{1-\gamma} u\left(c / h^{-1}(v)\right)
$$

where

$$
\begin{aligned}
& u(x)=\frac{x^{1-\frac{1}{\psi}}-1}{1-\frac{1}{\psi}}, \psi>0, \\
& h(x)=\left\{\begin{array}{cc}
\frac{x^{1-\gamma}}{1-\gamma}, & \gamma \geq 0, \gamma \neq 1 . \\
\ln x, & \gamma=1 .
\end{array}\right.
\end{aligned}
$$

The representative agent's value function is given by

$$
J_{t}=E_{t} \int_{t}^{\infty} f\left(C_{t}, J_{t}\right) d t
$$

Proposition OA.1 The SDF of a representative agent with the continuous-time version of EpsteinZin-Weil preferences is given by

$$
\pi_{t}=\left\{\begin{array}{c}
\left(\beta e^{-\beta t}\right)^{\frac{1-\gamma}{1-\frac{1}{\psi}}} C_{t}^{-\gamma}\left(p_{C, t} e^{\int_{0}^{t} p_{C, s}^{-1} d s}\right)^{-\frac{\gamma-\frac{1}{\psi}}{1-\frac{1}{\psi}}}, \quad \psi \neq 1 \\
\beta e^{-\beta \int_{0}^{t}\left[1+(\gamma-1) \ln \left(V_{s}^{-1}\right)\right] d s} C_{t}^{-\gamma} V_{t}^{-(\gamma-1)}, \quad \psi=1
\end{array} .\right.
$$


When $\psi \neq 1$, the price-consumption ratio in state $i, p_{C, i}$, satisfies the nonlinear equation system:

$$
p_{C, i}^{-1}=\bar{r}_{i}+\gamma \sigma_{C, i}^{2}-\mu_{C, i}-\left(1-\frac{1}{\psi}\right) \lambda_{i j}\left(\frac{\left(p_{C, j} / p_{C, i}\right)^{\frac{1-\gamma}{1-\frac{1}{\psi}}}-1}{1-\gamma}\right), i, j \in\{R, E\}, j \neq i
$$

where

$$
\bar{r}_{i}=\beta+\frac{1}{\psi} \mu_{C, i}-\frac{1}{2} \gamma\left(1+\frac{1}{\psi}\right) \sigma_{C, i}^{2}, i \in\{R, E\} .
$$

When $\psi=1$, define $V_{i}$ via

$$
J=\ln (C V) .
$$

Then $V_{i}$ satisfies the nonlinear equation system:

$$
\beta \ln V_{i}=\mu_{C, i}-\frac{\gamma}{2} \sigma_{C, i}^{2}+\lambda_{i} \frac{\left(V_{j} / V_{i}\right)^{1-\gamma}-1}{1-\gamma} i \in\{R, E\}, j \neq i
$$

\section{OA.C Derivation of the real SDF}

In this section, we derive the real SDF shown in Proposition OA.1. When we refer to states of the economy within this proof we mean only the real states, $L, H$.

Duffie and Skiadas (1994) show that the SDF for a general normalized aggregator $f$ is given by

$$
\pi_{t}=e^{\int_{0}^{t} f_{v}\left(C_{s}, J_{s}\right) d t} f_{c}\left(C_{t}, J_{t}\right)
$$

where $f_{c}(\cdot, \cdot)$ and $f_{v}(\cdot, \cdot)$ are the partial derivatives of $f$ with respect to its first and second arguments, respectively, and $J$ is the value function given in (OA.18). The Feynman-Kac Theorem implies

$$
\left.f\left(C_{t}, J_{t-}\right)\right|_{\nu_{t-}=i} d t+E_{t}\left[d J_{t} \mid \nu_{t-}=i\right]=0, i \in\{R, E\} .
$$

Using Ito's Lemma we rewrite the above equation as

$$
0=f\left(C, J_{i}\right)+C J_{i, C} \mu_{C, i}+\frac{1}{2} C^{2} J_{i, C C} \sigma_{C, i}^{2}+\lambda_{i}\left(J_{j}-J_{i}\right),
$$

for $i, j \in\{R, E\}, j \neq i$. We guess and verify that $J=h(C V)$, where $V_{i}$ satisfies the nonlinear equation system

$$
0=\beta u\left(V_{i}^{-1}\right)+\mu_{C, i}-\frac{1}{2} \gamma \sigma_{C, i}^{2}+\lambda_{i}\left(\frac{\left(V_{j} / V_{i}\right)^{1-\gamma}-1}{1-\gamma}\right), i, j \in\{R, E\}, j \neq i .
$$


Substituting (OA.17) into (OA.24) and simplifying gives

$$
\pi_{t}=\beta e^{-\beta \int_{0}^{t}\left[1+\left(\gamma-\frac{1}{\psi}\right) u\left(V_{s}^{-1}\right)\right] d t} C_{t}^{-\gamma} V_{t}^{-\left(\gamma-\frac{1}{\psi}\right)} .
$$

When $\psi=1$, the above equation gives the second expression in (OA.19). We rewrite (OA.26) as

$\beta\left[1+\left(\gamma-\frac{1}{\psi}\right) u\left(V_{i}^{-1}\right)\right]=\bar{r}_{i}-\left(\gamma-\frac{1}{\psi}\right) \lambda_{i}\left(\frac{\left(V_{j} / V_{i}\right)^{1-\gamma}-1}{1-\gamma}\right)-\left[\gamma \mu_{C, i}-\frac{1}{2} \gamma(1+\gamma) \sigma_{C, i}^{2}\right], i, j \in\{R, E\}, j \neq i$,

where $\bar{r}_{i}$ is given in (OA.21). Setting $\psi=1$ in (OA.28) gives (OA.23). To derive the first expression in (OA.19) from (OA.27) we prove that

$$
V_{i}=\left(\beta p_{C, i}\right)^{\frac{1}{1-\frac{1}{\psi}}}, \psi \neq 1
$$

We proceed by considering the optimization problem for the representative agent. She chooses her optimal consumption, $C^{*}$, and risky asset portfolio, $\varphi$, to maximize her expected utility

$$
J_{t}^{*}=\sup _{C^{*}, \varphi} E_{t} \int_{t}^{\infty} f\left(C_{t}^{*}, J_{t}^{*}\right) d t
$$

Observe that $J^{*}$ depends on optimal consumption-portfolio choice, whereas the $J$ defined previously in (OA.22) depends on exogenous aggregate consumption. The optimization is carried out subject to the dynamic budget constraint, which we now describe. If the agent consumes at the rate, $C^{*}$, invests a proportion, $\varphi$, of her remaining financial wealth in the claim on aggregate consumption (the risky asset), and puts the remainder in the locally risk-free asset, then her financial wealth, $W$, evolves according to the dynamic budget constraint:

$$
\frac{d W_{t}}{W_{t-}}=\varphi_{t-}\left(d R_{C, t}-r_{t-} d t\right)+r_{t-} d t-\frac{C_{t-}^{*}}{W_{t-}} d t
$$

where $d R_{C, t}$ is the cumulative return on the claim to aggregate consumption. We define $N_{i, t}$ as the Poisson process which jumps upward by one whenever the real state of the economy switches from $i$ to $j \neq i$. The compensated version of this process is the Poisson martingale

$$
N_{i, t}^{P}=N_{i, t}-\lambda_{i} t, i \in\{R, E\}
$$

It follows from applying Ito's Lemma to $P=p_{C} C$ that the cumulative return on the claim to aggregate consumption is

$$
d R_{C, t}=\frac{d P_{t}+C_{t} d t}{P_{t-}}=\mu_{R_{C}, t-} d t+\sigma_{C, t-} d B_{C, t}+\sigma_{R_{C}, t-}^{P} d N_{\nu_{t-}, t}^{P}
$$


where

$$
\begin{aligned}
\left.\mu_{R_{C}, t-}\right|_{\nu_{t-}=i} & =\mu_{R_{C}, i}=\mu_{C, i}+\frac{1}{2} \sigma_{C, i}^{2}+\lambda_{i}\left(\frac{p_{C, j}}{p_{C, i}}-1\right)+\frac{1}{p_{C, i}}, \\
\left.\sigma_{C, t-}\right|_{\nu_{t-}=i} & =\sigma_{C, i}, \\
\left.\sigma_{R_{C}, t-}^{P}\right|_{\nu_{t-}=i} & =\sigma_{R_{C}, i}^{P}=\frac{p_{C, j}}{p_{C, i}}-1,
\end{aligned}
$$

for $i \in\{R, E\}, j \neq i$. The total volatility of the return to holding the consumption claim, when the current state is $i$, is given by

$$
\sigma_{R_{C}, i}=\sqrt{\sigma_{C, i}^{2}+\lambda_{i}\left(\sigma_{R_{C}, i}^{P}\right)^{2}}
$$

Note that $C^{*}$ is the consumption to be chosen by the agent, i.e. it is a control, and at this stage we cannot rule out the possibility that it jumps with the state of the economy. In contrast, $C$ is aggregate consumption, and since it is continuous, its left and right limits are equal, i.e. $C_{t-}=C_{t}$.

The system of Hamilton-Jacobi-Bellman partial differential equations for the agent's optimization problem is

$$
\left.\sup _{C^{*}, \varphi} f\left(C_{t-}^{*}, J_{t-}^{*}\right)\right|_{\nu_{t-}=i} d t+E_{t}\left[d J_{t}^{*} \mid \nu_{t-}=i\right]=0, i \in\{R, E\}
$$

Applying Ito's Lemma to $J_{t}^{*}=J^{*}\left(W_{t}, \nu_{t}\right)$ allows us to write the above equation as

$$
\begin{aligned}
0= & \sup _{C_{i}^{*}, \varphi_{i}} f\left(C_{i}^{*}, J_{i}^{*}\right)+W_{i} J_{i, W}^{*}\left(\varphi_{i}\left(\mu_{R_{C}, i}-r_{i}\right)+r_{i}-\frac{C_{i}^{*}}{W_{i}}\right)+\frac{1}{2} W_{i}^{2} J_{i, W W}^{*} \varphi_{i}^{2} \sigma_{R_{C}, i}^{2}+ \\
& +\lambda_{i}\left(J_{j}^{*}-J_{i}^{*}\right), i \in\{R, E\}, j \neq i .
\end{aligned}
$$

We guess and verify that $J_{t}^{*}=h\left(W_{t} F_{t}\right)$, where $F_{i}$ satisfies the nonlinear equation system

$0=\sup _{C_{i}^{*}, \varphi_{i}} \beta u\left(\frac{C_{i}^{*}}{W_{i} F_{i}}\right)+\left(\varphi_{i}\left(\mu_{R_{C}, i}-r_{i}\right)+r_{i}-\frac{C_{i}^{*}}{W_{i}}\right)-\frac{1}{2} \gamma \varphi_{i}^{2} \sigma_{R_{C}, i}^{2}+\lambda_{i}\left(\frac{\left(F_{j} / F_{i}\right)^{1-\gamma}-1}{1-\gamma}\right), i \in\{R, E\}, j \neq i$.

From the first order conditions of the above equations, we obtain the optimal consumption and portfolio policies:

$$
\begin{aligned}
C_{i}^{*} & =\beta^{\psi} F_{i}^{-(\psi-1)} W_{i}, i \in\{R, E\}, \\
\varphi_{i} & =\frac{1}{\gamma} \frac{\mu_{R_{C}, i}-r_{i}}{\sigma_{R_{C}, i}^{2}}, i \in\{R, E\} .
\end{aligned}
$$

The market for the consumption good must clear, so $\varphi_{i}=1, W_{i}=P_{i}, C_{i}^{*}=C$ (and thus $J=J^{*}$ ). Note that this forces the optimal portfolio proportion to be one and the optimal consumption policy 
to be continuous. Hence

$$
\mu_{R_{C}, i}-r_{i}=\gamma \sigma_{R_{C}, i}^{2}
$$

and

$$
p_{C, i}=\beta^{-\psi} F_{i}^{1-\psi} .
$$

The above equation implies that for $\psi=1, p_{C, i}=1 / \beta$. The equality, $J=J^{*}$, implies that $C V_{i}=W F_{i}$. Hence, $F_{i}=p_{C, i}^{-1} V_{i}$. Using this equation to eliminate $F_{i}$ from (OA.30) gives (OA.29). Substituting (OA.29) into (OA.27) and (OA.28) gives the expression in (OA.19) for $\psi \neq 1$ and (OA.20).

\section{OA.D The evolution of the real SDF}

In this section we derive the evolution of the real SDF, as given in (14).

We define $N_{\nu_{t-}, \nu_{t}, t}$ as the Poisson process which jumps upward by one whenever the real state of the economy switches from $\nu_{t-}$ to $\nu_{t} \neq \nu_{t-}$. The compensated version of this process is the Poisson martingale (under the physical probability measure $\mathbb{P}$ ), $N_{\nu_{t-}, \nu_{t}, t}^{P}=N_{\nu_{t-}, \nu_{t}, t}-\lambda_{\nu_{t-}, \nu_{t}} t$. We start by proving that the real SDF satisfies the stochastic differential equation

$$
\left.\frac{d \pi_{t}}{\pi_{t-}}\right|_{\nu_{t-}=i}=-r_{i} d t+\left.\frac{d M_{t}}{M_{t-}}\right|_{\nu_{t-}=i},
$$

where $M$ is a martingale under $\mathbb{P}$ such that

$$
\left.\frac{d M_{t}}{M_{t-}}\right|_{\nu_{t-}=i}=-\Theta_{i}^{B} d Z_{t}+\Theta_{i j}^{P} d N_{i j, t}^{P}, j \in\{E, R\}, j \neq i
$$

$r_{i}$ is the risk-free rate in state $i$ given by

$$
r_{i}=\left\{\begin{array}{cl}
\bar{r}_{R}+\lambda_{R E}^{\text {real }}\left[\frac{\gamma-\frac{1}{\psi}}{\gamma-1}\left(\omega^{-\frac{\gamma-1}{\gamma-\frac{1}{\psi}}}-1\right)-\left(\omega^{-1}-1\right)\right] & , i=R \\
\bar{r}_{E}+\lambda_{E R}^{\text {real }}\left[\frac{\gamma-\frac{1}{\psi}}{\gamma-1}\left(\omega^{\frac{\gamma-1}{\gamma-\frac{1}{\psi}}}-1\right)-(\omega-1)\right] & , i=E
\end{array}\right.
$$

where $\omega$ is the solution of

$$
G(\omega)=0
$$

and

$$
G(x)=\left\{\begin{array}{cc}
x^{-\frac{1-\frac{1}{\psi}}{\gamma-\frac{1}{\psi}}}-\frac{\bar{r}_{R}+\gamma \sigma_{C, E}^{2}-g_{E}+\lambda_{E R}^{\text {real }} \frac{1-\frac{1}{\gamma}}{\gamma-1}\left(x^{\frac{\gamma-1}{\gamma-\frac{1}{\psi}}}-1\right)}{\bar{r}_{R}+\gamma \sigma_{C, R}^{2}-g_{R}+\lambda_{E R}^{\text {real }} \frac{1-\frac{1}{\psi}}{\gamma-1}\left(x^{-\frac{\gamma-1}{\gamma-\frac{1}{\psi}}}-1\right)}, & \psi \neq 1 \\
\ln x^{\frac{1}{\gamma-1}-\frac{\mu_{C, E}-\frac{1}{2} \gamma \sigma_{C, E}^{2}+\lambda_{2}(x-1)}{\mu_{C, R}-\frac{1}{2} \gamma \sigma_{C, R}^{2}+\lambda_{E R}^{\text {real }}\left(x^{-1}-1\right)},} & \psi=1 .
\end{array}\right.
$$


$\Theta_{i}^{B}$ is the market price of risk due to Brownian shocks in real state $i$, given by

$$
\Theta_{i}^{B}=\gamma \sigma_{C, i}, i \in\{R, E\}
$$

and $\Theta_{i}^{P}$ is the market price of risk due to Poisson shocks when the economy switches out of state $i$ :

$$
\Theta_{i j}^{P}=\omega_{i j}-1, i, j \in\{R, E\}, j \neq i \text {. }
$$

We begin the proof by noting that if we define

$$
\omega_{i j}=\left.\frac{\pi_{t}}{\pi_{t-}}\right|_{\nu_{t-}=i, \nu_{t}=j}, i, j \in\{R, E\}, j \neq i
$$

then (OA.19) implies that

$$
\omega_{i j}= \begin{cases}\left(\frac{p_{C, j}}{p_{C, i}}\right)^{-\frac{\gamma-\frac{1}{\psi}}{1-\frac{1}{\psi}}}, & \psi \neq 1 \\ \left(\frac{V_{j}}{V_{i}}\right)^{-(\gamma-1)}, & \psi=1 .\end{cases}
$$

The above equation implies that $\omega_{E R}=\omega_{R E}^{-1}$, so we can set $\omega_{E R}=\omega_{R E}^{-1}=\omega$.

We now show how to determine $\omega$. Using (OA.39) we rewrite (OA.20) and (OA.23) as

$$
p_{C, i}=\frac{1}{\bar{r}_{i}+\gamma \sigma_{C, i}^{2}-\mu_{C, i}+\lambda_{i j}^{\mathrm{real}} \frac{1-\frac{1}{\psi}}{\gamma-1}\left(\omega_{i j}^{\frac{\gamma-1}{\gamma-1 / \psi}}-1\right)}, i, j \in\{R, E\}, j \neq i
$$

and

$$
\beta \ln V_{i}=\mu_{C, i}-\frac{1}{2} \gamma \sigma_{C, i}^{2}+\lambda_{i j}^{\mathrm{real}} \frac{\omega_{i j}-1}{1-\gamma}, i, j \in\{R, E\}, j \neq i,
$$

respectively. Therefore, from (OA.39) and the above two equations it follows that $\omega$ is the solution of Equation (OA.34).

We now derive expressions for the risk-free rate and risk prices. Ito's Lemma implies that the state-price density evolves according to

$$
\begin{aligned}
\frac{d \pi_{t}}{\pi_{t-}}= & \frac{1}{\pi_{t-}} \frac{\partial \pi_{t-}}{\partial t} d t+\frac{1}{\pi_{t-}} C_{t} \frac{\partial \pi_{t-}}{\partial C_{t}} \frac{d C_{t}}{C_{t}}+\frac{1}{2} \frac{1}{\pi_{t-}} C_{t}^{2} \frac{\partial^{2} \pi_{t-}}{\partial C_{t}^{2}}\left(\frac{d C_{t}}{C_{t}}\right)^{2} \\
& +\lambda_{\nu_{t-}, \nu_{t}}^{\text {real }} \frac{\Delta \pi_{t}}{\pi_{t-}} d t+\frac{\Delta \pi_{t}}{\pi_{t-}} d N_{\nu_{t-}, \nu_{t}, t}^{P}
\end{aligned}
$$

where $\Delta \pi_{t}=\pi_{t}-\pi_{t-}$. The definition (OA.38) implies

$$
\frac{\Delta \pi_{t}}{\pi_{t-}}=\omega_{\nu_{t-}, \nu_{t}}-1
$$


Together with some standard algebra that allows us to rewrite (OA.42) as $\frac{d \pi_{t}}{\pi_{t-}}=-\left(\kappa_{\nu_{t-}}+\gamma \mu_{C, \nu_{t-}}-\frac{1}{2} \gamma(1+\gamma) \sigma_{C, \nu_{t-}}^{2}+\lambda_{\nu_{t-}, \nu_{t}}^{\mathrm{real}}\left(1-\omega_{\nu_{t-}, \nu_{t}}\right)\right) d t-\gamma \sigma_{C, \nu_{t}} d Z_{t}+\left(\omega_{\nu_{t-}, \nu_{t}}-1\right) d N_{\nu_{t-}, \nu_{t}, t}^{P}$.

Comparing the above equation with (OA.31), which is standard in an economy with jumps, gives (OA.36) and (OA.37), in addition to

$$
r_{i}=\kappa_{i}+\gamma \mu_{C, i}-\frac{1}{2} \gamma(1+\gamma) \sigma_{C, i}^{2}+\lambda_{i j}^{\text {real }}\left(1-\omega_{i j}\right), i, j \in\{R, E\}, j \neq i,
$$

where

$$
\kappa_{i}=\left\{\begin{aligned}
\beta\left[1+\left(\gamma-\frac{1}{\psi}\right) \frac{\left(\beta p_{C, i}\right)^{-1}-1}{1-\frac{1}{\psi}}\right], & \psi \neq 1, i, j \in\{R, E\}, j \neq i, \\
\beta\left[1+(\gamma-1) \ln \left(V_{i}^{-1}\right)\right], & \psi=1, i, j \in\{R, E\}, j \neq i,
\end{aligned}\right.
$$

We use Equations (OA.40) and (OA.41) to eliminate $p_{C, i}$ and $V_{i}$ from (OA.43) to obtain

$$
\kappa_{i}=\left\{\begin{array}{cl}
\bar{r}_{i}-\left(\gamma-\frac{1}{\psi}\right) \lambda_{i j}^{\mathrm{real}}\left(\frac{\omega_{i j}^{\frac{\gamma-1}{\gamma-1 / \psi}}-1}{1-\gamma}\right)-\left[\gamma \mu_{C, i}-\frac{1}{2} \gamma(1+\gamma) \sigma_{C, i}^{2}\right], & \psi \neq 1, i, j \in\{R, E\}, j \neq i \\
\bar{r}_{i}+\lambda_{i j}^{\mathrm{real}}\left(\omega_{i j}-1\right)-\left[\gamma \mu_{C, i}-\frac{1}{2} \gamma(1+\gamma) \sigma_{C, i}^{2}\right], & \psi=1, i, j \in\{R, E\}, j \neq i,
\end{array}\right.
$$

so

$$
r_{i}=\left\{\begin{array}{cc}
\bar{r}_{i}-\left(\gamma-\frac{1}{\psi}\right) \lambda_{i j}^{\text {real }}\left(\frac{\omega_{i j}^{\frac{\gamma-1}{\gamma-1 / \psi}}-1}{1-\gamma}\right)+\lambda_{i j}^{\text {real }}\left(1-\omega_{i j}\right), & \psi \neq 1, i, j \in\{R, E\}, j \neq i, ; \\
\bar{r}_{i}, & \psi=1, i \in\{R, E\} .
\end{array}\right.
$$

Taking the limit of the upper expression in the above equation gives the lower expression, so (OA.33) follows. The total market price of consumption risk in real state $i$ accounts for both Brownian and Poisson shocks, and is thus given by

$$
\Theta_{i}=\sqrt{\left(\Theta_{i}^{B}\right)^{2}+\lambda_{i j}\left(\Theta_{i}^{P}\right)^{2}}, i, j \in\{R, E\}, j \neq i
$$

Because the Poisson and Brownian shocks in (OA.32) are independent and their respective prices of risk are bounded, $M$ is a martingale under the actual measure $\mathbb{P}$. Thus, $M$ defines the Radon-Nikodym derivative $\frac{d \mathbb{Q}}{d \mathbb{P}}$ via $M_{t}=E_{t}\left[\frac{d \mathbb{Q}}{d \mathbb{P}}\right]$. It is a standard result (see Elliott (1982)) that the risk-neutral switching probabilities per unit time are given by

$$
\widehat{\lambda}_{i j}^{\mathrm{real}}=\lambda_{i j}^{\mathrm{real}} E_{t}\left[\frac{M_{t}}{M_{t-}} \mid \nu_{t-}=i, \nu_{t}=j\right], j \neq i .
$$


The jump component in $d \pi$ comes purely from $d M$. Thus, using (OA.38), we can simplify the above expression to obtain $\hat{\lambda}_{i j}^{\text {real }}=\lambda_{i j}^{\text {real }} \omega_{i j}$, from which we can derive (17).

We deduce the properties of the risk distortion factor, $\omega$, from the properties of the function $G$ defined in (OA.35). We restrict the domain of $G$ to $x>0$. First we consider the case where $\psi \neq 1$. We assume that the price-consumption ratios, $p_{C, i}, i \in\{R, E\}$, are strictly positive. Therefore, $G$ is continuous. We observe that if $G$ is monotonic, then by continuity, $G(1)$ and $G^{\prime}(1)$ are the same (opposite) in sign iff $\omega<1(\omega>1)$. Clearly, in both cases, $\omega$ is unique. To establish monotonicity note that

$$
\begin{aligned}
& G^{\prime}(x)=-\frac{1-\frac{1}{\psi}}{\gamma-\frac{1}{\psi}}\left[\frac { 1 } { ( \overline { r } _ { 1 } + \gamma \sigma _ { C , R } ^ { 2 } - \mu _ { C , R } + \lambda _ { 1 } \frac { 1 - \frac { 1 } { \psi } } { \gamma - 1 } ( x ^ { - \frac { \gamma - 1 } { \gamma - \frac { 1 } { \psi } } } - 1 ) ) ^ { 2 } } \left(\bar{r}_{1}+\gamma \sigma_{C, R}^{2}-\mu_{C, R}+\lambda_{R E} \frac{1-\frac{1}{\psi}}{\gamma-1}\left(x^{-\frac{\gamma-1}{\gamma-\frac{1}{\psi}}}-1\right) \lambda_{E R} x^{\frac{1 / \psi-1}{\gamma-1 / \psi}}\right.\right. \\
& \left.\left.+\left(\bar{r}_{2}+\gamma \sigma_{C, E}^{2}-\mu_{C, E}+\lambda_{2} \frac{1-\frac{1}{\psi}}{\gamma-1}\left(\omega^{\frac{\gamma-1}{\gamma-\frac{1}{\psi}}}-1\right)\right) \lambda_{1} x^{-\frac{1 / \psi-1}{\gamma-1 / \psi}-2}\right)+x^{-\frac{1-\frac{1}{\psi}}{\gamma-\frac{1}{\psi}}-1}\right]
\end{aligned}
$$

The above equation implies that for $x>0$, if $p_{C, R}$ and $p_{C, E}$ are strictly positive, then $G^{\prime}(x)$ does not change sign. Therefore, $G$ must be monotonic. Now we use the following expressions:

$$
G(1)=1-\frac{\bar{r}_{E}+\gamma \sigma_{C, E}^{2}-\mu_{C, E}}{\bar{r}_{R}+\gamma \sigma_{C, R}^{2}-\mu_{C, R}}
$$

and

$$
G^{\prime}(1)=-\frac{1-\frac{1}{\psi}}{\gamma-\frac{1}{\psi}}\left[1+\frac{\left(\bar{r}_{R}+\gamma \sigma_{C, R}^{2}-\mu_{C, R}\right) \lambda_{R E}^{\text {real }}+\left(\bar{r}_{E}+\gamma \sigma_{C, E}^{2}-\mu_{C, E}\right) \lambda_{E R}^{\text {real }}}{\left(\bar{r}_{R}+\gamma \sigma_{C, R}^{2}-\mu_{C, R}\right)^{2}}\right],
$$

to relate the signs of $G(1)$ and $G^{\prime}(1)$ to the properties of the agent's preferences. Note that $G^{\prime}(1)<0$, $\left(G^{\prime}(1)>0\right)$ iff $\frac{1-\frac{1}{\psi}}{\gamma-\frac{1}{\psi}}>0,\left(\frac{1-\frac{1}{\psi}}{\gamma-\frac{1}{\psi}}<0\right)$. We assume that $\bar{r}_{i}+\gamma \sigma_{C, i}^{2}-\mu_{C, i}>0$ for $i \in\{R, E\}$, which is equivalent to assuming that if the economy were always in real state $i$, then the price-consumption ratio would be positive. Simple algebra tells us that $\bar{r}_{i}+\gamma \sigma_{C, i}^{2}-\mu_{C, i}=\beta+\left(\frac{1}{\psi}-1\right)\left(\mu_{C, i}-\frac{1}{2} \gamma \sigma_{C, i}^{2}\right)$. We know that $\mu_{C, R}-\frac{1}{2} \gamma \sigma_{C, R}^{2}<\mu_{C, R}-\frac{1}{2} \gamma \sigma_{C, E}^{2}$. Therefore $G(1)<0,(G(1)>0)$ iff $\psi>1,(\psi<1)$. Consequently, $G(1)$ and $G^{\prime}(1)$ are the same (opposite) in sign iff $\gamma<1 / \psi(\gamma>1 / \psi)$. It then follows that $\omega>1(\omega<1)$ iff $\gamma>1 / \psi(\gamma<1 / \psi)$, assuming that $\psi \neq 1$.

Similarly, when $\psi=1$, if we assume that $V_{i}>0$ for $i \in\{R, E\}$, then we can prove that: $\omega>1$ if $\gamma>1(\gamma<1)$ and $g_{i}-\frac{1}{2} \gamma \sigma_{C, i}^{2}, i \in\{R, E\}$ are of the same (opposite) sign. Now, if $\gamma<1$, then $\bar{r}_{R}+\gamma \sigma_{C, R}^{2}-\mu_{C, R}>0$ implies $\mu_{C, R}-\frac{1}{2} \gamma \sigma_{C, R}^{2}>0$, which means $\mu_{C, i}-\frac{1}{2} \gamma \sigma_{C, i}^{2}, i \in\{R, E\}$ cannot be of opposite sign. Therefore, $\omega>1$ iff $\gamma>1$.

So, for $\psi>0, \omega>1(\omega<1)$ iff $\gamma>1 / \psi(\gamma<1 / \psi)$. It follows that $\omega=1$ iff $\gamma=1 / \psi$. 


\section{OA.E Liquidation Value}

The abandonment or liquidation value of a firm is just its unlevered value, i.e. the present value of future cashflows, ignoring coupon payments to debtholders and default risk. Small, but frequent shocks to a firm's real cashflow growth are modelled by changes in the standard Brownian motion $W_{t}$. Small, but frequent shocks to the real SDF are modelled by changes in the standard Brownian motion $Z_{t}$. The assumption that $d Z_{t} d W_{t}=0$ means that small, but frequent shocks to cashflow growth are not priced. However, changes in the expected real cashflow growth rate are driven by the same Markov chain as those driving jumps in the SDF. Hence, changes in unlevered firm value driven by changes in the expected real cashflow growth rate will be priced.

Suppose the economy is currently in state $i$. Then, the risk-neutral probability of the economy switching into a different state $j \neq i$ during a small time interval of length $\Delta t$ is $\widehat{\lambda}_{i j} \Delta t$ and the riskneutral probability of not switching is $1-\widehat{\lambda}_{i j} \Delta t$. We can therefore write the unlevered nominal firm value in state $i$ as

$$
A_{i, t}^{\$}=(1-\eta) X_{t} \Delta t+e^{-\left(r_{i}^{\$}-\mu_{X, i}\right) \Delta t}\left[\left(1-\widehat{\lambda}_{i j} \Delta t\right) A_{i}^{\$}+\sum_{j \neq i} \widehat{\lambda}_{i j} \Delta t A_{j}^{\$}\right], i, j \in\{1, \ldots, N\}, j \neq i,
$$

where $N=6$ is the number of states in the economy.

The first term in (OA.47) is the after-tax cash flow received in the next instant and the second term is the discounted continuation value. The discount rate is just the standard discount rate for a perpetuity. Observe that the volatility of cashflow growth does not appear in the discount rate, because $d Z_{t} d W_{t}=0$. The continuation value is the average of $A_{i, t}^{\$}$ and $A_{j, t}^{\$}$, weighted by the riskneutral probabilities of being in states $i$ and $j \neq i$ a small instant $\Delta t$ from now. For example, with risk-neutral probability $\widehat{\lambda}_{i j} \Delta t$ the economy will be in state $j \neq i$ and the unlevered nominal firm value will be value will be $A_{j}^{\$}$. The continuation value is discounted back at a rate reflecting the nominal interest rate rate $r_{i}^{\$}$ and the expected nominal earnings growth rate over that instant which is $\mu_{X, i}$ - observe that there is no difference between the physical and risk-neutral nominal earnings growth rates, because $d Z_{t} d W_{t}=0$.

We take the limit of (OA.47) as $\Delta t \rightarrow 0$, to obtain

$$
0=(1-\eta) X-\left(r_{i}^{\$}-\mu_{X, i}\right) A_{i}^{\$}+\sum_{j \neq i} \widehat{\lambda}_{i j}\left(A_{j}^{\$}-A_{i}^{\$}\right), i \in\{1, \ldots, N\}, j \neq i .
$$

To obtain the solution of the above linear equation system, we define

$$
v_{A, i}=\frac{1}{(1-\eta)} \frac{A_{i}^{\$}}{X}
$$


the before-tax nominal price-earnings ratio in state $i$. Therefore

$$
\left(\operatorname{diag}\left(r_{1}^{\$}-\mu_{X, 1}, \ldots, r_{N}^{\$}-\mu_{X, N}\right)-\widehat{\Lambda}\right)\left(\begin{array}{c}
v_{A, 1} \\
\vdots \\
v_{A, N}
\end{array}\right)=1_{N \times 1}
$$

where $1_{N \times 1}$ is a $6 \times 1$ vector of ones, $\operatorname{diag}\left(r_{1}^{\$}-\mu_{X, 1}, \ldots, r_{N}^{\$}-\mu_{X, N}\right)$ is a $N \times N$ diagonal matrix, with the quantities $r_{1}^{\$}-\mu_{X, 1}, \ldots, r_{N}^{\$}-\mu_{X, N}$ along the diagonal and $\widehat{\Lambda}$, defined by $[\widehat{\Lambda}]_{i j}=\widehat{\lambda}_{i j}, i, j \in$ $\{1, \ldots, N\}$, where

$$
\begin{aligned}
& \widehat{\lambda}_{i j}=\omega_{i j} \lambda_{i j}, j \neq i \\
& \widehat{\lambda}_{i i}=-\sum_{j \neq i} \omega_{i j} \lambda_{i j}, j \neq i
\end{aligned}
$$

is the generator matrix of the Markov chain for the combined state of the economy under the riskneutral measure. Solving (OA.48) gives (26), if $\operatorname{det}\left(\operatorname{diag}\left(r_{1}^{\$}-\mu_{X, 1}, \ldots, r_{N}^{\$}-\mu_{X, N}\right)-\widehat{\Lambda}\right) \neq 0$.

Similarly, we can show that the before-tax value of the claim to the real earnings stream $Y$, when the current state is $i$ is given by $P_{i, t}^{Y}=p_{i} Y_{t}$, where

$$
\left(p_{1}, \ldots, p_{N}\right)^{\top}=\left(\operatorname{diag}\left(r_{1}-\mu_{Y, 1}, \ldots, r_{N}-\mu_{Y, N}\right)-\widehat{\Lambda}\right)^{-1} 1_{6 \times 1}
$$

Hence, from the basic asset pricing equation

$$
E_{t}\left[\frac{d P_{t}^{Y}+Y d t}{P_{t}^{Y}}-r_{\nu_{t-}} d t \mid \nu_{t-}=i\right]=-E_{t}\left[\frac{d \pi_{t}}{\pi_{t}} \frac{d P_{t}^{Y}}{P_{t}^{Y}} \mid \nu_{t-}=i\right]
$$

we obtain the unlevered risk premium:

$$
E_{t}\left[\frac{d P_{t}^{Y}+Y_{t} d t}{P^{Y}}-r_{\nu_{t-}} d t \mid \nu_{t-}=i\right]=-\sum_{j \neq i}\left(\widehat{\lambda}_{i j}-\lambda_{i j}\right)\left(\frac{p_{j}}{p_{i}}-1\right) d t, i, j \in\{1, \ldots, M\},
$$

where $M=2$ is the number of real states in the economy. Applying Ito's Lemma,

$$
d P_{i, t}^{X}=p_{i} d X_{t}+\sum_{j \neq i} \lambda_{i j}\left(p_{j}-p_{i}\right) d t+\sum_{j \neq i}\left(p_{j}-p_{i}\right) d N_{i j, t}^{P}, i, j \in\{1, \ldots, M\}
$$

Thus, the volatility of returns on unlevered equity in state $i$ is given by

$$
\sigma_{R, i}=\sqrt{\sum_{j \neq i} \lambda_{i j}\left(\frac{p_{j}}{p_{i}}-1\right)^{2}}, i, j \in\{1, \ldots, M\}
$$




\section{OA.F Arrow-Debreu Securities - Default}

The Arrow-Debreu default claim denoted by $q_{D, i j}$ is the value of a unit of consumption paid if default occurs in state $j$ and the current state is $i$. In a static capital structure model, these are the only Arrow-Debreu claims needed. Given the initial state (in which the firm selected its capital structure, there are $N^{2}$ such claims: $\left\{q_{D, i j}\right\}_{i, j \in\{1, \ldots, N\}}$. We assume, without loss of generality, that the regimes are labelled so that the default boundaries respect a monotonic ordering $X_{D, 1}>\ldots>X_{D, N}$.

We say that a firm's earnings are in the default region $\mathcal{D}_{k}, k=0, \ldots, N-1$, when they fall in the interval $\left(X_{D, k+1}, X_{D, k}\right]$, assuming that $X_{D, 0} \rightarrow \infty$. Region $\mathcal{D}_{N}$ is $\left(-\infty, X_{D, N}\right]$.

Proposition OA.2 Let $A_{k}$ be

$$
A_{k}=\left(\begin{array}{cc}
0_{N-k \times N-k} & -I_{N-k \times N-k} \\
2 S_{x, k}^{-1}\left(\widehat{\Lambda}_{k}-R_{k}\right) & 2 S_{x, k}^{-1} M_{x, k}
\end{array}\right),
$$

where $0_{n \times m} \in \mathbb{R}^{n \times m}$ denotes a matrix of zeros, $I_{n \times n} \in \mathbb{R}^{n \times n}$ denotes the $n$-dimensional identity matrix, $\widehat{\Lambda}_{k}, R_{k}, M_{x, k}$, and $S_{x, k}$ are the $N-k$ by $N-k$ matrices obtained by removing the first $k$ rows and columns of $\widehat{\Lambda}$,

$$
R=\operatorname{diag}\left(r_{1}, \ldots, r_{N}\right), \quad M_{x}=\operatorname{diag}\left(\mu_{x, 1}, \ldots, \mu_{x, N}\right), \quad \text { and } \quad S_{x}=\operatorname{diag}\left(\sigma_{x, 1}^{2}, \ldots, \sigma_{x, N}^{2}\right),
$$

with $\widehat{\mu}_{x, i}=\widehat{\mu}_{X, i}-\frac{1}{2} \sigma_{X, i}^{2}$ and $\sigma_{x, i}=\sigma_{X, i}$ the drift and diffusion coefficient of $x=\log X$ under the risk-neutral measure.

Given the integration constants $h_{i, j}(\omega)$, the default Arrow-Debreu in region $\mathcal{D}_{k}$ are given by

\section{Region $\mathcal{D}_{0}$ :}

$$
q_{D, i j}(x)=\sum_{l=1}^{N} h_{i j}\left(\omega_{0, l}\right) e^{-\omega_{0, l} x}
$$

where $\omega_{0,1}>\ldots>\omega_{0, N}>0$ are the $N$ positive eigenvalues of $A_{0}$.

Region $\mathcal{D}_{k}, k \in\{1, \ldots, N-1\}$ :

$$
\begin{array}{rr}
q_{D, i j}(x)=\delta_{i j}, & i \in\{1, \ldots, k\}, j \in\{1, \ldots, N\}, \\
q_{D, i, j}(x)=\sum_{l=1}^{2(N-k)} h_{i j}\left(\omega_{l}\right) e^{-\omega_{l} x}-\left[A_{k}^{-1} B_{k}\right]_{i-k, j}, & i \in\{k+1, \ldots, N\}, j \in\{1, \ldots, N\} .
\end{array}
$$


where $\omega_{k, l}$ are the $2(N-k)$ eigenvalues of $A_{k}$ and

$$
B_{k}=\left(\begin{array}{cc}
0_{N-k \times k} & 0_{N-k \times N-k} \\
B_{k}^{\varnothing} & 0_{N-k \times N-k}
\end{array}\right), \quad B_{k}^{\varnothing}=\left(\begin{array}{cccc}
2 \frac{\widehat{\lambda}_{k+1,1}}{\sigma_{k+1}^{2}} & 2 \frac{\widehat{\lambda}_{k+1,2}}{\sigma_{k+1}^{2}} & \cdots & 2 \frac{\widehat{\lambda}_{k+1, k}}{\sigma_{k+1}^{2}} \\
2 \frac{\widehat{\lambda}_{k+2,1}}{\sigma_{k+2}^{2}} & 2 \frac{\widehat{\lambda}_{k+2,2}}{\sigma_{k+2}^{2}} & \cdots & 2 \frac{\widehat{\lambda}_{k+2, k}}{\sigma_{k+2}^{2}} \\
\vdots & \vdots & \cdots & \vdots \\
2 \frac{\widehat{\lambda}_{N, 1}}{\sigma_{N}^{2}} & 2 \frac{\widehat{\lambda}_{N, 2}}{\sigma_{N}^{2}} & \cdots & 2 \frac{\widehat{\lambda}_{N, k}}{\sigma_{N}^{2}}
\end{array}\right) .
$$

\section{Region $\mathcal{D}_{N}$ :}

$$
q_{D, k, i j}(x)=\delta_{i j}, \quad \forall i, j
$$

In each default region, for each $\omega$, the integration constants $h_{k+1, \bullet}(\omega) \equiv\left[h_{k+1, j}(\omega)\right]_{j=1, \ldots, N} \in \mathbb{R}^{1 \times N}$, are identified by the boundary conditions (Section OA.F.3), and the remaining integration constants

$$
H_{k}(\omega)=\left(\begin{array}{ccc}
h_{k+2,1}(\omega) & \cdots & h_{k+2, N}(\omega) \\
\vdots & \cdots & \vdots \\
h_{N, 1}(\omega) & \cdots & h_{N, N}(\omega)
\end{array}\right)
$$

are given by

$$
H_{k}(\omega)=G_{k}^{-1}(\omega) g_{k+\bullet, 1}(\omega) h_{k+1, \bullet}(\omega)
$$

where $g_{k+\bullet, k+1}(\omega) \equiv\left[g_{i, k+1}(\omega)\right]_{i=k+2, \ldots, N} \in \mathbb{R}^{(N-k-1) \times 1}$ comprises the last $N-k-1$ elements of the first column of

$$
G(\omega)=2 S_{x}^{-1}(\widehat{\Lambda}-R)-\omega\left(2 S_{x}^{-1} M_{x}-\omega I_{N \times N}\right) .
$$

and $G_{k}(\omega)$ is the $N-k-1$ by $N-k-1$ matrix obtained by removing the first $k+1$ rows and columns of $G(\omega)$.

The next two subsections outline the proof of Proposition OA.2.

\section{OA.F.1 Region $\mathcal{D}_{0}: X_{t}>X_{D, 1}$}

We start by analyzing the case where earnings at the current date $t$ are above the highest default boundary, i.e. $X_{t}>X_{D, 1}$. Hence, if earnings hit the boundary $X_{D, j}$ from above for the first time in state $j,\left\{q_{D, i j}\right\}_{i, j \in\{1, \ldots, N\}}$ will pay one unit of consumption; otherwise, the security expires worthless. Since each Arrow-Debreu default claim is effectively a perpetual digital put, their values can be derived by solving a system of ordinary differential equations, derived from the standard equations

$$
E_{t}^{\mathbb{Q}}\left[d q_{D, i j}-r_{i} q_{D, i j} d t\right]=0, i, j \in\{1, \ldots, N\} .
$$


Using Ito's Lemma, the above equation can be rewritten as the following second-order ordinary differential-equation system: ${ }^{19}$

$$
\frac{1}{2} \sigma_{x, i}^{2} \frac{d^{2} q_{D, i j}}{d x^{2}}+\widehat{\mu}_{x, i} \frac{d q_{D, i j}}{d x}+\sum_{k \neq i} \widehat{\lambda}_{i k}\left(q_{D, k j}-q_{D, i j}\right)=r_{i} q_{D, i j}, i, j \in\{1, \ldots, N\}
$$

where $\widehat{\mu}_{x, i}=\widehat{\mu}_{X, i}-\frac{1}{2} \sigma_{X, i}^{2}$ and $\sigma_{x, i}=\sigma_{X, i}$ are the drift and diffusion coefficient of $x=\log X$ under the risk-adjusted measure.

In order to solve this system of ODEs, define

$$
\begin{aligned}
z_{i j} & =q_{D, i j}, i, j \in\{1, \ldots, N\} \\
z_{N+i, j} & =\frac{d q_{D, i j}}{d x}, i, j \in\{1, \ldots, N\} .
\end{aligned}
$$

Then, we obtain the following first order linear system

$$
\begin{aligned}
\frac{d z_{i j}}{d x}-z_{N+i, j} & =0, i, j \in\{1, \ldots, N\}, \\
\frac{d z_{N+i, j}}{d x}+\frac{2 \widehat{\mu}_{x, i}}{\sigma_{x, i}^{2}} z_{N+i, j}+\sum_{k \neq i} \frac{2 \widehat{\lambda}_{i k}}{\sigma_{x, i}^{2}}\left(z_{k j}-z_{i j}\right)-\frac{2 r_{i}}{\sigma_{x, i}^{2}} z_{i j} & =0, i, j \in\{1, \ldots, N\} .
\end{aligned}
$$

Expressing the above equation system in matrix form gives

$$
Z^{\prime}+A_{0} Z=0_{2 N \times N},
$$

where the $i j$ 'th element of the $2 N$ by $N$ matrix, $Z$, is

$$
[Z]_{i j}=z_{i j}, i \in\{1, \ldots, 2 N\}, j \in\{1, \ldots, N\}
$$

and $Z^{\prime}=\frac{d Z}{d x}$.

To solve eq. (OA.63), one first finds the eigenvectors and eigenvalues of $A_{0}$. Their defining equation is

$$
A_{0} \underline{e}_{i}=\omega_{i} \underline{e}_{i}, i \in\{1, \ldots, 2 N\}
$$

where $\omega_{i}$ is the $i$ 'th eigenvalue and $\underline{e}_{i}$ is the corresponding eigenvector. Note that $A_{0}$ has $N$ positive and $N$ negative eigenvalues (Jobert and Rogers (2006)).

It follows from (OA.65) that the eigenvalues of $A_{0}$ are the roots of its characteristic polynomial; that is, any eigenvalue $\omega$ is a solution to the following $2 N^{\prime}$ th-order polynomial:

$$
\operatorname{det}\left(A_{0}-\omega I\right)=0
$$

\footnotetext{
${ }^{19}$ Note that since the puts are perpetual, $\frac{\partial q}{\partial t}=0$. Hence, $q$ is solely a function of the stochastic process $x=\log X$.
} 
To simplify the above expression for the characteristic polynomial, we then use the following identity from Silvester: If $F=\left(\begin{array}{ll}F_{11} & F_{12} \\ F_{21} & F_{22}\end{array}\right)$, where $F_{i j}, i, j \in\{1,2\}$ are $N$ by $N$ matrices, any two of which commute with each other, then

$$
\operatorname{det} F=\operatorname{det}\left(F_{11} F_{22}-F_{12} F_{21}\right) \text {. }
$$

Since

$$
A_{0}-\omega I=\left(\begin{array}{cc}
-\omega I & -I \\
2 S_{x}^{-1}(\widehat{\Lambda}-R) & 2 S_{x}^{-1} M_{x}-\omega I
\end{array}\right)
$$

and diagonal matrices commute with all other matrices of the same size, any pair of the $\mathrm{N}$ submatrices in $A_{0}$ commute. Therefore, one can apply (OA.66) and

$$
0=\operatorname{det}\left(A_{0}-\omega I\right)=\operatorname{det}\left(\omega\left(\omega I-2 S_{x}^{-1} M_{x}\right)-2 S_{x}^{-1}(\widehat{\Lambda}-R)\right) .
$$

When $N \leq 2$ the above polynomial is of order 4 or less and can be solved exactly in closed-form. When $N \geq 3$, it must be solved numerically. Once the eigenvalues have been obtained, the eigenvectors are obtained by solving (OA.65). We then define the $2 N$ by $2 N$ matrix of eigenvectors, $E$, by stacking the eigenvectors as follows

$$
E=\left(\underline{e}_{1}, \ldots, \underline{e}_{2 N}\right) .
$$

Hence, the $i j^{\prime}$ th component of $E$ is the $i$ 'th element of the $j$ 'th eigenvector, i.e.

$$
E_{i j}=\left(\underline{e}_{j}\right)_{i}
$$

Given the $E$ matrix, we can define the $2 N$ by $N$ matrix $W$ via

$$
E W=Z \text {. }
$$

We can then rewrite eq. (OA.63) as

$$
\begin{aligned}
E W^{\prime}+A_{0} E W & =0_{2 N \times N}, \\
\Leftrightarrow E^{-1}\left(E W^{\prime}+A_{0} E W\right)=W^{\prime}+E^{-1} A_{0} E W & =0_{2 N \times N}, \\
\Leftrightarrow W^{\prime}+D W & =0_{2 N \times N},
\end{aligned}
$$

where

$$
D=E^{-1} A_{0} E=\operatorname{diag}\left(\omega_{1}, \ldots, \omega_{2 N}\right) .
$$

The first order differential equation system of eq. (OA.71) is similar to that of eq. (OA.63), with the notable difference that $D$ is a diagonal matrix while $A_{0}$ isn't. Making use of this, we premultiply both sides of eq. (OA.71) by the integrating factor $e^{D x}$, which yields

$$
e^{D x} W^{\prime}+e^{D x} D W=\left(e^{D x} W\right)^{\prime}=0_{2 N \times N} .
$$


Integrating the above equation gives

$$
e^{D x} W=K
$$

where $K$ is a $2 N$ by $N$ matrix of constants of integration. Therefore, the general solution of eq. (OA.71) is

$$
W=e^{-D x} K
$$

which, given eq. (OA.68), implies

$$
Z=E e^{-D x} K=e^{-D x} E K
$$

given that $D$ is $2 N \times 2 N$ and diagonal, and that $E$ is $2 N \times 2 N$.

Thus,

$$
q_{D, i j}(x)=\sum_{l=1}^{2 N} h_{i j}\left(\omega_{l}\right) e^{-\omega_{l} x},
$$

where the $h_{i j}\left(\omega_{l}\right)$ are constants of integration that depend on the eigenvalues.

Note that, for any eigenvalue $\omega$ of $A_{0}$, the particular solution $q_{D, i j}=h_{i j}(\omega) e^{-\omega x}$, with $h_{i j}\left(\omega_{l}\right)=$ $0, \forall \omega_{l} \neq \omega$, solves (OA.74). Indeed, we then have

$$
Z=\left[\begin{array}{c}
H(\omega) \\
-\omega H(\omega)
\end{array}\right] e^{-\omega x}, \quad \text { where } H(\omega)=\left(\begin{array}{c}
h_{1, \bullet}(\omega) \\
H_{0}(\omega)
\end{array}\right)
$$

and

$$
Z^{\prime}=-\omega Z
$$

Hence, (OA.63) implies that

$$
\left(-\omega I_{2 N \times 2 N}+A_{0}\right) Z=0_{2 N \times N}
$$

or, equivalently,

$$
\left(\begin{array}{cc}
-\omega I_{N \times N} & -I_{N \times N} \\
2 S_{x}^{-1}(\widehat{\Lambda}-R) & 2 S_{x}^{-1} M_{x}-\omega I_{N \times N}
\end{array}\right)\left[\begin{array}{c}
H(\omega) \\
-\omega H(\omega)
\end{array}\right]=0_{2 N \times N} .
$$

This particular solution is important since it allows us to express $N(N-1)$ of the $N^{2}$ integation constants in terms of the first $N$ ones. Indeed, simplifying (OA.75) gives

$$
\begin{aligned}
-\omega I_{N \times N} H(\omega)+I_{N \times N} \omega H(\omega) & =0_{N \times N}, \\
\left(2 S_{x}^{-1}(\widehat{\Lambda}-R)-\omega\left(2 S_{x}^{-1} M_{x}-\omega I_{N \times N}\right)\right) H(\omega) & =0_{N \times N},
\end{aligned}
$$

where the first equation is trivial. To solve the second equation, we first consider

$$
G(\omega)\left(h_{1 j}(\omega), \ldots, h_{N j}(\omega)\right)^{T}=0_{N \times 1}
$$


where

$$
G(\omega)=2 S_{x}^{-1}(\widehat{\Lambda}-R)-\omega\left(2 S_{x}^{-1} M_{x}-\omega I_{N \times N}\right) .
$$

We denote the $i j$ 'th element of $G(\omega)$ by $g_{i j}(\omega)$. We know from (OA.67) that $\operatorname{det} G(\omega)=0$. Thus, the equations

$$
\sum_{k=1}^{N} g_{i k}(\omega) h_{k j}(\omega), i \in\{1, \ldots, N\}
$$

are linearly dependent. However, the system

$$
\sum_{k=1}^{N} g_{i k}(\omega) h_{k j}(\omega), i \in\{2, \ldots, N\}
$$

is linearly independent, allowing us to solve for $h_{k j}(\omega), k \in\{2, \ldots, N\}$ in terms of $h_{1 j}(\omega)$, for $j \in$ $\{1, \ldots, N\}$, that is

$$
H_{k}(\omega)=G_{k}^{-1}(\omega) g_{k+\bullet, 1}(\omega) h_{k+1, \bullet}(\omega) .
$$

Solving the above linear equation system gives us $h_{i j}(\omega), i \in\{2, \ldots, N\}, j \in\{1, \ldots, N\}$ in terms of $h_{1 j}(\omega), j \in\{1, \ldots, N\}$. Hence, for each eigenvalue $\omega$ of $A_{0}$, this leaves us with $N$ free integration constants. Then, to ensure the finiteness of the Arrow-Debreu prices as $x \rightarrow \infty$, focus on the $N$ positive eigenvalues of $A_{0}$. That is, we obtain $q_{D, i j}$, the Arrow-Debreu prices in region $\mathcal{D}_{0}$, where $X>X_{D, 1}$ :

$$
q_{D, i j}(x)=\sum_{l=1}^{N} h_{i j}\left(\omega_{0, l}\right) e^{-\omega_{0, l} x},
$$

where, without loss of generality, $\omega_{0,1}>\ldots>\omega_{0, N}>0$ are the $N$ positive eigenvalues of $A_{0}$. Note that (OA.79) contains $N^{2}$ free integrations constants $h_{1 j}\left(\omega_{0, l}\right)$, which will be identified by the value and smooth pasting conditions (Section OA.F.3).

OA.F.2 Region $\mathcal{D}_{k}: X_{D, k+1}<X \leq X_{D, k}$

We now turn to the analysis of Arrow-Debreu securities in region $\mathcal{D}_{k}$, i.e. when current earnings are above default boundary $k+1$, but below default boundary $k$. Note that the above analysis in default region $k=0$ can be seen as a special case of the analysis below, with $X_{D, 0} \rightarrow \infty$.

First, note that $q_{D, i j}=\delta_{i j}, \forall i \leq k$. Indeed, if earnings are currently lower than $X_{D, k}<X_{D, k-1}<\ldots$, and if the current state is $i \leq k$, then the firm is in default and the present value of a dollar when the firm defaults in state $j$ is 1 if $i=j$, and 0 otherwise. In particular, this means that, in region $\mathcal{D}_{N}$, where $X \leq X_{D, N}$, we have

$$
q_{D, i j}=\delta_{i j}
$$


Applying (OA.58) to the unknown $q_{D, i j}, i>k$, yields the following system of ODEs

$$
\begin{aligned}
& \frac{d z_{k+1, j}}{d x}-z_{N+k+1, j}=0, \\
& \frac{d z_{k+2, j}}{d x}-z_{N+k+2, j}=0, \\
& \frac{d z_{N, j}}{d x}-z_{2 N, j}=0, \\
& \frac{d z_{N+k+1, j}}{d x}+\frac{2 \widehat{\mu}_{x, k+1}}{\sigma_{x, k+1}^{2}} z_{N+k+1, j}+\sum_{l=1}^{k} \frac{2 \widehat{\lambda}_{k+1, l}}{\sigma_{x, k+1}^{2}}\left(\delta_{l j}-z_{k+1, j}\right) \\
& +\sum_{l=k+2}^{N} \frac{2 \widehat{\lambda}_{k+1, l}}{\sigma_{x, k+1}^{2}}\left(z_{l j}-z_{k+1, j}\right)-\frac{2 r_{k+1}}{\sigma_{x, k+1}^{2}} z_{k+1, j}=0, \\
& \frac{d z_{N+k+2, j}}{d x}+\frac{2 \widehat{\mu}_{x, k+2}}{\sigma_{x, k+2}^{2}} z_{N+k+2, j}+\sum_{l=1}^{k} \frac{2 \widehat{\lambda}_{k+2, l}}{\sigma_{x, k+2}^{2}}\left(\delta_{l, j}-z_{k+2, j}\right) \\
& +\sum_{l=k+1, l \neq k+2}^{N} \frac{2 \widehat{\lambda}_{k+2, l}}{\sigma_{x, k+2}^{2}}\left(z_{l, j}-z_{k+2, j}\right)-\frac{2 r_{k+2}}{\sigma_{x, k+2}^{2}} z_{k+2, j}=0 \\
& \frac{d z_{2 N, j}}{d x}+\frac{2 \widehat{\mu}_{x, N}}{\sigma_{x, N}^{2}} z_{2 N, j}+\sum_{l=1}^{k} \frac{2 \widehat{\lambda}_{N, l}}{\sigma_{x, N}^{2}}\left(\delta_{l, j}-z_{N, j}\right)+\sum_{l=k+1}^{N-1} \frac{2 \widehat{\lambda}_{N, l}}{\sigma_{x, N}^{2}}\left(z_{l, j}-z_{N, j}\right)-\frac{2 r_{N}}{\sigma_{x, N}^{2}} z_{N, j}=0,
\end{aligned}
$$

for $j=\{1, \ldots, N\}$. Rewriting the above equation system in matrix form, we obtain

$$
Z_{k}^{\prime}+A_{k} Z_{k}+B_{k}=Z_{k}^{\prime}+A_{k}\left(Z_{k}+A_{k}^{-1} B_{k}\right)=\widetilde{Z}_{k}^{\prime}+A_{k} \widetilde{Z}_{k}=0
$$

where $\widetilde{Z}_{k}=\left(Z_{k}+A_{k}^{-1} B_{k}\right), Z_{k}$ is the following $2(N-k)$ by $N$ matrix

$$
Z_{k}=\left(\begin{array}{cccc}
z_{k+1,1} & z_{k+1,2} & \cdots & z_{k+1, N} \\
z_{k+2,1} & z_{k+2,2} & \cdots & z_{k+2, N} \\
\vdots & \vdots & \cdots & \vdots \\
z_{N, 1} & z_{N, 2} & \cdots & z_{N, N} \\
z_{N+k+1,1} & z_{N+k+1,2} & \cdots & z_{N+k+1, N} \\
z_{N+k+2,1} & z_{N+k+2,2} & \cdots & z_{N+k+2, N} \\
\vdots & \vdots & \cdots & \vdots \\
z_{2 N, 1} & z_{2 N, 2} & \cdots & z_{2 N, N}
\end{array}\right) .
$$

Note that the $B_{k}$ matrix of constants arises from the $\delta_{l j}$ 's appearing in the above differential equations: 
(i) These appear only in the last $N-k$ equations. Hence, the first $N-k$ rows of the $B_{k}$ matrix will comprise of zeros.

(ii) Since the sum in which the $\delta_{l j}$ 's appear are from 1 to $k, \delta_{l j}$ will be zero for all $l$ whenever $j>k$. Hence, the last $N-k$ columns of the $B_{k}$ matrix will comprise of zeros.

Thereafter, the development made, in region $\mathcal{D}_{0}$, between equations (OA.65) and (OA.73) can be applied to $\widetilde{Z}_{k}$ in (OA.80) to yield

$$
\widetilde{Z}_{k}=e^{-D_{k} x} E_{k} K_{k}
$$

or, equivalently,

$$
Z_{k}=e^{-D_{k} x} E_{k} K_{k}-A_{k}^{-1} B_{k}
$$

Therefore,

$$
\begin{aligned}
q_{D, i j}(x) & =\delta_{i j}, i \in\{1, \ldots, k\}, j \in\{1, \ldots, N\} \\
q_{D, i, j}(x) & =\sum_{l=1}^{2(N-k)} h_{i j}\left(\omega_{l}\right) e^{-\omega_{l} x}-\left[A_{k}^{-1} B_{k}\right]_{i-k, j}, i \in\{k+1, \ldots, N\}, j \in\{1, \ldots, N\} .
\end{aligned}
$$

Note that the $-k$ offset on the rows of the $2(N-k) \times N$ matrix $A_{k}^{-1} B_{k}$ simply accounts for the fact the first row of this matrix corresponds to the $(k+1)^{\text {th }}$ Arrow-Debreu security. Once more, for each eigenvalue $\omega$ of $A_{k}$, the particular solution

$$
Z_{k}=\left(\begin{array}{c}
H_{k}(\omega) \\
-\omega H_{k}(\omega)
\end{array}\right) e^{-\omega y}-A_{k}^{-1} B_{k}, \quad \text { where } \quad H_{k}(\omega)=\left(\begin{array}{c}
h_{k+1, \bullet}(\omega) \\
\bar{H}_{k}(\omega)
\end{array}\right)
$$

can be used to express the constants in all lines of $H_{k}$ but the first, as functions of the $h_{k+1,1}, \ldots, h_{k+1, N}$ constants. This leaves us with $N$ free constants for each of the $2(N-k)$ eigenvalues.

\section{OA.F.3 Boundary Conditions for Arrow-Debreu Default Claims}

Given the above development, we are left with $N^{2}$ free integration constants in region $\mathcal{D}_{0}$, and $2(N-$ $k) N$ free constants in region $\mathcal{D}_{k}, k \in\{1, \ldots, N-1\}$. Hence, we still have to solve for the $N^{3}$ constants,

$$
N^{2}+\sum_{k=1}^{N-1} 2(N-k) N=N^{2}+2 N \sum_{k=1}^{N-1}(N-k)=N^{3}
$$

that satisfy the $N^{3}$ boundary conditions (value matching \& smooth pasting) of the problem at hand. For each default boundary $X_{D, k}, k \in\{1, \ldots, N\}$, we have that: 
(VM) The value of the $N+(N-k) N$ Arrow-Debreu securities with $i \geq k$, must be the same on both sides of the default boundary, i.e.

$$
q_{D_{k-1}, i j}\left(x_{D, k}\right)=q_{D_{k}, i j}\left(x_{D, k}\right), \text { where }, i \in\{k, \ldots, N\}, j \in\{1, \ldots, N\}
$$

(SP) The dynamics of the $(N-k) N$ Arrow-Debreu securities with $i>k$, must be the same on both side of the default boundary, i.e.

$$
\left.\frac{d q_{D_{k-1}, i j}}{d x}\right|_{x_{D, k}}=\left.\frac{d q_{D_{k}, i j}}{d x}\right|_{x_{D, k}}, \text { where }, i \in\{k+1, \ldots, N\}, j \in\{1, \ldots, N\}
$$

where the $q_{D_{k}}$ notation highlights that the Arrow-Debreu claim is computed int the $\mathcal{D}_{k}$ region.

\section{OA.G Modified Arrow-Debreu Default Claims}

Arrow-Debreu securities provide the expected value of a $1 \$$ cash flow conditional on the state of the world in which they occur. In particular, in region $\mathcal{D}_{k}$ at time $t$, Arrow-Debreu prices

$$
\begin{aligned}
q_{D, i j, t}(x) & =E_{t}\left[\frac{\pi_{\tau_{D}}}{\pi_{t}} 1_{\nu_{\tau_{D}}}=j \mid \nu_{t}=i\right] \\
& =E_{t}^{\mathbb{Q}}\left[1_{\nu_{\tau_{D}}=j} \mid \nu_{t}=i\right] \\
& =\mathbb{Q}\left[\nu_{\tau_{D}}=j \mid \nu_{t}=i\right],
\end{aligned}
$$

can be interpreted risk-adjusted probability that default, occurring at unknown time $\tau_{D}$, will occur in state $j$ conditional on the current state of the economy, $\nu_{t}$, being $i$. For cash flows that do not depend on the level of earnings when the firm defaults, $X_{\tau_{D}}=e^{x_{\tau_{D}}}$, these Arrow-Debreu securities yield a straightforward approach to derive the cash flows' expected values. If a cash flow does depend on $X_{\tau_{D}}$, the Arrow-Debreu securities may not be as useful.

In a continuous model, the earnings always approach the default boundary from above and default occur when $X_{\tau_{D}}=X_{D}$; that is, there is no uncertainty with respect to the level of earnings upon default and Arrow-Debreu securities can readily be used to compute expected cash flows. In our economy, however, "deep defaults" can occur when the state of the economy jumps from its current state to a worse state.

Recall that we ordered the default boundaries such that $X_{D, 1}>\ldots>X_{D, N}$; hence, state $N$ is the best state of the economy, state 1 is the worst. When the state of the economy jumps toward a better state, the default boundary decreases as growth opportunities improve; hence, if the firm was not in default, it is even further away from default after the jump. However, if the level of earnings is $X_{D, j+1}<X_{\tau_{D}^{-}} \leq X_{D, j}$ prior to a jump to state $j$ at time $\tau_{D}$, the firm automatically defaults. The level of earnings $X_{\tau_{D}}$ is then only a fraction of the default boundary $X_{D, j}$, and the firm will thus be able to honor its obligations to the debtholders, for instance, only partially. 
We thus introduce "modified" Arrow-Debreu securities

$$
\begin{aligned}
\tilde{q}_{D, i j, t}(x) & =E_{t}\left[\frac{\pi_{\tau_{D}}}{\pi_{t}} \frac{X_{\tau_{D}}}{X_{D, j}} 1_{\nu_{\tau_{D}}=j} \mid \nu_{t}=i\right] \\
& =E_{t}\left[\frac{\pi_{\tau_{D}}}{\pi_{t}} e^{x_{\tau_{D}}-x_{D, j}} 1_{\nu_{\tau_{D}}=j} \mid \nu_{t}=i\right] \\
& =E_{t}^{\mathbb{Q}}\left[e^{x_{\tau_{D}}-x_{D, j}} 1_{\nu_{\tau_{D}}=j} \mid \nu_{t}=i\right],
\end{aligned}
$$

to account for the uncertainty surrounding the recovery rate. Note that, as long as shareholders have no bargaining power, they shouldn't care about the depth of deep defaults.

Technically, the (standard) Arrow-Debreu securities are special cases of their modified counterparts, with $\frac{x_{\tau_{D}}}{x_{D, j}}=1$. Moreover, when in region $\mathcal{D}_{0}$, deep defaults are not a direct concern as the firm would survive even to a jump to the worse state, state 1. Hence, the general solution in (OA.79) holds. However, in region $\mathcal{D}_{k}, k>0$, applying (OA.58) to the unknown $\tilde{q}_{D, i j}, i>k$, accounting for deep defaults, yields the following system of ODEs

$$
\begin{aligned}
\frac{d z_{i, j}}{d x}-z_{N+i, j} & =0, \\
\frac{d z_{N+i, j}}{d x}+\frac{2 \widehat{\mu}_{x, i}}{\sigma_{x, i}^{2}} z_{N+i, j}+\sum_{l=1}^{k} \frac{2 \widehat{\lambda}_{i, l}}{\sigma_{x, i}^{2}}\left(e^{x-x_{D, j}} \delta_{l j}-z_{i, j}\right) & \\
+\sum_{l=k+1, l \neq i}^{N} \frac{2 \widehat{\lambda}_{i, l}}{\sigma_{x, i}^{2}}\left(z_{l, j}-z_{i, j}\right)-\frac{2 r_{i}}{\sigma_{x, i}^{2}} z_{i, j} & =0,
\end{aligned}
$$

with $i \in\{k+1, \ldots, N\}$ and $j \in\{1, \ldots, N\}$. This can be written equivalently in matrix form as

$$
Z_{k}^{\prime}+A_{k} Z_{k}+\widetilde{B}_{k}=0
$$

where

$$
\widetilde{B}_{k}=\left(\begin{array}{cc}
0_{N-k \times k} & 0_{N-k \times N-k} \\
\widetilde{B}_{k}^{\varnothing} & 0_{N-k \times N-k}
\end{array}\right),
$$

and

$$
\widetilde{B}_{k}^{\sigma}=\left(\begin{array}{cccc}
2 \frac{\widehat{\lambda}_{k+1,1}}{\sigma_{k+1}^{2}} e^{x-x_{D, 1}} & 2 \frac{\widehat{\lambda}_{k+1,2}}{\sigma_{k+1}^{2}} e^{x-x_{D, 2}} & \cdots & 2 \frac{\widehat{\lambda}_{k+1, k}}{\sigma_{k+1}^{2}} e^{x-x_{D, k}} \\
2 \frac{\widehat{\lambda}_{k+2,1}}{\sigma_{k+2}^{2}} e^{x-x_{D, 1}} & 2 \frac{\widehat{\lambda}_{k+2,2}}{\sigma_{k+2}^{2}} e^{x-x_{D, 2}} & \cdots & 2 \frac{\widehat{\lambda}_{k+2, k}}{\sigma_{k+2}^{2}} e^{x-x_{D, k}} \\
\vdots & \vdots & \cdots & \vdots \\
2 \frac{\widehat{\lambda}_{N, 1}}{\sigma_{N}^{2}} e^{x-x_{D, 1}} & 2 \frac{\widehat{\lambda}_{N, 2}}{\sigma_{N}^{2}} e^{x-x_{D, 2}} & \cdots & 2 \frac{\widehat{\lambda}_{N, k}}{\sigma_{N}^{2}} e^{x-x_{D, k}}
\end{array}\right) .
$$


Now, $\widetilde{B}_{k}$ is not constant with respect to $x$ anymore, but $\widetilde{B}_{k}^{\prime}=\widetilde{B}_{k}$. Hence, letting $\widetilde{Z}_{k}=Z_{k}+\left(A_{k}+\right.$ $I)^{-1} \widetilde{B}_{k}$, we have $\widetilde{Z}_{k}^{\prime}=Z_{k}^{\prime}+\left(A_{k}+I\right)^{-1} \widetilde{B}_{k}$

$$
\begin{aligned}
\widetilde{Z}_{k}^{\prime}+A_{k} \widetilde{Z}_{k} & =Z_{k}^{\prime}+\left(A_{k}+I\right)^{-1} \widetilde{B}_{k}+A_{k} Z_{k}+A_{k}\left(A_{k}+I\right)^{-1} \widetilde{B}_{k} \\
& =Z_{k}^{\prime}+A_{k} Z_{k}+\widetilde{B}_{k}=0 .
\end{aligned}
$$

Once more, the development made between equations (OA.65) and (OA.73) can be applied to $\widetilde{Z}_{k}$ in (OA.94) to yield

$$
\widetilde{Z}_{k}=e^{-D_{k} x} E_{k} K_{k}
$$

or, equivalently,

$$
Z_{k}=e^{-D_{k} x} E_{k} K_{k}-\left(A_{k}+I\right)^{-1} \widetilde{B}_{k}
$$

Therefore,

$$
\begin{aligned}
& \tilde{q}_{D, i j}(x)=\delta_{i j} e^{x-x_{D j}}=\delta_{i j} \frac{X}{X_{D i}}, \quad i \in\{1, \ldots, k\}, j \in\{1, \ldots, N\} \\
& \tilde{q}_{D, i, j}(x)=\sum_{l=1}^{2(N-k)} h_{i j}\left(\omega_{l}\right) e^{-\omega_{l} x}-\left[\left(A_{k}+I\right)^{-1} \widetilde{B}_{k}\right]_{i-k, j}, \quad i \in\{k+1, \ldots, N\}, j \in\{1, \ldots, N\} .
\end{aligned}
$$

For $1 \leq i \leq k$, if the earnings at current time $t$ are $X_{t}<X_{D, i}$ while the current state is $i$, it must be that the state just jumped to state $i$ at time $t^{-}$and the firm is now in (deep) default, hence the first equation in the above system.

\section{OA.H Bond Prices}

In this proof it is not necessary to distinguish between the state of the economy at dates $t-$ and $t$. The central part of our proof consists of proving that

$$
E_{t}\left[\int_{t}^{\tau_{D}} \frac{\pi_{s}^{\$}}{\pi_{t}^{\$}} d s \mid s_{t}=i\right]=\frac{1}{r_{P, i}^{\$}}-\sum_{j=1}^{N} \frac{q_{D, i j}^{\$}}{r_{P, j}^{\$}}
$$

where $r_{P, i}^{\$}$, the discount rate for a fixed nominal perpetuity, when the economy is in state $i$, is given by

$$
r_{P, i}^{\$}=\left(E_{t}\left[\int_{t}^{\infty} \frac{\pi_{s}^{\$}}{\pi_{t}^{\$}} d s \mid s_{t}=i\right]\right)^{-1}
$$


and

$$
E_{t}\left[\frac{\pi_{\tau_{D}}^{\$}}{\pi_{t}^{\$}} \alpha A_{\tau_{D}}^{\$}\left(X_{\tau_{D}}\right) \mid s_{t}=i\right]=\sum_{j=1}^{N} \alpha A_{j}^{\$}\left(X_{D, j}\right) \tilde{q}_{D, i j}^{\$}
$$

To prove (OA.97), we note that

$$
E_{t}\left[\int_{t}^{\tau_{D}} \frac{\pi_{s}^{\$}}{\pi_{t}^{\$}} d s \mid s_{t}=i\right]=E_{t}\left[\int_{t}^{\infty} \frac{\pi_{s}^{\$}}{\pi_{t}^{\$}} d s \mid \nu_{t}=i\right]-E_{t}\left[\frac{\pi_{\tau_{D}}^{\$}}{\pi_{t}^{\$}} \int_{\tau_{D}}^{\infty} \frac{\pi_{s}^{\$}}{\pi_{\tau_{D}}^{\$}} d s \mid s_{t}=i\right]
$$

and conditioning on the event $\left\{\nu_{\tau_{D}}=j\right\}$, we obtain

$$
E_{t}\left[\frac{\pi_{\tau_{D}}^{\$}}{\pi_{t}^{\$}} \int_{\tau_{D}}^{\infty} \frac{\pi_{s}^{\$}}{\pi_{\tau_{D}}^{\$}} d s \mid s_{t}=i\right]=\sum_{j=1}^{N} E_{t}\left[\operatorname{Pr}\left(\nu_{\tau_{D}}=j \mid s_{t}=i\right) \frac{\pi_{\tau_{D}}^{\$}}{\pi_{t}^{\$}} \int_{\tau_{D}}^{\infty} \frac{\pi_{s}^{\$}}{\pi_{\tau_{D}}^{\$}} d s \mid s_{t}=i\right]
$$

Since consumption is Markovian, so is the state-price density, which implies that

$$
\begin{aligned}
& E_{t}\left[\operatorname{Pr}\left(s_{\tau_{D}}=j \mid s_{t}=i\right) \frac{\pi_{\tau_{D}}^{\$}}{\pi_{t}^{\$}} \int_{\tau_{D}}^{\infty} \frac{\pi_{s}^{\$}}{\pi_{\tau_{D}}^{\$}} d s \mid s_{t}=i\right] \\
= & E_{t}\left[\operatorname{Pr}\left(s_{\tau_{D}}=j \mid s_{t}=i\right) \frac{\pi_{\tau_{D}}^{\$}}{\pi_{t}^{\$}} \mid s_{t}=i\right] E_{t}\left[\int_{\tau_{D}}^{\infty} \frac{\pi_{s}^{\$}}{\pi_{\tau_{D}}^{\$}} d s \mid s_{\tau_{D}}=j\right] .
\end{aligned}
$$

Therefore

$$
\begin{aligned}
E_{t}\left[\int_{t}^{\tau_{D}} \frac{\pi_{s}^{\$}}{\pi_{t}^{\$}} d s \mid s_{t}=i\right]= & E_{t}\left[\int_{t}^{\infty} \frac{\pi_{s}^{\$}}{\pi_{t}^{\$}} d s \mid s_{t}=i\right] \\
& -\sum_{j=1}^{N} E_{t}\left[\operatorname{Pr}\left(\nu_{\tau_{D}}=j \mid \nu_{t}=i\right) \frac{\pi_{\tau_{D}}^{\$}}{\pi_{t}^{\$}} \mid \nu_{t}=i\right] E_{t}\left[\int_{\tau_{D}}^{\infty} \frac{\pi_{s}^{\$}}{\pi_{\tau_{D}}^{\$}} d s \mid s_{\tau_{D}}=j\right] .
\end{aligned}
$$

Conditional on being in state $i$, the value of a claim which pays one risk-free unit of consumption in perpetuity is $E_{t}\left[\int_{t}^{\infty} \frac{\pi_{s}^{\$}}{\pi_{t}^{\$}} d s \mid s_{t}=i\right]$, so the discount rate for this perpetuity, $r_{P, i}^{\$}$, is given by (OA.98). Consequently, (OA.100) implies

$$
E_{t}\left[\int_{t}^{\tau_{D}} \frac{\pi_{s}^{\$}}{\pi_{t}^{\$}} d s \mid s_{t}=i\right]=\frac{1}{r_{P, i}^{\$}}-\sum_{j=1}^{N} \frac{E_{t}\left[\operatorname{Pr}\left(s_{t}=i \mid s_{\tau_{D}}=j\right) \frac{\pi_{\tau_{D}}^{\$}}{\pi_{t}^{\$}} \mid s_{t}=i\right]}{r_{P, j}^{\$}}
$$


To obtain (OA.97) from the above expression, we note that

$$
q_{D, i j, t}^{\$}=E_{t}\left[\operatorname{Pr}\left(s_{\tau_{D}}=j \mid s_{\tau_{t}}=i\right) \frac{\pi_{\tau_{D}}^{\$}}{\pi_{t}^{\$}} \mid s_{t}=i,\right]
$$

To prove (OA.99), we condition on the event $\left\{s_{\tau_{D}}=j\right\}$ to obtain

$$
\alpha E_{t}\left[\frac{\pi_{\tau_{D}}^{\$}}{\pi_{t}^{\$}} A_{\tau_{D}}^{\$}\left(X_{\tau_{D}}\right) \mid s_{t}=i\right]=\alpha \sum_{j=1}^{N} A_{j}^{\$}\left(X_{D, j}\right) E_{t}\left[\frac{X_{\tau_{D}}}{X_{D, j}} \operatorname{Pr}\left(s_{\tau_{D}}=s_{j} \mid s_{t}=i\right) \frac{\pi_{\tau_{D}}^{\$}}{\pi_{t}^{\$}} \mid s_{t}=i\right]
$$

Using (OA.102) to simplify the above expression we obtain (33).

\section{OA.I Equity risk premium and equity volatility}

Applying Ito's Lemma to $S_{i, t}^{\$}$ gives

$$
\frac{d S_{i, t}^{\$}+\left(X_{t}-c\right) d t}{S_{i, t}^{\$}}=\frac{S_{i, t}^{\$}}{X_{t}} \frac{\partial S_{i, t}^{\$}}{\partial X_{t}} \frac{d X_{t}}{X_{t}}+\frac{1}{2} \frac{X_{t}^{2}}{S_{i, t}} \frac{\partial^{2} S_{i, t}^{\$}}{\partial X_{t}^{2}}\left(\frac{d X_{t}}{X_{t}}\right)^{2}+\sum_{j \neq i}^{N} \frac{S_{j, t}^{\$}-S_{i, t}^{\$}}{S_{i, t}^{\$}} d N_{i j, t}+\frac{\left(X_{t}-c\right) d t}{S_{i, t}^{\$}}, i, j \in\{1, \ldots, N\}
$$

Observe that

$$
\begin{aligned}
\frac{\partial S_{i, t}}{\partial X_{t}} & =(1-\eta) \frac{1}{r_{A, i}^{\$}}-\sum_{j=1}^{N}\left(A_{j}^{\$}\left(X_{D, j}\right) \frac{\partial \tilde{q}_{D, i j, t}^{\$}}{\partial X_{t}}-(1-\eta) \frac{\partial q_{D, i j, t}}{\partial X_{t}} \frac{c}{r_{P, j}^{\$}}\right) \\
\frac{\partial^{2} S_{i, t}}{\partial X_{t}^{2}} & =-\sum_{j=1}^{N}\left(A_{j}^{\$}\left(X_{D, j}\right) \frac{\partial^{2} \tilde{q}_{D, i j, t}^{\$}}{\partial X_{t}^{2}}-(1-\eta) \frac{\partial^{2} q_{D, i j, t}}{\partial X_{t}^{2}} \frac{c}{r_{P, j}^{\$}}\right), i, j \in\{1, \ldots, N\} .
\end{aligned}
$$

Define the date- $t$ conditional nominal expected return

$$
\mu_{R, i, t}^{\$}=\frac{1}{d t} E_{t}\left[\frac{d S_{s_{t-}, t}^{\$}+\left(X_{t}-c\right) d t}{S_{s_{t-}, t}^{\$}} \mid s_{t-}=i\right], i \in\{1, \ldots, N\},
$$

and the date- $t$ conditional real expected return

$$
\mu_{R, i, t}=\frac{1}{d t} E_{t}\left[\frac{d S_{s_{t-}, t}+\left(Y_{t}-c / P_{t}\right) d t}{S_{s_{t-}, t}} \mid s_{t-}=i\right], i \in\{1, \ldots, N\} .
$$

Observe that $\mu_{R, i, t}$ depends on both real and nominal states, because of sticky leverage and sticky cash flows. 
The basic asset pricing equation is

$$
\mu_{R, i, t}^{\$}-r_{i, t}^{\$}=-\frac{1}{d t} E_{t}\left[\frac{d \pi_{t}^{\$}}{\pi_{t}^{\$}} \frac{d S_{s_{t-}, t}^{\$}}{S_{s_{t-}, t}^{\$}} \mid s_{t-}=i\right], i \in\{1, \ldots, N\} .
$$

Hence

$$
\mu_{R, i, t}^{\$}-r_{i, t}^{\$}=\sum_{j \neq i}\left(1-\omega_{i j}\right) \frac{S_{j}^{\$}-S_{i}^{\$}}{S_{i}^{\$}} \lambda_{i j}, i, j \in\{1, \ldots, N\} .
$$

Observe that because

$$
\mu_{R, i, t}^{\$}=\mu_{R, i, t}+\mu_{P, i}, i \in\{1, \ldots, N\},
$$

and

$$
r_{i, t}^{\$}=r_{i, t}+\mu_{P, i}, i \in\{1, \ldots, N\},
$$

we have

$$
\mu_{R, i, t}-r_{i, t}=\mu_{R, i, t}^{\$}-r_{i, t}^{\$}, i \in\{1, \ldots, N\} .
$$

The unexpected stock return in state $i$ is given by

$$
\sum_{j \neq i} \sigma_{R, i j}^{P} d N_{i j, t}^{P}, i, j \in\{1, \ldots, N\}
$$

where

$$
\sigma_{R, i j}^{P}=\frac{S_{j}}{S_{i}}-1, i, j \in\{1, \ldots, N\} .
$$

Now the risk premium in state $i$ is

$$
\mu_{R, i}-r_{i}=\sum_{j \neq i}\left(\omega_{i j}-1\right) \sigma_{R, i j}^{P} \lambda_{i j}, i, j \in\{1, \ldots, N\} .
$$

First, note that if $\log S=\log f(X)$ and $x \equiv \log X$, then

$$
\frac{\partial \log S}{\partial \log X}=\frac{\partial f\left(e^{x}\right)}{\partial x}=\frac{1}{f\left(e^{x}\right)} f^{\prime}\left(e^{x}\right) e^{x}=\frac{X}{S} f^{\prime}(X) .
$$


Second, recall that

$$
\begin{aligned}
S_{i, t}^{\$} & =A_{i}^{\$}\left(X_{t}\right)-(1-\eta) v_{B, i} c-\sum_{j=1}^{N}\left(A_{j}^{\$}\left(X_{D, j}\right) \tilde{q}_{D, i j, t}^{\$}\left(X_{t}\right)-(1-\eta) q_{D, i j, t}^{\$}\left(X_{t}\right) v_{B, i} c\right) \\
& =(1-\eta) X_{t} v_{A, i}-(1-\eta) v_{B, i} c-\sum_{j=1}^{N}\left(A_{j}^{\$}\left(X_{D, j}\right) \tilde{q}_{D, i j, t}^{\$}\left(X_{t}\right)-(1-\eta) q_{D, i j, t}^{\$}\left(X_{t}\right) v_{B, i} c\right)
\end{aligned}
$$

where we made explicit that the Arrow-Debreu prices, $q_{D, \cdot, i j, t}^{\$}$, depend on the current value of $X_{t}$. Hence,

$$
\frac{\partial \log S_{i, t}}{\partial \log X_{t}}=\frac{X_{t}}{S_{i, t}}\left[\frac{A_{i}^{\$}\left(X_{t}\right)}{X_{t}}-\sum_{j=1}^{N}\left(A_{j}^{\$}\left(X_{D, j}\right) \frac{\partial \tilde{q}_{D, i j, t}^{\$}}{\partial X_{t}}-(1-\eta) \frac{\partial q_{D, i j, t}^{\$}}{\partial X_{t}} v_{B, i} c\right)\right] .
$$

